Courrier hebdomadaire

$\mathrm{n}^{\circ} 2138-2139 \cdot 2012$

\title{
Action publique et responsabilité gouvernementale : la gestion de la grippe $A(H 1 N 1)$ en 2009
}

François Thoreau

Cédric Cheneviere

Nicolas Rossignol

CR'SP 
Courrier hebdomadaire

Rédacteur en chef : Cédric Istasse

Le Courrier hebdomadaire répond à un cahier des charges méthodologique défini par le CRISP et est élaboré en étroite association avec le rédacteur en chef. Il bénéficie des remarques et suggestions faites par l'équipe de recherche du CRISP et par des spécialistes bénévoles choisis en fonction des sujets traités.

Le Courrier hebdomadaire est soutenu par l'Administration générale de l'Enseignement et de la Recherche scientifique de la Fédération Wallonie-Bruxelles.

Une version numérique du Courrier hebdomadaire est disponible en pay per view (au numéro) et en accès gratuit pour les abonnés sur le site portail de CAIRN (http://www.cairn.info).

Le numéro simple : 6,90 euros - le numéro double : 12,40 euros

Abonnement : 235,00 euros

Souscription, commandes et informations :

CRISP - Place Quetelet, 1A - 1210 Bruxelles

Tél : 32 (0)2 2110180 - Fax : 32 (0)2 2197934

http://www.crisp.be - info@crisp.be

Banque 310-0271576-62

IBAN BE51 310027157662 - Swift BBRUBEBB

Éditeur responsable : Vincent de Coorebyter - Place Quetelet, 1A - 1210 Bruxelles

Tous droits de traduction, d'adaptation ou de reproduction par tous procédés, y compris la photographie et le microfilm, réservés pour tous pays.

ISSN 00089664 


\section{TABLE DES MATIÈRES}

INTRODUCTION

1. RÉGIMES DE RESPONSABILITÉ INSTITUÉS PAR LE CONTRAT CONCLU ENTRE L'ÉTAT BELGE ET GSK

1.1. Règles de responsabilité applicables entres les parties

1.2. Règles de responsabilité applicables en cas de préjudice subi par une personne vaccinée

1.2.1. Un contrat peut-il produire des effets à l'égard des tiers?

1.2.2. Directive européenne 85/374/CEE relative à la responsabilité du fait des produits défectueux

17

1.2.3. Clauses du contrat relatives au remboursement des frais exposés par GSK 20

1.2.4. Clauses du contrat relatives aux garanties offertes à l'État belge 21

1.2.5. La Belgique pourrait-elle se retourner contre la Commission européenne ? 23

1.3. Conclusion intermédiaire : un contrat légal mais déséquilibré 27

2. ANALYSE DU PROCESSUS DÉCISIONNEL ET DE L'ACTION DU GOUVERNEMENT FÉDÉRAL

2.1. Logiques de prévention et de précaution

2.2. Caractériser la logique d'action : une décision sous le signe du principe de prévention

2.2.1. Instances et mécanismes de la décision gouvernementale

2.2.2. Un phénomène aux contours flous et alarmants : le risque de pandémie de grippe

2.2.3. L'échec des campagnes de vaccination

2.2.4. Les facteurs décisifs de la décision gouvernementale 40

2.2.5. Les risques liés au vaccin Pandemrix

2.3. Conclusion intermédiaire : principe de prévention et conception étatique de la responsabilité 


\section{INTRODUCTION}

Au printemps 2009, une nouvelle forme de grippe apparaît en Amérique du Nord. D'abord appelée " grippe mexicaine » ou encore "grippe porcine», c'est sous le nom de « grippe $\mathrm{A}(\mathrm{H} 1 \mathrm{~N} 1)$ » qu'elle sera, au final, retenue ${ }^{1}$.

La propagation de ce virus est extrêmement rapide, en raison de la mondialisation des transports de passagers. Le 24 avril 2009, l'Organisation mondiale de la santé (OMS) ne recense que quelques cas de contamination confirmés au Mexique et aux États-Unis. Une semaine plus tard, le $1^{\text {er }}$ mai 2009, la maladie s'est déjà dispersée dans 13 pays, touchant 5 régions du globe : l'Amérique du Nord (Mexique, États-Unis et Canada), l'Europe (Allemagne, Autriche, Espagne, Pays-Bas, Royaume-Uni et Suisse), le Moyen-Orient (Israël), l'Océanie (Nouvelle-Zélande) et l'Asie (Chine et Hong Kong). Deux semaines plus tard, le 8 mai 2009, des cas de grippe A(H1N1) sont confirmés dans 25 pays. En Belgique, le premier cas est officiellement constaté le 12 mai $2009^{2}$. À cette date, la maladie a atteint 34 pays sur l'ensemble des continents, à l'exception de l'Afrique. On dénombre plus de 7500 cas d'infection dans le monde, dont 65 ont entraîné la mort (60 au Mexique, 3 aux États-Unis, 1 au Canada et 1 au Costa Rica).

Le 11 juin 2009, la directrice générale de l'OMS, Margaret Chan, annonce que son organisation considère l'épidémie de grippe $\mathrm{A}(\mathrm{H} 1 \mathrm{~N} 1)$ comme une pandémie mondiale $^{3}$. Il faudra attendre le 10 août 2010 pour que l'alerte soit levée et que le monde entre dans une période post-pandémie ${ }^{4}$ - même si le virus demeure alors encore relativement actif en Inde, en Australie et en Nouvelle-Zélande. Au total, des cas de grippe $\mathrm{A}(\mathrm{H} 1 \mathrm{~N} 1)$ auront été répertoriés dans 214 pays et il y aura eu près de 18500 morts recensés au $1^{\text {er }}$ août $2010^{5}$.

Les informations fournies par l'OMS et massivement répercutées par les médias obligent les gouvernements à réagir rapidement, parfois dans la précipitation. De

* François Thoreau, Cédric Cheneviere et Nicolas Rossignol sont respectivement aspirant du F.R.S.-FNRS (Spiral, ULg), assistant (Centre Charles De Visscher pour le droit international et européen et Institut d'études européennes, UCL) et chercheur (Spiral, ULg).

Ce changement de terminologie est officialisé, dans l'Union européenne, par la décision 2009/540/CE de la Commission du 10 juillet 2009 modifiant la décision 2002/253/CE en ce qui concerne les définitions de cas pour la déclaration de la grippe $\mathrm{A}(\mathrm{H} 1 \mathrm{~N} 1)$ au réseau communautaire (Journal officiel de l'Union européenne, L 180, 11 juillet 2009, p. 24).

Commissariat interministériel Influenza, Premier cas confirmé de A/H1N1 en Belgique, Communiqué de presse, 12 mai 2009, www.influenza.be. Quatre cas sont déclarés officiellement dans les jours qui suivent, jusqu'au 16 mai 2009, suite à quoi le recensement de nouveaux cas connaît un net ralentissement.

Organisation mondiale de la santé (OMS), World now at the start of 2009 influenza pandemic, Communiqué de presse, 11 juin 2009, www.who.int.

4 OMS, H1N1 in post-pandemic period, Communiqué de presse, 10 août 2010, www.who.int.

Sauf mention contraire, l'ensemble de ces informations sont issues des messages d'alerte de l'OMS. Ceux-ci sont disponibles sur le site www.who.int. 
nombreux pays, par exemple, ont pour première réaction d'installer des caméras thermiques dans leurs aéroports afin de repérer les voyageurs fiévreux, porteurs de la maladie. Cette mesure se révèle toutefois inefficace, car elle ne permet pas de détecter les personnes en phase d'incubation. D'autres mesures sont envisagées, comme des restrictions au voyage, mais elles seraient synonymes de catastrophe économique pour le secteur aérien. Du reste, de telles restrictions s'avèreraient également peu efficaces car le virus s'est déjà propagé à travers le monde ${ }^{6}$.

C'est dans ce contexte que, le 22 juillet 2009, l'État belge, représenté par sa ministre de la Santé publique, Laurette Onkelinx (PS), conclut un contrat d'un montant de 110190000 euros avec le groupe pharmaceutique GlaxoSmithKline (GSK) pour l'achat de 12,6 millions de doses de Pandemrix, un vaccin contre la grippe $\mathrm{A}(\mathrm{H} 1 \mathrm{~N} 1)$. Aux termes de son article 16.1, ce contrat doit demeurer confidentiel ${ }^{7}$. Toutefois, moins d'un an plus tard, le journal Le Soir en révèle la teneur ${ }^{8}$.

La presse est unanime : ce contrat a exonéré GSK de toute responsabilité et a mis celleci entièrement à charge de l'État belge. Ainsi, peut-on lire que ledit contrat garantit «à GSK le rejet de toute la responsabilité sur le gouvernement en cas de décès et d'effets secondaires graves liés à son vaccin (...). C'est donc l'État qui serait chargé d'indemniser les éventuelles victimes du produit. Or au moment de la signature du contrat, le vaccin n'avait pas encore reçu d'autorisation de mise sur le marché européen. Le Pandemrix contient du AS03, un adjuvant controversé qui n'a jamais été testé sur les populations à risque (femmes enceintes, personnes âgées, etc.) ${ }^{9}$ avant les campagnes de vaccination contre la grippe $\mathrm{A} / \mathrm{H} 1 \mathrm{~N} 1$, menées dès l'automne 2009 » ${ }^{10}$.

Certains organes de presse ont qualifié le Pandemrix de « vaccin expérimental " ${ }^{11}$. Or, si le contrat évoque un vaccin "prototype ${ }^{12}$, le Commissariat interministériel

6 «Grippe porcine : les caméras thermiques ne “marchent pas” ", L’Express, 28 avril 2009.

Les dispositions pertinentes du contrat figurent en annexe de la présente étude.

"H1N1 : voici le contrat entre GSK et le gouvernement belge », Le Soir, 5 mai 2010.

Deux erreurs sont ici à relever. Premièrement, les vaccins ne sont traditionnellement jamais testés sur les femmes enceintes. Le Commissariat interministériel Influenza a d'ailleurs explicitement fait état de cette pratique: "Il n'est pas éthique de pratiquer de telles études cliniques chez les femmes enceintes. Plus de 4500 femmes devraient être incluses pour en tirer quelque enseignement, et plus de 13000 pour exclure un accroissement de $30 \%$ de risque avec une puissance statistique suffisante... Seule donc une pharmacovigilance active d'un vaccin administré en phase pandémique, dans un contexte de risque de complication nettement accru chez la femme enceinte (vaccin dont aucun élément ne permet d'augurer d'un problème), peut répondre déontologiquement à cette question " (Commissariat interministériel Influenza, Fiche de vaccination grippe pandémique. Vaccin Pandemrix, 3 novembre 2009, www.influenza.be, p. 3). Deuxièmement, dans le cas de la grippe $\mathrm{A}(\mathrm{H} 1 \mathrm{~N} 1)$, les personnes âgées n'ont pas figuré au rang des groupes "présentant un risque »(cf. infra).

${ }^{10}$ «H1N1 : voici le contrat entre GSK et le gouvernement belge », Le Soir, 5 mai 2010. Cf. également "Le contrat avec GSK rejette la responsabilité sur le gouvernement", La Libre, 5 mai 2010 ; "Regering verantwoordelijk voor griepdoden na gebruik vaccin», Het Nieuwsblad, 5 mai 2010; «A/H1N1-griep: contract met GSK legt verantwoordelijkheid bij regering », De Tijd, 5 mai 2010.

11 «H1N1 : voici le contrat entre GSK et le gouvernement belge », Le Soir, 5 mai 2010.

12 En l'espèce, le gouvernement fédéral a décidé de ne pas recourir à la procédure classique de passation des marchés publics et lui a préféré une procédure négociée sans publicité. Ce choix s'explique, selon le considérant G du contrat, par le fait que, au moment de la conclusion du contrat, « GSK est la seule firme pharmaceutique ayant enregistré un vaccin prototype comprenant un composé antigène et un composé adjuvant séparés ». Du reste, la Commission européenne avait autorisé, sous conditions, la mise sur le marché de ce vaccin dès le 20 mai 2008. Le vaccin avait donc déjà franchi le stade purement expérimental (cf. infra). 
Influenza a, quant à lui, insisté dès novembre 2009 sur le fait que ce vaccin n'était pas, pour autant, "expérimental»: "Le vaccin Pandemrix, comme d'autres vaccins enregistrés par [l'Agence européenne des médicaments (EMEA)] depuis cet automne, ont été mis au point selon les normes classiques de tous les vaccins. Son étude a commencé en 2005, en réponse à la menace de grippe aviaire, et a abouti en 2006 à la reconnaissance d'un mode de mise au point d'un vaccin pandémique dont il ne resterait plus qu'à modifier l'antigène (ici, H1 [à la place de] H5) en temps voulu, permettant ainsi de gagner un temps considérable en ne devant plus faire la preuve, en quelques mois, que de résultats de sécurité et d'immunogénicité de cette nouvelle formulation. Aucune des étapes précliniques (dont l'étude de tératogénicité, d'embryo ou foetotoxicité) n'a été négligée ou accélérée » ${ }^{13}$.

Le cas de la Belgique n'est pas unique : presque tous les pays européens ont conclu des conventions similaires avec des groupes pharmaceutiques. Ces contrats sont largement critiqués dans toute l'Europe. À cet égard, un rapport de l'Assemblée parlementaire du Conseil de l'Europe juge préoccupant le fait que «les gouvernements nationaux ont subi des pressions pour accélérer la conclusion de contrats majeurs, que le prix des vaccins ont fait l'objet de pratiques douteuses, qu'ils ne répondaient pas à des conditions normales de marché et que l'on a essayé de faire endosser aux gouvernements nationaux la responsabilité concernant les vaccins et les médicaments, lesquels n'ont peut-être pas subi suffisamment de tests " ${ }^{14}$. Partant de ce constat, l'Assemblée parlementaire recommande aux 47 États membres du Conseil de l'Europe «de garantir que le secteur privé ne tire pas un profit abusif des alarmes de santé publique et qu'il ne puisse pas se dégager de ses responsabilités en vue de privatiser ses gains, tout en partageant les risques $» 15$.

De son côté, le Parlement européen rappelle que «selon la législation européenne relative aux médicaments, la responsabilité de la qualité, de la sécurité et de l'efficacité d'un médicament pour les indications autorisées incombe au fabricant » et invite les États membres «à appliquer pleinement cette disposition dans tous leurs contrats d'achat de vaccins car c'est un facteur important pour maintenir ou retrouver la confiance des gens en la sécurité des vaccins ${ }^{16}$. Les députés européens fustigent également la « réticence des fabricants de vaccins à endosser la pleine responsabilité de leurs produits» car celle-ci «peut avoir contribué à réduire la confiance de la population dans la sécurité des vaccins ${ }^{17}$.

Il ressort de ces rapports officiels, mais également de la commission d'enquête de l'Assemblée nationale française, que les groupes pharmaceutiques ont tenté, au début des négociations en vue de conclure les contrats de fourniture de vaccins, d'imposer

13 Commissariat interministériel Influenza, Fiche de vaccination grippe pandémique. Vaccin Pandemrix, op. cit., p. 3. Cf. aussi le considérant $\mathrm{H}$ du contrat, qui précise que "le vaccin pandémique fait l'objet d'études cliniques dont les résultats ne sont pas encore connus à la date d'entrée en vigueur ".

14 Assemblée parlementaire du Conseil de l'Europe, La gestion de la pandémie H1N1 : nécessité de plus de transparence. Rapport de la Commission des questions sociales, de la santé et de la famille, Document 12283, point 66, 7 juin 2010.

Ibidem; Assemblée parlementaire du Conseil de l'Europe, Gestion de la pandémie H1N1 : nécessité de plus de transparence, Résolution 1749, point 8.6, 24 juin 2010.

16 Parlement européen, Rapport sur l'évaluation de la gestion en 2009-2010 de la grippe H1N1 en Europe, approuvé le 8 mars 2011, point 13.

Ibidem, considérant $\mathrm{O}$. 
des clauses d'irresponsabilité par lesquels ils n'auraient pas été juridiquement tenus de réparer les éventuels dommages causés par leurs vaccins. Ces clauses ont apparemment été rejetées par tous les États européens ${ }^{18}$, et c'est un régime intermédiaire qui a, en définitive, été mis en place.

Les contrats conclus par les États avec les groupes pharmaceutiques conduisent à la tenue de nombreux débats et les interrogations qu'ils suscitent sont légion ${ }^{19}$. Certaines personnes s'emparent de la question, notamment pour dénoncer, de manière quelques peu caricaturale, une «supercherie» téléguidée par le lobby pharmaceutique ${ }^{20}$. Par ailleurs, et de manière générale, l'endossement de la responsabilité en cas de défectuosité des vaccins apparaît comme l'un des points les plus controversés.

Le présent Courrier hebdomadaire propose une analyse à la fois juridique et politique de cette question, sur la base des informations disponibles au 15 avril 2012. Pour ce faire, il se fondera sur le contrat conclu par le gouvernement belge et le groupe GSK. Précisons que nous n'entendons pas mettre en cause spécifiquement GSK, ni défendre ses intérêts. Si nous évoquons cette entreprise, c'est uniquement parce que notre étude repose sur le contrat que cette entreprise a conclu avec la Belgique, qui est l'un des rares contrats qui aient été rendus publics ${ }^{21}$. De nombreux rapports officiels - que nous évoquerons infra - affirment que les clauses contractuelles sont similaires d'un pays à un autre. Par conséquent, notre analyse est probablement transposable aux autres États, même si pareille démarche, qui sort du cadre fixé à la présente contribution, ne peut évidemment être entreprise qu'en introduisant des nuances tenant notamment aux spécificités de chaque droit national.

La première partie de notre étude précisera la portée exacte de l'éventuel transfert de responsabilité de GSK vers l'État belge, sur un plan juridique. Quant à la seconde, elle analysera la logique de l'action publique et les considérations ayant conduit le gouvernement belge à accepter les conditions posées par le groupe pharmaceutique, dans ce cas précis. Certes, sans doute notre étude présente-t-elle un certain parti pris en se concentrant sur la question de la «responsabilité gouvernementale». Les médias, les groupes pharmaceutiques, la population et diverses instances internationales (l'OMS et l'Union européenne, entre autres) ont en effet également leur part de responsabilité dans de telles situations, marquées par leur complexité. Néanmoins, notre approche se justifie par le fait que se concentrer sur le contrat conclu par le gouvernement belge permet d'établir une symétrie entre l'action

18 Assemblée nationale française, Rapport fait au nom de la commission d'enquête sur la manière dont a été programmée, expliquée et gérée la campagne de vaccination contre la grippe A(H1N1), Document 2698, 6 juillet 2010, p. 52-53.

19 Mentionnons, par exemple, la plainte pour corruption et coalition de fonctionnaires qui est déposée au parquet de Bruxelles ("Vaccin A/H1N1: une plainte déposée pour corruption», Le Soir, 25 novembre 2010) ou encore les interrogations de certains médias au sujet du respect des règles de marché public («Vaccin anti-H1N1 : un contrat qui pose question», L’Écho, 6 mai 2010).

20 Cf. par exemple J. CORTI-VARELA, "Quelle responsabilité pour les décisions des organisations scientifiques internationales? Le cas de la grippe porcine (A-H1N1) et l'OMS », in E. VerGĖs (dir.), Droit, sciences et techniques: quelles responsabilités? (Actes du colloque: Palais du Luxembourg, Paris, 25-26 mars 2011), LexisNexis, coll. «Colloques et débats », n 5, Paris, 2011, p. 33-50.

${ }^{21}$ Un contrat similaire a également été rendu public en Suède. En France, des pans entiers des contrats signés avec les groupes pharmaceutiques ont été dévoilés, avec l'accord des parties prenantes, à l'exclusion de certains éléments comme le prix. 
publique et celle du groupe pharmaceutique GSK. Pour les aspects connexes de la problématique que nous avons choisi de développer, de plus amples études devront être menées. 


\section{RÉGIMES DE RESPONSABILITÉ INSTITUÉS PAR LE CONTRAT CONCLU ENTRE L'ÉTAT BELGE ET GSK}

Commentant le contrat conclu le 22 juillet 2009 entre l'État belge et le groupe pharmaceutique GlaxoSmithKline (GSK) - document dont le contenu était censé demeurer confidentiel, mais dont le journal Le Soir a révélé la teneur dans son édition du 5 mai 2010 -, la presse a largement confondu plusieurs concepts et questions. $\mathrm{Au}$ gré des articles, le contrat liant le groupe pharmaceutique au gouvernement belge a été décrit comme "limitant ", " exonérant " voire "transférant » la responsabilité civile de GSK en cas de décès ou de dommages corporels causés par le vaccin.

Si l'existence de telles clauses s'avérait exacte, elle poserait assurément question au sujet tant de la légalité de ces dispositions que de leur effet obligatoire à l'égard des tiers. En réalité, la rédaction des clauses relatives à la responsabilité est plus subtile et bien moins radicale que ce qu'en a dit la presse. La convention opère une distinction claire entre le régime de responsabilité applicable entre les parties, c'est-à-dire entre GSK et le gouvernement belge, et celui qui pourrait être mis en œuvre à la suite d'un dommage subi par un tiers au contrat, c'est-à-dire d'un préjudice enduré par un citoyen vacciné.

Quoique différents, ces deux régimes - que nous aborderons successivement dans les deux sections de ce chapitre - participent d'une même logique : réduire au maximum les conséquences financières de la mise en cause de la responsabilité de GSK. On peut aisément comprendre le point de vue du groupe pharmaceutique. Ce type de comportement ne lui est pas propre. Il a été très bien décrit par le juriste français Johann Abras: "Chaque homme porte en lui un sentiment de responsabilité (...). Néanmoins, si la responsabilité est dans la nature de l'homme, la non-responsabilité figure au rang de ses aspirations ${ }^{22}$. Or, il en va de même des sociétés commerciales que des êtres humains. Par ailleurs, cette idée peut aussi être rapprochée des stratégies de gestion des risques développées au sein des entreprises; ces stratégies imposent à une entreprise donnée d'identifier et d'évaluer les risques auxquels elle s'expose, mais

J. ABRAS, L'aménagement conventionnel anticipé de la responsabilité extra-contractuelle, Presses universitaires Aix-Marseille, Aix-en-Provence, 2008, p. 17-18. 
également de les maîtriser en ayant notamment recours à divers mécanismes d'assurance ${ }^{23}$.

\subsection{RÈGLES DE RESPONSABILITÉ APPLICABLES ENTRES LES PARTIES}

Le contrat contient bel et bien une clause limitant la responsabilité de GSK (article 14.2). Mais loin de viser la responsabilité envers le citoyen qui subirait un préjudice du fait de sa vaccination (cf. infra), cette clause se contente de fixer le plafond des indemnités qui, dans certaines circonstances, seront dues par le groupe pharmaceutique à l'État belge.

Le champ d'application de cette disposition est très large :

«Par dérogation au droit commun ${ }^{24}$, la responsabilité de GSK envers le [ministre de la Santé] pour l'ensemble des réclamations et/ou demandes généralement quelconques découlant de ou en relation avec la présente convention, indépendamment de la forme dans laquelle la responsabilité doit être invoquée, que ce soit en matière contractuelle, extracontractuelle (en ce compris quasi délictuelle), violation d'une obligation légale, violation d'une garantie, faute propre ou toute autre action de toute nature, et pour toute mesure de redressement, quelle qu'elle soit, quelle que soit sa cause ou le moment auquel elle se produit, sera limitée à et n'excèdera pas, selon le cas :

a) un montant équivalant à cinquante pourcents $(50 \%)$ du prix du volume pandémique total, à majorer, le cas échéant, du prix des nouveaux composés commandés conformément à l'article 3.2 et 3.3 de la présente convention ;

b) un montant équivalant à cinquante pourcents (50\%) du prix du nouveau volume pandémique total »(art. 14.2) ${ }^{25}$.

Il est donc prévu que dans tout litige, en lien avec ce contrat, qui opposera l'État belge à GSK, les dédommagements maximaux que le groupe pharmaceutique devra payer à la Belgique ne pourront dépasser la moitié du prix payé par l'État belge pour l'achat des doses de Pandemrix ${ }^{26}$. En pratique, le montant pour lequel GSK pourrait être redevable ne devrait pas excéder 40,1 millions d'euros, puisque l'État belge a, au final, déboursé 80206490 euros pour l'acquisition des vaccins.

Ce coût final (80 206490 euros) diverge du prix initial d'achat que nous avons évoqué dans l'introduction (110 190000 euros). Pour comprendre cette différence, il y a lieu de revenir sur l'historique du contrat.

23 Pour un descriptif de ces dynamiques, cf. L. EECKHOUDT, C. VERDURE, «Quelques réflexions relatives à la gestion des risques", in Les assurances de responsabilité de l'entreprise. Questions choisies, Anthémis, Limal, 2010, p. 11.

24 Suivant le droit commun, c'est-à-dire le droit habituellement applicable en Belgique, il n'existe généralement aucun plafond pour les indemnités reçues en compensation du préjudice subi. Le contrat GSK/État belge déroge donc bel et bien à ce droit commun (absence de plafonnement des indemnités) en prévoyant que les dédommagements éventuellement dus par le groupe pharmaceutique ne dépasseront pas la moitié du prix payé par l'État belge pour l'achat des vaccins.

25 Le principe de limitation de la responsabilité de GSK est également évoqué à l'article 11.5, sous d, point $\mathrm{v}$.

26 La rédaction de cette disposition du contrat est à ce point large qu'elle nous semble embrasser tous les litiges potentiels entre les cocontractants, dès lors que ces contentieux présentent un lien avec le contrat et qu'ils mettent en cause la responsabilité de GSK. 
Le contrat initial de juillet 2009 prévoit l'achat de 12,6 millions de doses pour un coût de 110190000 euros. En effet, le prix unitaire d'une dose, aux termes de l'article 3.4.2. du contrat et de son annexe $\mathrm{B}$, points 4 et 5 , s'élève à 1 euro pour le composé antigène pandémique, et 6 euros pour le composé adjuvant ${ }^{27}$. À ces tarifs s'ajoute un "droit de mise à disposition" (qui permet d'acheter les vaccins par priorité), qui s'élève à 1,50 euros par dose. Ce surcoût doit être acquitté sur la "première vague » de livraison du vaccin. En Belgique, cela concerne les 10500000 premières doses livrées, à l'exclusion des 2100000 doses suivantes, lesquelles reviennent donc au prix de 7 euros l'unité. Les doses effectivement payées par le gouvernement, incluant le droit de mise à disposition, s'élèvent à un prix unitaire de 8,50 euros (hors taxe sur la valeur ajoutée, celle-ci étant fixée à $6 \%$ sur les produits pharmaceutiques).

Toutefois, le 9 février 2010, le gouvernement fédéral signe un avenant au contrat afin de revoir sa commande à la baisse ${ }^{28}$, vu la faible virulence du virus et la réticence des Belges - comme de la plupart des Européens - à se faire vacciner (le taux de vaccination de la population n'atteint que 6,6 \% dans le pays). Cette décision est prise par la Cellule de gestion Influenza, présidée par les ministres de l'Intérieur, Annemie Turtleboom (Open VLD), et de la Santé publique, Laurette Onkelinx (PS) ${ }^{29}$. En accord avec GSK, la Belgique annule dès lors, sans compensation, $32 \%$ de la commande, soit l'achat de 4032000 doses de Pandemrix ${ }^{30}$. Finalement, la livraison porte sur un total de 8568000 vaccins, pour un coût de 80206490 euros (en ce inclus différents coûts logistiques : cf. infra, tableau 2) ${ }^{31}$.

Le phénomène d'annulation d'une partie de la commande initiale n'est pas propre à la Belgique. La plupart des pays européens s'engagent dans des stratégies d'ajustement ou d'adaptation de leurs commandes ${ }^{32}$. C'est notamment le cas de la France qui décide, unilatéralement, de résilier en janvier 2010 une commande de 50 millions de doses (sur un total de 94 millions) qu'elle a passée avec les laboratoires GSK, Novartis et Sanofi Pasteur. Une commission d'enquête, instituée le 24 février 2010 par l'Assemblée nationale française ${ }^{33}$, rappellera à cet égard, dans son rapport déposé en juillet 2010, que « le 4 janvier 2010, l'État a notifié à trois laboratoires la résiliation unilatérale de 50 millions de doses de vaccins. (...) L'indemnisation proposée par l'État a été fixée au prorata des quantités non livrées, en l'occurrence $16 \%$ du montant des doses annulées (...). Si un accord transactionnel sur l'indemnisation

27 Le contrat prévoit différentes modalités supplémentaires pour le remplacement des stocks des composés antigènes pandémiques ou adjuvants : si ceux-ci atteignent leur date de péremption et que le délai de garantie est éteint, le gouvernement peut racheter ces composés au prix respectif de 1 et 3 euros (article 3.2).

28 Cour des comptes, $168^{e}$ Cahier de la Cour des comptes. Observations et documents soumis à la Chambre des représentants, volume 1 : Commentaires, s.l.n.d. [Bruxelles, décembre 2011], p. 117. Contrairement au contrat initial, qui a été rendu public, le contenu de cet avenant demeure toujours confidentiel.

29 Un aperçu des structures et mécanismes décisionnels est proposé infra (point 2.2).

Assemblée nationale française, Rapport fait au nom de la commission d'enquête sur la manière dont a été programmée, expliquée et gérée la campagne de vaccination contre la grippe A(H1N1), op. cit., p. 32.

31 Cour des comptes, $168^{e}$ Cahier de la Cour des comptes, op. cit., p. 117. Cf. aussi "Grippe A : on renégocie à la baisse », La Libre Belgique, 9 janvier 2010 ; "Onkelinx annonce un audit externe sur la gestion de la grippe A », La Libre Belgique, 23 février 2010.

«Concurrence sur les résiliations de vaccins », Le Figaro, 12 janvier 2010.

33 Assemblée nationale française, Résolution créant une commission d'enquête sur la manière dont a été programmée, expliquée et gérée la campagne de vaccination contre la grippe $A(H 1 N 1), \mathrm{n}^{\circ} 427$, 24 février 2010. 
proposée a été acceptée par [les laboratoires Sanofi Pasteur et Novartis], les discussions se poursuivent toujours avec le laboratoire GlaxoSmithKline : comme l'a indiqué son président, $\mathrm{M}$. Hervé Gisserot, à la commission d'enquête, il souhaiterait obtenir une indemnisation à hauteur des deux tiers de la commande initiale, niveau équivalent à ce qui aurait été arbitré par d'autres États ayant procédé à des résiliations équivalentes, notamment l'Allemagne, le Royaume-Uni, les Pays-Bas, la Belgique et le Japon. Une telle demande équivaut à un montant de 233,33 millions d'euros ${ }^{34}$. En Belgique, le montant versé in fine correspond bien aux deux tiers de la commande initiale. Le caractère "d'indemnisation" résulte sans doute de la différence entre les montants versés et la commande effectivement livrée, bien qu'aucun chiffre disponible ne permette d'étayer cette hypothèse.

La surévaluation des besoins résulte essentiellement des recommandations formulées par le conseil consultatif mis sur pied par l'OMS, le Strategic Advisory Group of Experts (SAGE), qui a préconisé, au début du mois de juillet 2009, de prévoir une double dose par personne vaccinée ${ }^{35}$. Le même conseil a suggéré aux États d'établir un ordre de priorité concernant les populations vaccinées («[Comme] on ne disposera pas de suffisamment de vaccins au début, on peut envisager de procéder par étapes et de vacciner certaines catégories de la population »), proposant à cet égard de prendre en compte des catégories particulières, qu'il a énoncées " tout en notant que les pays doivent déterminer leur ordre de priorité ${ }^{36}$ : femmes enceintes, sujets âgés de moins de 6 mois présentant une affection chronique et, enfin, différentes tranches d'âge de population en "bonne santé » (jeunes adultes de 15 à 49 ans, enfants, adultes de 49 à 65, adultes de plus de 65). Si donc l'État belge a commandé 12,6 millions de doses, il l'a fait en vertu d'une décision politique discrétionnaire qui a tenu compte, dans une mesure indéterminée à ce jour, de cette recommandation du SAGE de vacciner à l'aide d'une double dose et selon un certain ordre de priorité.

La question du caractère facultatif ou obligatoire de la vaccination contre la grippe $\mathrm{A}(\mathrm{H} 1 \mathrm{~N} 1)$ avait aussi été posée en son temps. Il avait tout d'abord été prévu de laisser au gouvernement toute latitude d'imposer la vaccination par voie légale, s'il estimait que l'évolution de la situation le nécessitait ${ }^{37}$. Mais cette possibilité avait été finalement rejetée par l'adoption d'un amendement ${ }^{38}$, adopté à l'unanimité en

34 Assemblée nationale française, Rapport fait au nom de la commission d'enquête sur la manière dont a été programmée, expliquée et gérée la campagne de vaccination contre la grippe A(H1N1), op. cit., p. 17-18.

3 «En l'absence d'informations contraires, il est prudent de supposer que deux doses de vaccin contre le virus pandémique seront nécessaires pour la protection individuelle. Le nombre de doses nécessaires sera ajusté à mesure que l'on disposera de nouveaux éléments " (Strategic Advisory Group of Experts, «Rapport de la réunion extraordinaire sur la pandémie 2009 de grippe $\mathrm{A}(\mathrm{H} 1 \mathrm{~N} 1)$, Genève, 7 juillet 2009 », The Weekly Epidemiological Record, volume 84, n² 20, 2009, p. 304).

Ibidem, p. 303.

37 Chambre des représentants, Projet de loi accordant des pouvoirs au Roi en cas d'épidémie ou de pandémie de grippe, DOC 52 2156/001, 11 septembre 2009.

"Le Roi ne peut pas rendre la vaccination obligatoire en exécution en exécution de la présente loi » (amendement $\mathrm{n}^{\circ}$ 1, déposé par M.-C. Lambert (PS), N. Muylle (CD\&V), C. Fonck (CDH) et K. Della Faille (Open VLD) : Chambre des représentants, Projet de loi accordant des pouvoirs au Roi en cas d'épidémie ou de pandémie de grippe. Amendements déposés en séance plénière, DOC 52 2156/004 15 octobre 2009, p. 1-2). Un amendement similaire avait été introduit par d'autres députés « Toutefois, sont exclues les mesures visant à rendre obligatoire une vaccination » (amendement $\mathrm{n}^{\circ} 2$ déposé par T. Snoy (Écolo-Groen), M. Gerkens (Écolo-Groen) et M. Detiège (SP.A) : Ibidem, p. 2). 
Commission de la Santé pulbique de la Chambre ${ }^{39}$. À cette occasion, le parti Écolo, par la voix de la députée Thérèse Snoy et d'Oppuers, avait critiqué la proportionnalité du dispositif prévu pour répondre à la pandémie de grippe $\mathrm{A}(\mathrm{H} 1 \mathrm{~N} 1)$ et formulé des réserves quant au caractère vraiment facultatif de la vaccination: "Nous ne voulons pas nous opposer au vaccin ni à son administration mais bien à une campagne qui va, en quelque sorte, mettre une pression morale sur l'opinion publique, sur les entreprises et leurs patrons. Par exemple, certains responsables de la grande distribution ont déjà dit à leurs employés qu'ils devaient se faire vacciner » ${ }^{40}$.

Au surplus, l'obligation de vaccination aurait pu être problématique sur le plan juridique. En effet, la loi du 22 août 2002 relative aux droits du patient ${ }^{41}$ pose le principe du libre consentement à l'égard de tout acte médical. Cette solution découle de la jurisprudence que la Cour européenne des droits de l'homme. S'agissant spécifiquement des vaccinations obligatoires, les juges de Strasbourg ont en effet estimé qu'un tel acte médical non consenti entre en conflit avec le droit au respect de la vie privée ${ }^{42}$, qui inclut le droit à l'intégrité physique. Des ingérences sont toutefois admissibles, à la condition qu'elles soient clairement prévues par la loi, qu'elles poursuivent un objectif légitime de santé publique (par exemple, contrôler la propagation d'une maladie infectieuse) et qu'elles soient nécessaires dans une société démocratique ${ }^{43}$.

En Belgique, bien que la vaccination ait donc été officiellement facultative, il n'en demeure pas moins qu'elle a été en pratique sensiblement "encouragée " pour les groupes qualifiés de "prioritaires» et ceux "présentant un facteur de risque». Les premiers regroupaient la totalité du personnel hospitalier, toutes catégories incluses y compris les étudiants en médecine, les candidats spécialistes, les élèves infirmiers et les services logistiques et administratifs. Ils ont fait l'objet d'une première phase de vaccination, entamée dès la mi-octobre 2009. Les seconds rassemblaient une série de personnes davantage exposées au risque de pandémie, et pour lesquelles la vaccination était fortement suggérée: "les autres dispensateurs de soins et personnel des institutions de santé agréés, en ce compris le personnel de la Croix-Rouge et les pharmaciens; les personnes présentant une pathologie préexistante les définissant comme à risque de complications ${ }^{44}$; les femmes enceintes (au deuxième et troisième

39 Chambre des représentants, Compte rendu intégral, CRIV 52 PLEN 117, 15 octobre 2009, p. 10. Quant à lui, le projet de loi dans lequel cet amendement a été inséré (Chambre des représentants, Projet de loi accordant des pouvoirs au Roi en cas d'épidémie ou de pandémie de grippe. Texte adopté par la Commission de la Santé publique, de l'environnement et du renouveau de la société, DOC 52 2156/006, 15 octobre 2009) a été voté, dans son ensemble, par 112 voix pour et 28 abstentions (aucune voix contre). Chambre des représentants, Compte rendu intégral, CRIV 52 PLEN 117, 15 octobre 2009, p. 11.

Moniteur belge, 26 septembre 2002.

Article $8, \$ 1^{\text {er }}$ de la Convention européenne des droits de l'homme.

Cf. notamment Cour européenne des droits de l'homme, "S.D. Solomakhin contre Ukraine », Affaire $\mathrm{n}^{\circ} 24429 / 03$, arrêt du 15 mars 2012, points 33 et s. Cf. également le jugement du tribunal correctionnel de Tournai du 16 mars 2011 qui, se fondant sur la loi du 22 août 2002, a acquitté des parents poursuivis pour avoir refusé de faire vacciner leur enfant contre la poliomyélite alors que cette vaccination a été rendue obligatoire en Belgique par l'arrêté royal du 26 octobre 1966.

44 Étaient repris dans ce groupe les patients suivants : ceux atteints d'une maladie chronique affectant la fonction respiratoire (comme les patients atteints d'asthme sévère, BPCO, mucoviscidose, bronchodysplasie, etc.), ceux souffrant d'une pathologie cardiaque chronique (à l'exception d'hypertension non compliquée), ceux diabétiques, ceux porteurs de pathologies neuromusculaires chroniques, ceux 
trimestres) et les femmes inscrites dans un programme de procréation assistée; les parents d'enfants de moins de 6 mois ou les personnes en ayant la garde ; le personnel d'encadrement des crèches, écoles maternelles, écoles primaires et secondaires ${ }^{45}$. Cette deuxième phase de vaccination débute environ un mois après la première. Quant aux personnes âgées, elles n'avaient pas été reprises parmi les groupes ciblés par le Commissariat interministériel Influenza. Elles avaient pourtant été identifiées par le gouvernement comme constituant un "groupe à risque» dans le cas de la grippe saisonnière, suivant en cela une recommandation du Conseil supérieur d'hygiène adoptée le 8 septembre 2005, consécutivement à la situation sanitaire issue de la grippe aviaire ${ }^{46}$.

Malgré la modification à la baisse de leurs commandes, la plupart des pays se retrouvent avec des surplus de vaccins. Ils décident en conséquence de s'en départir. Une partie de ces vaccins est offerte à l'OMS pour aider les pays en voie de développement. La Belgique cède ainsi gracieusement quelque $10 \%$ de sa commande initiale, soit 1,26 million de doses ${ }^{47}$; quant à la France, elle transmet à l'organisation internationale 12,6 millions de doses ${ }^{48}$. Outre leurs buts caritatifs, ces dons s'expliquent par la difficulté rencontrée par la plupart des États pour revendre leurs surplus de vaccins : la demande en vaccination dans le monde est trop faible et l'offre en vaccins surabondante. À titre d'exemple, les Pays-Bas ont acquis 34 millions de vaccins et ont cherché à en revendre 19 millions ${ }^{49}$. En Belgique, il semble qu'il ne soit jamais entré dans les intentions des autorités de revendre leurs surplus ${ }^{50}$.

En bout de course, les vaccins qui ne peuvent être vendus ou offerts et qui ne sont plus utilisables sont purement et simplement détruits. Ainsi, s'agissant de l'Allemagne, 16 millions de doses - sur un total de 28 millions - sont incinérées ${ }^{51}$. En France, sur les 44 millions doses effectivement livrées, 12,6 millions sont offertes à l'OMS, 314000 sont revendues au Qatar et à Monaco, et 18,9 millions sont détruites ${ }^{52}$. Il en va de même en Belgique: selon la Cour des comptes, sur les 8568000 doses de vaccin finalement livrées, 2179500 sont réellement utilisées, 1260000 sont données à l'OMS et le solde, soit 5128500 doses, sera toujours entreposé en stock à la fin de l'année $2011^{53}$. À cet égard, la Cour des comptes notera, dans un rapport de décembre 2011 : «Comme tout médicament, les vaccins ont une date de péremption prédéfinie. Ils ne peuvent plus être administrés après cette date et doivent être détruits. Néanmoins, la durée de vie d'un médicament ou d'un produit de santé peut être prolongée si le

souffrant d'une atteinte neurologique sévère, ceux atteints d'une insuffisance rénale ou hépatique modérée à sévère, ceux immunodéprimés suite à une maladie ou un traitement, ceux porteurs de désordres métaboliques héréditaires (Commissariat interministériel Influenza, Grippe A/H1N1 : FAQ Citoyens (questions les plus fréquemment posées par les citoyens), www.influenza.be).

I5 Ibidem.

46 Compte rendu de la Conférence interministérielle extraordinaire Santé publique "grippe aviaire", présidée par le Premier ministre et le ministre des Affaires sociales et de la Santé publique, Communiqué de presse, 20 octobre 2005, www.influenza.be.

47 Cour des comptes, $168^{e}$ Cahier de la Cour des comptes, op. cit., p. 117 ; «Grippe A/H1N1: 10 pc du stock de vaccins belge offert à l'OMS », La Libre Belgique, 26 novembre 2009.

«H1N1 : les vaccins bientôt tous détruits », Le Figaro, 12 septembre 2011.

« Grippe A (H1N1) : la France peine à écouler ses vaccins », Le Figaro, 3 janvier 2010.

«H1N1 : La France revend ses vaccins, la Belgique les offre », Le Vif / L'express, 4 janvier 2010.

"L'Allemagne incinère le vaccin H1N1 », Le Figaro, 17 août 2011.

«H1N1 : les vaccins bientôt tous détruits », Le Figaro, 12 septembre 2011.

Cour des comptes, $168^{\circ}$ Cahier de la Cour des comptes, op. cit., p. 119. 
fabricant confirme la stabilité à plus long terme du produit par des tests effectués par des laboratoires agréés indépendants. Les composants adjuvant et antigène du vaccin anti-pandémique ont des durées de vie initiales différentes (18 mois pour l'antigène et 36 mois pour l'adjuvant) ${ }^{54}$. Jusqu'à présent, aucune demande de prolongation n'a été effectuée pour prolonger la durée de vie des produits. Tous les composants antigènes sont par conséquent périmés et ne peuvent plus être utilisés, tant pour les vaccins $\mathrm{du}$ stock du SPF [Santé publique, Sécurité de la Chaîne alimentaire et Environnement] que pour les vaccins stockés dans les pharmacies du royaume. Des firmes spécialisées devront détruire les substances périmées, ce qui représente un coût futur impossible à évaluer actuellement. Au 31 octobre 2011, aucune décision n'avait été prise en vue d'une éventuelle destruction des vaccins périmés » ${ }^{55}$.

Il est à noter qu'une erreur factuelle s'est glissée dans le rapport de la Cour des comptes, concernant la date de péremption du Pandemrix. En effet, en date du 19 novembre 2010, l'Agence européenne des médicaments avait notifié à GSK une autorisation de prolongation de la date de péremption (shelf life), qui est portée à deux ans ${ }^{56}$. Cette décision, qui a fait l'objet d'une mise à jour de la notice pharmaceutique accompagnant le Pandemrix, vaut pour les stocks existant ${ }^{57}$.

Dans le cas de la Belgique, la renégociation du contrat devrait, en définitive, avoir un impact sur le plafond des indemnités que GSK pourrait être amené à verser à l'État belge : le plafonnement ne serait plus fixé à 55,1 millions d'euros (soit $50 \%$ du prix de la commande initiale) mais à 40,1 millions d'euros (soit $50 \%$ du prix des vaccins finalement fournis) ${ }^{58}$.

\subsection{RÈGLES DE RESPONSABILITÉ APPLICABLES EN CAS DE PRÉJUDICE SUBI PAR UNE PERSONNE VACCINÉE}

Le contrat contient diverses clauses relatives au régime de responsabilité qui sera mis en œuvre si des personnes vaccinées devaient décéder ou subir un préjudice physique causé par l'utilisation ou l'administration du Pandemrix (article 11.5, sous d, point iii et articles 12 et 16.12). Notre analyse va déterminer la portée de ces clauses à l'égard des éventuelles victimes et vérifier si leurs droits sont menacés ou, au contraire, préservés.

54 À cet extrait du rapport de la Cour des comptes, il convient d'ajouter que la livraison des vaccins s'est étalée selon le contrat du 15 octobre 2009 au 15 février 2010, élément d'information important lorsqu'il s'agit de calculer la date de péremption du Pandemrix.

55 Cour des comptes, $168^{e}$ Cahier de la Cour des comptes, op. cit., p. 120-121.

Agence européenne des médicaments, Notification IB/0047 intégrée à la notice Pandemrix. Procedural steps taken and scientific information after the autorisation, www.ema.europa.eu.

57 Agence européenne des médicaments, Annex 1. Summary of product characteristics, www.ema.europa.eu. Cf. également Agence européenne des médicaments, CHMP Assessment Report for Pandemrix, 24 septembre 2009, p. 10-11.

58 Précisons qu'il s'agit là d'une déduction que nous tirons du contrat initial. L'avenant au contrat demeurant confidentiel, il est en effet impossible de savoir s'il a modifié les règles relatives à la responsabilité de GSK. Une telle modification nous paraît néanmoins peu probable, compte tenu de la position de force détenue alors par le groupe pharmaceutique dans le contexte de la renégociation. 


\subsubsection{Un contrat peut-il produire des effets à l'égard des tiers?}

Certains commentateurs ont laissé entendre que le contrat pouvait méconnaître les droits des victimes. Il convient donc, avant toute chose, de rappeler la portée de ce contrat à leur égard. Est-il concevable, en effet, qu'un groupe pharmaceutique et les pouvoirs publics mettent à mal, par contrat, les droits des personnes vaccinées ?

La réponse à cette question se trouve à l'article 1165 du Code civil, lequel consacre l'effet relatif des conventions ${ }^{59}$. Reprenant la règle contenue dans l'adage latin «Res inter alios acta aliis neque nocere neque prodesse potest $"{ }^{60}$, cet article précise que "les conventions n'ont d'effet qu'entre les parties contractantes; elles ne nuisent point au tiers, et elles ne lui profitent que dans le cas prévu par l'article $1121{ }^{61}$.

Autrement dit, un contrat ne peut pas créer de droits ou d'obligations à l'égard des tiers ; seuls ceux qui ont conclu le contrat sont, en principe, tenus de le respecter.

Cette règle souffre, néanmoins, des exceptions; si bien que le principe de la relativité des conventions est, selon le mot du professeur de droit Patrick Wéry (UCL), luimême relatif ${ }^{62}$. Ce constat est conforté par la jurisprudence. La Cour de cassation admet depuis longtemps la distinction entre les «effets internes» et les "effets externes " d'un contrat. Le principe des effets internes d'un contrat signifie que celuici n'est obligatoire que pour les parties qui l'ont conclu (en l'occurrence, dans le cas qui nous préoccupe, l'État belge et GSK). Mais le contrat produit également des effets externes : les tiers au contrat doivent en tenir compte (il leur est opposable) mais ils peuvent aussi s'en prévaloir ${ }^{63}$. Dans notre cas d'espèce, une personne qui s'estimerait lésée par le Pandemrix pourrait donc, si elle y trouve un intérêt, faire référence aux dispositions du contrat pour asseoir ses prétentions.

En résumé, quand bien même le contrat GSK-Belgique méconnaîtrait les droits des victimes, il demeurerait sans effet à leur égard en raison de la relativité des effets internes du contrat. L'État belge et GSK ne pourraient pas, en conséquence, opposer les clauses du contrat aux éventuelles victimes pour nier leurs droits.

59 Sur ce principe, cf. notamment A. BÉNABENT, Droit civil. Les obligations, Montchrestien, Paris, 2007 (11 édition), p. 192-194; P. Malaurie, L. Aynès, P. STOFFel-MunCK, Les obligations, Defrénois, Paris, 2007 ( $3^{\mathrm{e}}$ édition), p. 409-419; M. PITTIE, «Le principe de l'effet relatif des contrats à la lumière des législations récentes en matière d'obligations conventionnelles ", Annales de droit de Louvain, 1997, p. 325 ; F. Terré, P. Simler, Y. Lequette, Droit civil. Les obligations, Dalloz, Paris, 2009 (10 édition), p. 499 et $\mathrm{s}$.

60 Littéralement: «La chose [comprendre : le contrat] conclue entre les uns ne peut nuire ou profiter aux autres. »

${ }^{61}$ L'article $1121 \mathrm{du}$ Code civil organise la «stipulation pour autrui » : «On peut pareillement stipuler au profit d'un tiers, lorsque telle est la condition d'une stipulation que l'on fait pour soi-même ou d'une donation que l'on fait à un autre. Celui qui a fait cette stipulation, ne peut plus la révoquer, si le tiers a déclaré vouloir en profiter. »

62 P. WéRY, Droit des obligations, tome 1 : Théorie générale du contrat, Larcier, Bruxelles, 2010, p. 721.

3 Cour de cassation, 27 mai 1909, Pasicrisie (...), tome ??? [La Pasicrisie existant depuis 1814, ce ne peut être le tome I], Bruxelles, ? [date : 1909 ou 1910 ?], p. 272 ; M. FONTAINE, « Les "effets internes" et les "effets externes" des contrats ", in Les effets du contrat à l'égard des tiers. Comparaisons franco-belges, Librairie générale de droit et de jurisprudence (Lextenso), Paris, 1992, p. 40 ; P. WÉRY, Droit des obligations, op. cit., p. 709 et 719-793. 


\subsubsection{Directive européenne 85/374/CEE relative à la responsabilité du fait des produits défectueux}

En outre, si de telles clauses existaient, elles seraient illégales. En effet, la directive 85/374/CEE relative à la responsabilité du fait des produits défectueux ${ }^{64}$ interdit explicitement que la responsabilité du producteur (ici, GSK) puisse «être limitée ou écartée à l'égard de la victime par une clause limitative ou exonératoire de responsabilité» (article 12). Ce rejet de toute dérogation, par contrat, de la responsabilité du producteur à l'égard de la victime est justifié par le souci de préserver les droits des consommateurs : "Pour assurer une protection efficace des consommateurs, il ne doit pas pouvoir être dérogé par clause contractuelle à la responsabilité du producteur à l'égard de la victime », indique le onzième considérant de la directive ${ }^{65}$. Précisons-le d'emblée : de notre l'analyse, il ressort que le contrat conclu entre l'État belge et GSK ne contient aucune clause qui permettrait de déroger aux dispositions de la directive 85/374/CEE.

Cette directive européenne, bien connue des praticiens, requiert que la victime apporte une triple preuve pour pouvoir demander réparation au producteur: la preuve du caractère défectueux du produit, la preuve du dommage subi et la preuve du lien de causalité entre le dommage et le défaut (article 4) ${ }^{66}$. Il s'agit d'un mécanisme de « responsabilité objective » : il n'est nul besoin que la victime prouve la faute du producteur, il suffit que les trois conditions susmentionnées soient réunies.

64 Directive 85/374/CEE du Conseil du 25 juillet 1985 relative au rapprochement des dispositions législatives, réglementaires et administratives des États membres en matière de responsabilité du fait des produits défectueux, Journal officiel des Communautés européennes, L 210, 7 août 1985, p. 29; transposée par la loi du 25 février 1991 relative à la responsabilité du fait des produits défectueux, Moniteur belge, 22 mars 1991. Pour une présentation de cette directive et de la loi belge de transposition, cf. notamment P. Henry, J.-T. DEBRY, "La responsabilité du fait des produits défectueux : derniers développements ", in B. Dubuisson, P. HenRY (dir.), Droit de la responsabilité. Morceaux choisis, Larcier, coll. "Formation permanente Commission Université-Palais ", $\mathrm{n}^{\circ} 68$, Bruxelles, 2004, p. 129 et s. ; J.-L. FAGNART, « La directive du 25 juillet 1985 sur la responsabilité du fait des produits », Cahiers de droit européen, 1987, p. 1 et s. ; M. FALLON, " La loi du 25 février 1991 relative à la responsabilité du fait des produits ", Journal des tribunaux-Droit européen, 1991, p. 465 et s. ; É. MONTERO, J.-P. TRIAILLE, «La responsabilité du fait des produits en Belgique après l'adoption de la loi du 25 février 1991 », Droit de la consommation, 1991, p. 678 et s.; D. STRUYven, «La transposition de la directive européenne en matière de responsabilité du fait des produits défectueux dans le droit des États membres : bilan et perspective ", Revue internationale de droit comparé, 1989, p. 140 et s. ; C. WENIGER, La responsabilité du fait des produits pour les dommages causés à un tiers au sein de la Communauté européenne, Droz, Genève, 1994, p. 98 et $\mathrm{s}$.

65 Cette solution n'a rien d'original: on la retrouve également dans la législation relative aux clauses abusives (même si cette législation n'est pas applicable ici, dès lors que GSK n'a pas conclu le contrat avec un "consommateur» mais avec l'État belge). Aux termes de cette législation, doivent être considérées comme abusives les clauses qui ont pour objet «[d']exclure ou de limiter la responsabilité légale de l'entreprise en cas de mort du consommateur ou de dommages corporels causés à celui-ci et résultant d'un acte ou d'une omission de cette entreprise » (article 74, 25 de la loi du 6 avril 2010 relative aux pratiques du marché et à la protection du consommateur, Moniteur belge, 12 avril 2010). Cf. également l'article $3, \$ 3$ et le point a de l'annexe de la directive 93/13/CEE du Conseil du 5 avril 1993 concernant les clauses abusives dans les contrats conclus avec les consommateurs, Journal officiel des Communautés européennes, L 95, 21 avril 1993, p. 29.

66 Cette disposition a été transposée en droit belge par l'article 7 de la loi du 25 février 1991 (cf. supra). 
La directive définit le «produit » comme « tout meuble ${ }^{67}(\ldots)$ même s'il est incorporé dans un autre meuble ou dans un immeuble» (article 2). La jurisprudence a déjà affirmé à plusieurs reprises que les vaccins doivent être considérés comme des produits au sens de cette disposition : c'est notamment le cas de deux arrêts de la Cour de justice de l'Union européenne ayant pour objet des vaccins antihaemophilus ${ }^{68}$ et d'un arrêt de la Cour de cassation française concernant un vaccin antihépatite $\mathrm{B}^{69}$. Il ne fait donc aucun doute que le Pandemrix entre dans le champ d'application de cette directive.

Encore faudrait-il que la victime démontre que le Pandemrix est défectueux. Aux termes de l'article 6 de la directive, un produit est réputé défectueux s'il «n'offre pas la sécurité à laquelle on peut légitimement s'attendre compte tenu de toutes les circonstances, et notamment: a) de la présentation du produit ; b) de l'usage du produit qui peut être raisonnablement attendu; c) du moment de la mise en circulation du produit ${ }^{70}$. Il est aussi précisé qu'un produit ne peut être considéré comme défectueux par le seul fait qu'un produit plus perfectionné a été mis en circulation postérieurement à lui.

Si une personne devait démontrer la défectuosité du Pandemrix, cette première condition requise par la directive serait donc remplie. Toutefois, GSK pourrait, malgré ce défaut, tenter d'échapper à sa responsabilité en invoquant le bénéfice de l'une des clauses d'exonération mentionnées à l'article 7 de la directive. Parmi celles-ci, mentionnons en particulier la clause dite du "risque de développement", laquelle prévoit que « le producteur n'est pas responsable (...) s'il prouve (...) que l'état des connaissances scientifiques et techniques au moment de la mise en circulation du produit par lui n'a pas permis de déceler l'existence du défaut » (article 7 , sous e) ${ }^{71}$.

67 En droit, le terme «meuble» signifie « toute chose matérielle qui peut être déplacée » (G. CORNU, Vocabulaire juridique, Presses universitaires de France, Paris, 2008, $\mathrm{v}^{\circ}$ meuble).

${ }^{68}$ Cour de justice des Communautés européennes (première chambre), «D. O’Byrne contre Sanofi Pasteur MSD Ltd and Sanofi Pasteur SA », Affaire C-127/04, arrêt du 9 février 2006, Recueil de la jurisprudence, 2006, p. I-1313; Cour de justice de l'Union européenne (grande chambre), «Aventis Pasteur SA contre OB ", Affaire C-358/08, arrêt du 2 décembre 2009, Recueil de la jurisprudence, 2009, p. I-11305.

69 Cour de cassation [France] (première chambre civile), "Société Sanofi Pasteur MSD contre A. X. et al. », arrêt $\mathrm{n}^{\circ} 605$ du 9 juillet 2009 ; J.-L. FAGNART, I. LUTTE, "Vaccination contre l'hépatite B et sclérose en plaques", Revue belge du dommage corporel et de médecine légale, 2010, p. 47-56. Plus globalement, la doctrine a déjà analysé l'application de la directive 85/374/CEE dans le secteur pharmaceutique : M.-E. ARBOUR, L'indemnisation du dommage causé par des médicaments défectueux et le droit harmonisé européen: entre l'émergence d'une obligation de sécurité et le respect des valeurs rattachées au libre-marché, in F. SNYDER (dir.), Quels droits pour les consommateurs en Europe?, Bruylant, Bruxelles, 2003, p. 93-112 ; G. GenICOT, Droit médical et biomédical, Larcier, Bruxelles, 2010, p. 407 et s.; A. WARE, « 20 Years On. The Product Liability Directive Applied to the Pharmaceutical Sector ", Revue européenne de droit de la consommation, 2009, p. 397 et s.

70 B. Dubuisson, «La notion de défaut dans la directive européenne du 25 juillet 1985 », Droit de la consommation, 1989 , p. 76-89.

${ }^{71} \bar{A}$ ce sujet, cf. notamment J. CALAIS-AuloY, «Le risque de développement: une exonération contestable », in Mélanges Michel Cabrillac, Dalloz-Litec, Paris, 1999, p. 89 et s.; C. LARroumet, "La notion de risque de développement, risque du XxI siècle", in Clés pour le siècle, Dalloz, Paris, 2000, p. 1589; T. VANSWEEVELT, "Les risques de développement", in Les assurances de l'entreprise, volume II, Bruylant, Bruxelles, 1993, p. 317 et s. ; C. VERDURE, « Le risque de développement dans le cadre de la responsabilité du fait des produits défectueux », Revue générale de droit civil belge, 2007, p. 131 et s. ; A. WARE, « 20 Years On. The Product Liability Directive Applied to the Pharmaceutical Sector », op. cit., p. 407 et s. 
En deuxième lieu, l'éventuelle victime devrait prouver son dommage. La directive ne couvre pas l'ensemble du champ des dommages potentiels : seuls les décès et lésions corporelles sont visés (article 9 , sous a) ${ }^{72}$. Notons, dès à présent, que le contrat liant GSK et l'État belge évoque également ces deux types de préjudice (cf. infra 1.2.3.).

Enfin, il lui faudrait établir le lien de causalité entre le Pandemrix et les éventuels préjudices subis. À cet égard, notons que certains rapports officiels finlandais et suédois apportent de premiers éléments. Ainsi, en février 2011, l'Institut finlandais pour la santé et le bien-être (THL) a rendu public un "rapport intermédiaire " ${ }^{73}$ constatant que les enfants et adolescents de quatre à dix-neuf ans à qui l'on a administré le Pandemrix présentent un risque de souffrir de narcolepsie ${ }^{74}$ neuf fois plus élevé que les personnes du même âge qui n'ont pas été vaccinées. Des constats similaires ont également été posés en Suède, en Islande et en France ${ }^{75}$. Leurs conclusions n'ont pas été infirmées depuis lors, même s'il est possible que les risques de narcolepsie soient plus grands en cas d'interaction entre le vaccin et d'autres facteurs (génétiques ou environnementaux) ${ }^{76}$.

En l'état actuel des informations disponibles, la question de la causalité demeure épineuse : il ne peut être établi de lien incontestable entre l'augmentation des cas de narcolepsie et l'administration du Pandemrix. Or, la jurisprudence de la Cour de cassation belge exige que ce lien soit certain: «[Il] incombe au demandeur en réparation d'établir l'existence d'un lien de causalité entre la faute et le dommage tel qu'il s'est réalisé; que ce lien suppose que, sans la faute, le dommage n'eût pu se produire tel qu'il s'est produit. (...) [Le] juge ne peut condamner l'auteur de la faute à réparer le dommage réellement subi s'il décide qu'une incertitude subsiste quant au lien causal entre la faute et ce dommage $"$ ".

En résumé, quand bien même une victime parviendrait à remplir les deux premières conditions (dommage et défectuosité du vaccin), il ne lui serait pas aisé de démontrer qu'il existe un lien de causalité indiscutable entre ces éléments.

Par ailleurs, cette difficulté serait d'autant plus grande que la directive 85/374/CEE érige plusieurs limites d'ordre procédural. L'action en réparation doit en effet être introduite dans les trois ans à compter du jour auquel la victime a eu (ou aurait dû

72 Cette disposition a été transposée en droit belge par l'article 11, $\$ 1^{\mathrm{er}}$ de la loi du 25 février 1991 (cf. supra).

73 Ce rapport intermédiaire (31 janvier 2011) est disponible sur le site Internet du Terveyden ja hyvinvoinnin laitos, institut national finlandais pour la santé et le bien-être : www.thl.fi.

74 La narcolepsie est une affection neurologique qui se caractérise par une somnolence excessive durant la journée. D'autres symptômes peuvent également survenir telle la cataplexie (perte de tonus musculaire).

${ }^{5}$ "Une étude lie un vaccin contre le H1N1 à des cas de narcolepsie », Le Monde, $1^{\text {er }}$ février 2011; «Un vaccin anti-H1N1 peut-être lié à des cas de narcolepsie », Le Figaro, 2 février 2011.

Cette question sera davantage développée dans la seconde partie de notre étude (cf. infra, 2.2.4).

77 Cf. par exemple Cour de cassation (chambres réunies), «État belge contre B. A. et al. », C.01.0211.FC.01.0217.F, arrêt du $1^{\mathrm{er}}$ avril 2004, Journal des tribunaux, 2005, p. 357. Sur la causalité, cf. notamment B. DuBuisson, I. DURANT, «Quelques traits saillants de la causalité dans le droit belge de la responsabilité civile ", Revue Lamy de droit civil, n 40, 2007, p. 67-88 ; J.-L. FAGNART, La causalité, Kluwer, Waterloo, 2008 ; I. DURANT, "À propos de ce lien qui doit unir la faute au dommage ", in B. Dubuisson, P. HenRY (dir.), Droit de la responsabilité, op. cit., p. 27. [Explication CRISP : Les exemples pourraient être multipliés à l'envi, et depuis des périodes plus anciennes. Inutile donc d'en citer plus d'un.] 
avoir) connaissance du dommage, du défaut et de l'identité du producteur (article 10). En tout état de cause, l'action est prescrite si elle est intentée dix ans après la mise en circulation du produit défectueux par le producteur; ce délai décennal peut, néanmoins, être dépassé si la victime a engagé une procédure judiciaire avant l'expiration de celui-ci (article 11) ${ }^{78}$.

\subsubsection{Clauses du contrat relatives au remboursement des frais exposés par GSK}

Le principe général posé par le contrat veut qu'en cas de condamnation de GSK sur la base de la législation relative aux produits défectueux (ou de reconnaissance volontaire de sa responsabilité), le groupe pharmaceutique indemnisera les victimes puis réclamera à l'État belge le remboursement d'une série de frais qu'il aura supportés. À cet égard, il y a lieu de souligner que les frais exposés par GSK et qui seront remboursés par l'État belge dépassent les seules indemnités versées aux victimes et surtout, qu'ils ne connaissent aucun montant maximal. En pratique, la Belgique s'engage à assumer "tous frais, dépenses, honoraires, exposés ou payés pour le traitement de la réclamation, en ce compris la contestation de celle-ci, ainsi que les indemnités qui seraient payées par [GSK] en vertu d'une décision ou d'une transaction, à l'exclusion des amendes pénales » (articles 12.1, al. 2 et 12.2, al. 2).

Toutefois, le contrat précise que cette règle souffre plusieurs exceptions. Dans cinq cas, l'État belge ne devra pas rembourser GSK :

- pour les conséquences financières qui auraient été supportées par un tiers. C'est l'hypothèse de l'intervention d'une compagnie d'assurance; cette dérogation ne vaut que si la compagnie d'assurance n'appartient pas au groupe GSK (article 12.3, sous a);

- si les réclamations des victimes découlent de l'utilisation ou de l'administration d'un vaccin pandémique qui n’a pas été agréé par le ministre de la Santé (article 12.3, sous b) ;

- si les réclamations n'ont pas été notifiées au ministre de la Santé dans un délai de trente jours prenant cours au jour où le groupe GSK en a pris connaissance ou devait raisonnablement en avoir pris connaissance (article 12.3, sous c);

- lorsque les réclamations se rapportent à tout décès ou préjudice physique dont le groupe GSK a eu connaissance par le biais de son système de pharmacovigilance et qu'il a omis de notifier, alors que les recommandations de l'Agence européenne des médicaments l'y contraignent. Ce dernier motif ne pourra être excipé que s'il apparaît que l'omission de GSK constitue une faute lourde eu égard à l'ensemble des circonstances pertinentes (article 12.3, sous d);

- et, enfin, si GSK renonce à son droit aux indemnités (article 16.12, sous i du contrat).

Le contrat ne contient, en définitive, aucune limitation ou exonération de responsabilité à l'égard des tiers. De même, il est abusif - sur le plan du droit - de parler de transfert de responsabilité. GSK sera toujours juridiquement responsable des dommages que le Pandemrix occasionnerait chez les personnes vaccinées. En revanche, les conséquences financières découlant de la mise en cause de cette responsabilité (c'est-à-dire les indemnités dues aux victimes et tous les frais visés par le contrat) seront in fine assumées par l'État belge dans les limites décrites ci-dessus.

78 Cette disposition a été transposée en droit belge par l’article 12 de la loi du 25 février 1991 (cf. supra). 
Le contrat ne déroge donc pas au droit commun de la responsabilité. Il n'organise qu'un régime de remboursement des frais exposés par GSK.

Puisque le contrat a été rendu public, ce régime de remboursement est également susceptible d'être connu des tiers. Se pose alors la question des liens entre les éventuelles victimes et l'État belge: pourraient-elles invoquer à leur profit ces dispositions (effets externes du contrat) et réclamer le dédommagement de leur préjudice directement auprès des pouvoirs publics, sans attraire préalablement en justice le groupe pharmaceutique?

Nous ne le pensons pas. Certes, les conséquences financières seront, au final, à charge de l'État belge. Mais les indemnités à payer aux éventuelles victimes supposent que la responsabilité du groupe pharmaceutique soit auparavant établie. Il est inimaginable que des indemnités soient versées par la Belgique alors que l'on ignore si GSK est, ou non, responsable du point de vue juridique. Du reste, le contrat ne contient aucune disposition en faveur des tiers : on ne se situe pas dans l'hypothèse visée à l'article 1121 du Code civil, c'est-à-dire celle de la stipulation pour autrui. Autrement dit, l'État belge ne s'est pas engagé à indemniser les victimes. Au contraire, le contrat n'institue qu'un droit au remboursement dont le seul bénéficiaire est GSK. Cette analyse est, au surplus, corroborée par la faculté laissée à GSK de «renoncer à son droit aux indemnités qui seraient dues par le [ministre de la Santé] en exécution de la présente convention » (article 16.12, sous i). Il n'est, en conclusion, pas possible pour une éventuelle victime de se fonder sur le contrat pour réclamer directement à l'État belge l'indemnisation de son prétendu dommage.

\subsubsection{Clauses du contrat relatives aux garanties offertes à l'État belge}

Dès lors que la Belgique supportera le coût final des éventuelles indemnisations, le contrat l'autorise à "intervenir dans toute procédure ou toute négociation de transaction résultant d'une réclamation, ou d'une demande susceptible de conduire à une réclamation, formulée à l'encontre de GSK» (article 16.12, al. 1). Pour s'assurer de l'effectivité de ce droit d'intervention, le contrat offre certaines garanties à l'État belge. Celles-ci - sous forme de droits, mais également d'obligations - couvrent l'ensemble de la procédure judiciaire ou de la négociation de transaction et peuvent être rassemblées en trois catégories : un droit à défendre ses intérêts, une obligation d'information et une obligation de concertation.

\section{Droit à défendre ses intérêts}

«Le [ministre de la Santé] nommera, s’il le souhaite, des conseils externes. (...) Dans la conduite de la procédure ou de la négociation, selon le cas, le [ministre de la Santé] fera ses meilleurs efforts pour ne rien faire ou ne rien communiquer qui puisse avoir un impact défavorable sur les intérêts commerciaux, la réputation de GSK ou du vaccin ou qui emporterait dénigrement de GSK, du vaccin, de ses composants ou d'autres produits de GSK, ou des sociétés affiliées » (article 16.12, sous d et g). 
Le ministre de la Santé peut, s'il le désire, faire appel à des conseils externes, c'est-àdire aux avocats de son choix. Ce droit est accompagné d'un devoir : celui de ne pas porter atteinte aux intérêts de GSK. En conséquence, dans la conduite de la procédure ou de la négociation, le ministre doit s'abstenir de toute déclaration et de tout comportement qui mettrait à mal les intérêts commerciaux de GSK ou sa réputation, ou qui dénigrerait le vaccin et ses composants.

Cette dernière exigence explique certainement les propos, on ne peut plus timorés, de la ministre de la Santé, L. Onkelinx, quand elle a été interrogée au sujet de l'innocuité du Pandemrix ou de la teneur des dispositions contractuelles.

\section{Obligation d'information}

«GSK notifiera sans délai au [ministre de la Santé] l'existence de toute réclamation, ou d'une demande susceptible de conduire à une réclamation, formulée à son encontre, informera régulièrement le [ministre de la Santé] de l'état de la procédure ou de la négociation, selon le cas (...).

GSK communiquera immédiatement au [ministre de la Santé] une copie de tout document qui lui est adressé par la partie ayant formulé la réclamation, ou la demande susceptible de conduire à une réclamation, en rapport avec cette dernière et donnera au [ministre de la Santé] la possibilité de faire valoir ses observations et arguments.

GSK communiquera immédiatement au [ministre de la Santé] une copie de toute note de frais qui lui est adressée dans le cadre de la gestion de la procédure ou de la négociation d'une transaction. (...)

À la demande du [ministre de la Santé], GSK pourra fournir des informations confidentielles aux conseils externes du [ministre de la Santé] à la condition que lesdits conseils respectent le caractère confidentiel desdites informations, notamment - sauf avis contraire de GSK - à l'égard du [ministre de la Santé] » (article 16.12, sous a, b, c et h).

GSK doit notifier sans délai au ministre de la Santé l'existence de toute réclamation formée à son encontre et il doit l'informer régulièrement de l'état de la procédure ou de la négociation. GSK doit, en outre, communiquer au ministre tout document qui lui aurait été adressé par l'un des plaignants et lui donner la possibilité de faire valoir son point de vue. Il doit également lui fournir la copie de toute note de frais en lien avec la procédure judiciaire ou la négociation. Le ministre peut, enfin, exiger que GSK communique aux avocats de l'État belge des informations confidentielles mais ceux-ci devront - sauf avis contraire du groupe pharmaceutique - garantir la confidentialité de ces documents même à l'égard de leur client.

\section{Obligation de concertation}

« [GSK] consultera le [ministre de la Santé] au préalable avant de prendre quelque décision que ce soit susceptible d'avoir un effet sur le résultat de la procédure ou de la négociation. (...)

Le [ministre de la Santé] prendra en considération les arguments raisonnables de GSK en sorte d'assurer, dans la mesure du possible, la cohérence de la défense développée à 
l'encontre de la réclamation avec les défenses développées le cas échéant dans d'autres pays à l'encontre de réclamations similaires.

Aucune reconnaissance de responsabilité ne peut avoir lieu, aucune obligation de faire ou ne pas faire ne peut être contractée et aucune transaction ne peut être conclue sans que les parties n'y aient au préalable donné leur accord écrit. (...)

À tout moment, GSK pourra renoncer à son droit aux indemnités qui seraient dues par le [ministre de la Santé] en exécution de la présente convention au titre de la réclamation concernée et mener librement la conduite de la procédure ou de la négociation, selon le cas. L'exercice par GSK de son droit à renonciation dans le cadre d'un litige est sans incidence sur le droit à indemnité de GSK de la part du [ministre de la Santé] dans le cadre des autres litiges.

Lorsque le [ministre de la Santé] interviendra dans la défense du litige en application du présent paragraphe, et sous réserve de l'application des paragraphes (a) à (h) ci-dessus, le [ministre de la Santé] pourra choisir librement la stratégie de défense.

Dans l'hypothèse où le [ministre de la Santé] choisit d'intervenir dans le cadre de la procédure, les parties demanderont à leurs conseils externes de collaborer dans la mesure du possible » (article 16.12, sous a, e, f, i, j et article 16.12, al. 3).

GSK doit consulter l'État belge avant d'adopter une décision qui serait susceptible d'avoir un effet sur le résultat de la procédure ou de la négociation. Cette obligation interdit qu'une reconnaissance de responsabilité soit contractée sans que les parties n'y aient donné leur accord écrit; cet accord écrit est également requis avant la conclusion de toute transaction. On comprend aisément l'intérêt de ces clauses pour la Belgique: l'État belge devant assumer le coût final de ces procédures, il serait malvenu pour lui que GSK reconnaisse trop rapidement (ou avec trop de légèreté) sa responsabilité civile.

Il est aussi demandé au ministre de prendre en considération les arguments raisonnables de GSK en vue d'assurer, dans la mesure du possible, la cohérence de la défense adoptée par le groupe pharmaceutique tant en Belgique que dans d'autres États. Enfin, si l'État belge choisit d'intervenir dans le cadre de la procédure, les parties demanderont à leurs avocats respectifs de collaborer dans la mesure du possible.

Toutefois, nous l'avons déjà évoqué, GSK dispose du droit de renoncer aux indemnités qui lui seraient dues par l'État belge. L'activation de cette faculté emporte la renonciation à l'obligation de concertation. En effet, dans un tel cas de figure, les parties pourront agir librement: GSK pourra mener la conduite de la procédure ou de la négociation comme il l'entend et, de son côté, le ministre pourra adopter la stratégie de défense de son choix. Le contrat prend soin de préciser qu'une éventuelle renonciation de la part de GSK n'aura aucune incidence sur les autres procédures ou négociations en cours ou à venir. C'est une approche au cas par cas.

\subsubsection{La Belgique pourrait-elle se retourner contre la Commission européenne?}

Pour tenter de justifier le fait que l'État fédéral a pris l'engagement de supporter les conséquences financières qui découleraient de la mise en cause de la responsabilité de 
GSK, la ministre de la Santé publique explique en mai 2010 que «si la responsabilité de GSK est reconnue, la firme, par contrat, est couverte par l'État belge, c'est vrai, mais l'État peut à son tour se retourner contre la Commission européenne, qui a autorisé GSK à mettre le vaccin sur le marché » ${ }^{79}$. Bref, les finances publiques belges n'auraient pas à souffrir car la Belgique réclamerait, à son tour, à la Commission le remboursement des indemnités qu'elle aurait versées à GSK. À notre estime, il est loin d'être évident que la Commission puisse être ainsi tenue responsable, uniquement pour avoir accordé à GSK une autorisation de mise sur le marché pour le Pandemrix.

Une telle action en responsabilité à l'encontre de la Commission ne pourrait être portée que devant la Cour de justice de l'Union européenne, à l'exclusion donc des juridictions belges. En vertu du traité sur le fonctionnement de l'Union européenne (TFUE), cette cour de justice dispose, en effet, d'un monopole pour connaître des contentieux relatifs à la responsabilité extra-contractuelle de l'Union européenne ${ }^{80}$. Or, les juges européens imposent des conditions strictes pour que la responsabilité de l'Union puisse être mise en cause $^{81}$ : «L'engagement de la responsabilité non contractuelle de [1'Union] pour comportement illicite de ses organes, au sens de l'article [340, alinéa 2 du TFUE], est subordonné à la réunion d'un ensemble de conditions, à savoir l'illégalité du comportement reproché aux institutions, la réalité du dommage et l'existence d'un lien de causalité entre le comportement allégué et le préjudice invoqué (...). Étant donné le caractère cumulatif de ces conditions, le recours doit être rejeté dans son ensemble lorsqu'une seule de ces conditions n'est pas remplie ${ }^{82}$.

La première condition exige que l'une des institutions de l'Union européenne (en l'occurrence, ici, la Commission) ait commis une violation «suffisamment caractérisée », c'est-à-dire "manifeste et grave», d'une "règle de droit ayant pour objet de conférer des droits aux particuliers ${ }^{83}$.

79 «Laurette Onkelinx: "Aucun autre État n’a obtenu de GSK des conditions plus favorables que la Belgique" ", Le Soir, 6 mai 2010.

80 «En matière de responsabilité non contractuelle, l’Union doit réparer, conformément aux principes généraux communs aux droits des États membres, les dommages causés par ses institutions ou par ses agents dans l'exercice de leurs fonctions " ("Version consolidée du traité sur le fonctionnement de l'Union européenne ", art. 340, alinéa 2 [ex-art. 288, alinéa 2 du traité instituant la Communauté européenne], Journal officiel de l'Union européenne, C 83, 30 mars 2010, p. 47) ; " La Cour de justice de l'Union européenne est compétente pour connaître des litiges relatifs à la réparation des dommages visés à l'article 340, deuxième (...) alinéa » (art. 268 TFUE [ex-art. 235 TCE]).

81 Des conditions identiques sont exigées pour mettre en cause la responsabilité des États membres pour violation du droit européen (cf. la jurisprudence : Cour de justice des Communautés européennes, "A. Francovich, D. Bonifaci et al. contre République italienne», Affaires jointes C-6/90 et C-9/90, arrêt du 19 novembre 1991, Recueil de jurisprudence, 1995, p. I-5357; Cour de justice des Communautés européennes, «Brasserie du Pêcheur SA contre Bundesrepublik Deutschland et The Queen contre Secretary of State for Transport (ex parte: Factortame Ltd et al.) », Affaires jointes C-46/93 et C-48/93, arrêt du 5 mars 1996, Recueil de jurisprudence, 1996, p. I-1029).

82 Cf. par exemple Tribunal de l'Union européenne (troisième chambre), "Arcelor SA contre Parlement européen et Conseil », Affaire T-16/04, arrêt du 2 mars 2010, points 139 et 140, Recueil de la jurisprudence, 2000, p. II-211. Pour plus de développements, cf. M. WATHELET, J. WiLDEMEERSCH, Contentieux européen, Larcier, Bruxelles, 2010, p. 288 et s.

83 Cour de justice des Communautés européennes, «Laboratoires pharmaceutiques Bergaderm SA et Jean-Jacques Goupil contre Commission des Communautés européennes », Affaire C 352/98 P, arrêt du 4 juillet 2000, point 42, Recueil de la jurisprudence, 2000, p. I-5291. 
D'ores et déjà, nous exprimons notre scepticisme quant à la possibilité pour la Belgique d'introduire une telle action: en effet, s'il est certain que GSK dispose de différents "droits qui lui sont conférés " par la législation européenne relative aux médicaments, il est douteux qu'il en aille de même avec l'État belge. Même à considérer qu'il faille interpréter largement la condition " [violer] une règle de droit ayant pour objet de conférer des droits aux particuliers » (l'État belge n'étant pas un "particulier »), quel serait ce droit reconnu par le droit européen à l'État belge ? Nous l'ignorons; à dire vrai, nous doutons même que la législation européenne ait accordé le moindre droit à la Belgique dans ce contexte.

Indépendamment de cette remarque liminaire, la mise en cause de la responsabilité de l'Union européenne suppose donc que l'on vérifie si la Commission a, ou non, respecté la législation européenne en octroyant cette autorisation de mise sur le marché. Et même s'il devait y avoir eu infraction à cette législation, encore faudrait-il que cette violation présente un haut degré de gravité. Comme le rappelle la Cour de justice de l'Union européenne, c'est seulement lorsque cette institution ne dispose que "d'une marge d'appréciation considérablement réduite, voire inexistante, [que] la simple infraction au droit [européen] peut suffire à établir l'existence d'une violation suffisamment caractérisée ${ }^{84}$.

$\mathrm{Au}$ regard de la législation européenne relative aux médicaments, la Commission dispose bel et bien d'une marge d'appréciation. Elle peut accorder l'autorisation de mise sur le marché, la refuser, voire la conditionner ${ }^{85}$. En l'espèce, la Commission a délivré une autorisation de mise sur le marché valide dans toute l'Union européenne pour le Pandemrix le 20 mai 2008. «À l'origine, [le] Pandemrix a été autorisé dans des "circonstances exceptionnelles", étant donné que, pour des motifs scientifiques, les informations disponibles étaient limitées au moment de l'approbation. La société ayant fourni les informations supplémentaires requises, les "circonstances exceptionnelles" ont pris fin le 12 août 2010. ${ }^{86}$ Cette autorisation de mise sur le marché sous condition ${ }^{87}$ a été précédée de l'avis positif ${ }^{88}$ du Comité des médicaments à usage humain ${ }^{89}$.

Ibidem, point 44

Règlement (CE) n 726/2004 du Parlement européen et du Conseil du 31 mars 2004, établissant des procédures communautaires pour l'autorisation et la surveillance en ce qui concerne les médicaments à usage humain et à usage vétérinaire, et instituant une Agence européenne des médicaments, Journal officiel de l'Union européenne, 30 avril 2004, L 136, p. 1. Cf. aussi M. GOBERT, «Les autorisations de mise sur le marché des médicaments - Médicaments à usage humain ", Revue européenne de droit de la consommation, 2009, p. 239-279.

86 European Medicines Agency, Résumé EPAR [European Public Assessment Report] à l'intention du public. Pandemrix, vaccin grippal pandémique (H1N1) (virion fragmenté, inactivé, adjuvé), EMA/706566/2011 - EMEA/H/C/000832, août 2011, p. 3.

87 La Commission européenne avait exigé que GSK réponde à un certain nombre d'exigences : "Nous attendons des firmes qu'elles remplissent un certain nombre d'obligations, une fois l'autorisation délivrée. Au rang de ces dernières figure, en particulier, la poursuite de tests cliniques additionnels et le respect de certaines obligations de pharmacovigilance. Nous attendons des donnés cliniques, qui devraient nous être soumises dans les prochaines semaines ou prochains mois. En parallèle, les firmes sont tenues de mener des études épidémiologiques prospectives sur de larges pans de la population, comprenant au moins 9000 patients de différents groupes d’âge, en respectant les séquences du calendrier adopté en accord avec l'Agence européenne des médicaments (EMEA). Un rapport simplifié de mise à jour périodique (PSUR), comprenant toute information sur l'ensemble des éventuels problèmes qui se seraient manifestés sur cette période, nous sera soumis sur une base 
Si l'État belge entendait mettre en cause la responsabilité de l'Union européenne, il lui appartiendrait donc de prouver que la Commission n'a pas respecté les procédures fixées par la législation européenne, et singulièrement par le règlement $(\mathrm{CE}) \mathrm{n}^{\circ}$ 726/2004 précité. Si elle n'y parvenait pas, son action serait déclarée non fondée et, partant, serait rejetée.

S'agissant de la deuxième condition, la Belgique devrait démontrer qu'elle a subi un dommage. Cette démonstration ne devrait guère poser de problème dans l'hypothèse du versement d'indemnités à GSK : l'appauvrissement du Trésor public pourrait être considéré comme un dommage.

En revanche, nous sommes plus que dubitatifs au sujet de la dernière condition, qui suppose qu'il existe un lien de causalité directe entre la violation du droit européen (première condition) et le dommage subi (deuxième condition). Même si la Belgique parvenait à démontrer que ces deux premières conditions sont remplies, il lui resterait à établir la causalité entre la méconnaissance du droit européen et le préjudice. Or, ce lien logique est loin d'être évident. L'écueil, selon nous, tient au fait que l'origine de l'éventuel préjudice subi par la Belgique serait de nature contractuelle : l'État belge a pris l'engagement de supporter les frais exposés par GSK. En d'autres termes, ce ne serait pas le potentiel comportement illicite de la Commission qui causerait un préjudice à l'État belge, mais la mise en œuvre des dispositions du contrat liant le gouvernement fédéral à GSK. Or, cette mise en œuvre serait activée, non pas parce que la Commission aurait violé la législation européenne, mais uniquement parce que la responsabilité de GSK aurait été reconnue pour les dommages que le Pandemrix aurait causés aux personnes vaccinées. Du reste, il n'est pas impossible que le Pandemrix puisse générer des décès ou des lésions corporelles chez les personnes vaccinées alors que toutes les procédures européennes ont été respectées à la lettre. En effet, l'autorisation de mise sur le marché n'est pas un blanc seing accordé aux groupes pharmaceutiques, ni même la garantie que le médicament ne présente aucun effet nocif. Tout médicament présente des effets secondaires indésirables et son fabricant demeure, dans tous les cas, responsable tant sur le plan civil que sur le plan pénal ${ }^{90}$.

En résumé, il apparaît qu'a priori aucune condition (excepté, le cas échéant, la condition relative au dommage) ne serait remplie par l'État belge pour pouvoir valablement mettre en cause la responsabilité de l'Union européenne.

mensuelle. Sur la base de ces PSUR, le Comité des médicaments à usage humain (CHMP) continuera à évaluer et à recommander des mises à jour pour ce qui concerne l'autorisation, en ce compris tout changement apporté à la maîtrise statistique des procédés, la notice et l'étiquetage, au besoin. Sur la base de cet avis scientifique, la Commission est susceptible de modifier, révoquer ou suspendre l'autorisation - selon ce qui s'avère nécessaire» (Parlement européen, Questions parlementaires, E-4959/2009: Réponse de la Commission à la question écrite P-5208/09 de R. Romeva i Reueda du 21 octobre 2009, 16 novembre 2009 [notre traduction]).

88 European Medicines Agency, CHMP [Committee for Medicinal Products for Human Use] Assessment Report for Pandemrix, EMEA/285631/2008, 2008.

89 Committee for Medicinal Products for Human Use (CHMP). Ce comité est composé d'experts issus des États membres. Il rend des avis scientifiques sur toutes les questions relatives aux médicaments à usage humain et il évalue les demandes d'autorisation de mise sur le marché de ces médicaments.

90 «L'octroi de l'autorisation n'affecte pas la responsabilité civile ou pénale du fabricant ou du titulaire de l'autorisation de mise sur le marché régie par le droit national en vigueur dans les États membres » (article 15 du règlement (CE) n ${ }^{\circ}$ 726/2004 du Parlement européen et du Conseil du 31 mars 2004, op. cit.). 


\subsection{CONCLUSION INTERMÉDIAIRE : UN CONTRAT LÉGAL MAIS DÉSÉQUILIBRÉ}

L'analyse juridique du contrat ne permet pas de déceler une disposition qui méconnaitrait les droits des éventuelles victimes. Pour autant, le contrat n'est pas exempt de critiques, puisque l'on constate un déséquilibre patent entre les obligations pécuniaires respectives des cocontractants. D'un côté, GSK voit sa responsabilité limitée : en cas de litige entre les parties, les indemnités auxquelles pourrait prétendre l'État belge ne pourront excéder la moitié du prix qu'il a payé pour l'achat des doses de Pandemrix (soit 40,1 millions d'euros). D’un autre côté, l'État belge accepte d'endosser l'ensemble des conséquences financières qui découleraient de la mise en cause de la responsabilité civile de GSK pour tout décès ou lésion corporelle causé par le Pandemrix. Or, dans ces hypothèses, le contrat prévoit un régime de responsabilité illimitée en montant : il n'institue aucun plafond aux remboursements qu'est en droit d'exiger GSK.

À l'absence de plafond contractuel, s'ajoute l'inexistence de plafond légal en droit belge. Pour rappel, la directive européenne 85/374/CEE relative à la responsabilité du fait des produits défectueux autorise les États à introduire, dans leur droit, une limite aux indemnités en cas de dommages sériels aux personnes : "Tout État membre peut prévoir que la responsabilité globale du producteur pour les dommages résultant de la mort ou de lésions corporelles et causés par des articles identiques présentant le même défaut est limitée à un montant qui ne peut être inférieur à 70 millions [d'euros] » $\left(\right.$ article $16, \$ 1^{\text {er }}$ ).

Toutefois, la Belgique n'a pas fait usage de cette faculté lors de la transposition de cette directive dans la loi du 25 février 1991. En d'autres mots, il n'existe aucun plafonnement des dédommagements qui soit fixé par la loi. Pourtant, le législateur belge n'a pas toujours été réticent à l'idée de limiter les indemnités dans l'hypothèse de dommages sériels: en matière de terrorisme, par exemple, une loi d'avril 2007 prévoit ainsi que l'indemnisation globale ne peut dépasser un milliard d'euros ${ }^{91}$.

91 Loi du $1^{\text {er }}$ avril 2007 relative à l'assurance contre les dommages causés par le terrorisme, Moniteur belge, 15 mai 2007. 


\section{ANALYSE DU PROCESSUS DÉCISIONNEL ET DE L'ACTION DU GOUVERNEMENT FÉDÉRAL}

À la lueur de l'analyse des termes du contrat, il apparait que ceux-ci sont nettement déséquilibrés en la défaveur de l'État belge, qui y a néanmoins librement consenti. Cependant, il faut convenir que, sur un plan strictement juridique, la responsabilité du gouvernement n'est pas engagée concernant d'éventuels effets secondaires du Pandemrix. Or, le discours médiatique dominant, au sujet du contrat, a évoqué "le rejet de toute responsabilité sur le gouvernement ${ }^{92}$. Faut-il alors en conclure, avec ces différents médias, que le contrat porte atteinte à la responsabilité politique de ce dernier? Telle est la question à laquelle répond cette seconde partie. Nous y formulerons l'hypothèse selon laquelle l'État belge, confronté à la nécessité de prendre une décision rapide dans un contexte de haute incertitude et d'information lacunaire, a en effet opté pour une mise en œuvre classique de l'idée qu'il se fait de sa propre responsabilité, marquée du sceau d'une logique de prévention des risques.

Pour commencer, ce chapitre reviendra sur les concepts de "prévention" et de "précaution », qui caractérisent typiquement la marche de l'action publique dans des situations de controverses technico-scientifiques. Ensuite, il s'attachera à caractériser la logique de l'action publique dans le cas du contrat de fourniture de vaccins Pandemrix. À cette fin, nous présentons une première situation génératrice de risques : la pandémie $\mathrm{A}(\mathrm{H} 1 \mathrm{~N} 1)$. Nous analysons la manière dont le gouvernement y a répondu, en se proposant de vacciner la population, pour ensuite constater que ladite population n'a pas embrayé sur cette option. Nous chercherons alors à comprendre cette divergence et tâcherons d'isoler, à contexte partagé, les facteurs décisifs qui ont engagé la décision gouvernementale. Enfin, avant de conclure, nous étudierons les questions qui n'ont, selon nous, pas fait l'objet d'une prise en considération suffisante dans cette décision, à savoir principalement la question des risques, aussi bien financiers que de santé publique, liés à la vaccination proprement dite.

Certes, une telle démarche analytique ne rend pas justice à la réalité du processus décisionnel in vivo, lorsque se mêlent l'urgence des enjeux et la balance des intérêts en présence. Toutefois, elle a le mérite de la pédagogie et de la clarification; elle permet en outre un examen circonstancié du déroulement des événements, avec le recul temporel nécessaire.

92

"H1N1 : voici le contrat entre GSK et le gouvernement belge », Le Soir, 5 mai 2010; « Le contrat avec GSK rejette la responsabilité sur le gouvernement », La Libre Belgique, 5 mai 2010. 


\subsection{LOGIQUES DE PRÉVENTION ET DE PRÉCAUTION}

La distinction entre prévention et précaution prend place dans le cadre plus large d'une évolution de type macro-sociologique, à l'œuvre depuis le milieu des années 1980 et qui a trouvé un très fort écho après la catastrophe de Tchernobyl en 1986. Le rapport de nos sociétés occidentales à la question des risques modernes en sort totalement bouleversé.

Ces "risques modernes", théorisés par le sociologue allemand Ulrich Beck, présentent quatre caractéristiques. Premièrement, ils sont intrinsèquement imprévisibles, notamment quant à la gravité du dommage que pourrait causer leur survenance. En ce sens, ils échappent à la stricte rationalisation et aux prévisions chiffrées qui sont le propre des systèmes assurantiels. Ils posent donc différemment la question de l'acceptabilité, en sortant du cadre restreint de l'expertise scientifique ${ }^{93}$. Deuxièmement, ils sont produits de manière endogène par nos sociétés contemporaines, par opposition aux risques exogènes que nous fait courir la nature ; ils sont principalement le produit de l'activité industrielle. Troisièmement, les dommages qu'ils sont susceptibles de causer sont souvent irréversibles et peuvent être, le cas échéant, d'une ampleur qui dépasse largement les frontières étroites de l'Étatnation. Quatrièmement et enfin, ils sont la plupart du temps invisibles; ils se dérobent à la perception et nécessitent, de ce fait, d'être appréhendés par des interprétations causales - forcément contestables ${ }^{94}$.

Bref, nous ne vivons pas dans une société marquée par davantage de risques qu'auparavant, sur une base absolue, mais bien dans une société où la nature des risques encourus se trouve profondément bouleversée et où la gravité de ces risques s'avère peu susceptible d'être déterminée avec précision ${ }^{95}$. C'est là un profond changement qualitatif, qui s'opère principalement en matière de sciences et de techniques et qui place l'incertitude au centre de la prise de décision politique ${ }^{96}$, reconfigurant les marges et les modalités d'action des pouvoirs publics ${ }^{97}$. De manière générale, cette évolution incite à une ouverture des processus décisionnels et des choix politiques ${ }^{98}$.

Ce changement qualitatif n'est pas sans incidence sur la notion de responsabilité. Cette dernière a connu de profondes évolutions du fait des sciences sociales, en particulier des sciences statistiques ${ }^{99}$; aujourd'hui, elle se trouve à nouveau reconfigurée à l'aune du paradigme de la société du risque. La survenance d'un dommage en particulier résulte le plus souvent de l'action combinée d'une série d'acteurs sociaux, dont il est difficile de départager les rôles exacts. U. Beck parle d'un

C. NoIvilLE, Du bon gouvernement des risques. Le droit et la question $d u$ « risque acceptable », Presses universitaires de France, Paris, 2003.

${ }^{9} \mathrm{U}$. BECK, La société du risque. Sur la voie d'une autre modernité, Flammarion, Paris, 2008, en particulier p. 41.

A. GIDDENS, « Risk and Responsibility », Modern Law Review, volume 62, n 1, p. 1-10.

M. Callon, P. Lascoumes, Y. BarThe, Agir dans un monde incertain, Seuil, Paris, 2001.

S. BRUNET, Société du risque : quelles réponses politiques? L'Harmattan, Paris, 2007.

P. Delvenne, G. Joris, F. Thoreau, «Appréhender l'incertitude : le "technology assessment" au service du processus décisionnel », Pyramides, volume 15, 2008, p. 51-70.

J.-L. GENARD, La grammaire de la responsabilité, Cerf, Paris, 1999. 
système "d'irresponsabilité organisée », en faisant référence à cette distribution des tâches qui rend compliquée, sinon illusoire, l'attribution unilatérale de responsabilité ${ }^{100}$. On le comprend, sur le plan politique et de l'action publique, la question de la responsabilité s'articule dans de nouveaux termes et s'apprécie en fonction de critères évolutifs. Ces termes, ce sont ceux de la précaution, en tant qu'ils se distinguent de la question de la prévention.

Cette distinction est longuement abordée dans le Traité des nouveaux risques de $\mathrm{O}$. Godard, C. Henry, P. Lagadec et E. Michel-Kerjan ${ }^{101}$. La prévention, classiquement, s'apparente à une logique assurantielle. Elle propose une mise en commun d'un risque connu et reconnu par une communauté, qui s'en prémunit pour chacun de ses membres par un mécanisme de solidarité. La survenance aléatoire du dommage est ainsi prise en charge par une collectivité. La prévention repose donc sur l'hypothèse que le dommage encouru peut être circonscrit, connu et calculé avec une précision raisonnable, par les instruments de la connaissance scientifique ${ }^{102}$.

À nouveaux risques, nouvelle logique d'action. C'est là le fondement d'une démarche de précaution, c'est-à-dire de cette nouvelle manière de caractériser l'action des pouvoirs publics dans un contexte marqué, cette fois, non plus par une connaissance stable et bien délimitée, comme dans le cas de la prévention, mais plutôt par un état d'incertitude prononcée ${ }^{103}$. Ainsi, le principe de précaution fonctionne sur des ressorts intrinsèquement politiques, puisqu'il revêt nécessairement une dimension spéculative quant à un danger plausible, mais non certain, qui peut entraîner un dommage dont l'ampleur peut difficilement être calculée ${ }^{104}$. Comment, par exemple, chiffrer les risques liés aux changements climatiques, le coût de la montée des océans ou des flux de réfugiés climatiques? De même, comment évaluer avec précision les éventuels dégâts causés par la dissémination d'organismes génétiquement modifiés dans l'environnement?

C'est la question politique des risques contemporains, telle que la pose le principe de précaution. Selon la Commission européenne, «le recours au principe de précaution présuppose que les effets potentiellement dangereux d'un phénomène, d'un produit ou d'un procédé ont été identifiés et que l'évaluation scientifique ne permet pas de déterminer le risque avec suffisamment de certitude $"{ }^{105}$. La Commission présente ce principe avant tout comme «la décision politique d'agir ou de ne pas agir » assortie,

100 U. BECK, La société du risque. Sur la voie d'une autre modernité, op. cit., p. 57-59.

101 O. GODARD et al., Traité des nouveaux risques, Gallimard, Paris, 2002.

Ibidem, en particulier le chapitre $1^{\mathrm{er}}$.

103 La conséquence principale de ce point est qu'il n'est plus possible de dissocier les différents aspects de la décision politique, selon qu'ils relèveraient de la prévention ou de la précaution. En effet, une telle dissociation repose sur la possibilité de caractériser le risque, et de séparer selon qu'il s'agit, par exemple, d'un risque politique ou scientifique. Le risque politique est connu et appelle une démarche de prévention; le risque scientifique est inconnu et appelle une démarche de précaution. Cette démarche n'est plus recevable, selon nous, à la lueur des risques modernes, qui ont précisément pour caractéristique d'être hybrides et de mélanger les aspects politiques et scientifiques de la question (cf. B. Latour, Politiques de la nature, La Découverte, Paris, 1999). Le risque, dans le cas d'espèce, met en présence, de manière inextricable, des virus mutants, des flux de voyageurs et de marchandises, un système international de réglementation des échanges, des gouvernements, des laboratoires, des agences sanitaires et des médias très réactifs.

104 O. GODARD et al., Traité des nouveaux risques, op. cit.

105 Commission des Communautés européennes, Communication de la Commission sur le recours au principe de précaution, COM (2000)1 final, 2 février 2000, p. 3. 
en cas d'action politique, de mesures à adopter ${ }^{106}$. Dans son acception politique la plus répandue, le principe de précaution ne peut donc être réduit à un principe d'immobilisme généralisé, une action publique qui se recroqueville sur elle-même ${ }^{107}$. Il est parfois assimilé à un principe de prudence, au sens d'une temporalité plus longue dans la prise de décision politique - autrement dit, du fait de laisser du temps au temps avant de trancher une décision ${ }^{108}$. En 2000, dans leur rapport au Premier ministre de la République française sur le principe de précaution, Philippe Kourilsky (biologiste, spécialiste entre autres de l'immunologie) et Geneviève Viney (juriste, spécialiste du droit de la responsabilité civile) donnent du principe de précaution une définition volontariste, puisque son application y commande que «l'absence de certitudes, compte tenu des connaissances scientifiques et techniques du moment, ne doit pas retarder l'adoption de mesures effectives et proportionnées visant à prévenir un risque de dommages graves et irréversibles $»{ }^{109}$.

Il importe de garder à l'esprit que les débats qui environnent l'application dudit principe sont fortement marqués par cette appréhension nouvelle des effets secondaires générés par la logique même de développement du système économique et industriel, et donc de ces "risques modernes " présentés ci-dessus. À ce titre, la «société du risque» agit comme paradigme dominant d'interprétation des risques multidimensionnels et complexes auxquels nos sociétés se trouvent exposées, et fonde la logique politique d'une démarche de précaution. En partant de cette prémisse théorique, notre étude propose de montrer que, en concluant le contrat de fourniture de vaccins avec GSK, le gouvernement belge a privilégié une action politique caractérisée par la prévention.

\subsection{CARACTÉRISER LA LOGIQUE D’ACTION : UNE DÉCISION SOUS LE SIGNE DU PRINCIPE DE PRÉVENTION}

Lorsqu'il conclut un contrat avec le groupe pharmaceutique GSK en juillet 2009, le gouvernement belge, par le truchement de sa ministre de la Santé publique, L. Onkelinx, déclare le faire en application du principe de précaution ${ }^{110}$. C’est ainsi

${ }^{106}$ Ibidem, en particulier p. 12.

${ }^{107}$ Son invocation abondante et les lectures parfois divergentes qui sont faites du principe de précaution ont conduit certains auteurs à faire l'analyse d'un outil politiquement anxiogène et, donc, paralysant (cf. G. Bronner, É. GéHIn, L'inquiétant principe de précaution, Presses universitaires de France, Paris, 2010).

108 M. Callon, P. Lascoumes, Y. Barthes, Agir dans un monde incertain, op. cit. (cf. en particulier le chapitre 6, "L'action mesurée, ou comment décider sans trancher?», p. 263-305).

109 P. Kourilsky, G. Viney, Le principe de précaution. Rapport au Premier ministre, 15 octobre 2000, p. 24). Toutefois, la définition de P. Kourilsky et G. Viney s'applique au domaine de l'environnement, pas de la santé sensu stricto. Il faut donc faire un usage prudent de cette définition dans le présent cas d'étude.

110 Chambre des représentants, Compte rendu intégral, CRIV 52 PLEN 136, 14 janvier 2010, p. 7. Nous ne nous attardons pas sur la portée juridique du principe de précaution en droit belge, l'objet étant ici d'en analyser la dimension politique. Toutefois, la jurisprudence du Conseil d'État interprète l'article 23 de la Constitution, qui reconnaît le droit à une vie conforme la dignité humaine, en ce compris le droit à la protection d'un environnement sain, comme permettant, le cas échéant, d'appliquer le principe de précaution, notamment en vue de protéger la santé (Conseil d'État (section d'administration), «SA Mobistar contre Région wallonne », Arrêt n ${ }^{\circ} 118.214$ du 10 avril 2003). Dans 
que la ministre précise préférer " respecter le principe de précaution ${ }^{111}$ en concluant, en l'absence d'un accord européen sur la constitution d'un stock, un contrat de fourniture de vaccins avec GSK. Nous verrons que cette considération ne résiste pas à l'analyse et constitue donc un abus de langage : en réalité, la fourniture de vaccins est une mesure essentiellement préventive. Avant toute chose, il apparaît en effet que la décision de constituer un stock de vaccins a été antérieure au cas de la grippe $\mathrm{A}(\mathrm{H} 1 \mathrm{~N} 1)$, et trouve ses origines dans la nécessité d'une gestion stratégique et d'une coordination accrue des pandémies, mise en lumière essentiellement par le précédent de la grippe aviaire (cf. infra).

Compte tenu du contexte d'incertitude autour du risque de pandémie, la question est de savoir quelles sont les options politiques qui, à l'été 2009, s'offrent aux autorités belges. Il s'agit ici d'étudier deux situations différentes, marquées chacune par une forme d'incertitude. La situation se décline en effet en deux cas de figure, puisque le cas de la grippe $\mathrm{A}(\mathrm{H} 1 \mathrm{~N} 1)$ met en jeu respectivement un phénomène (une pandémie de grippe) et un produit (le vaccin Pandemrix), au confluent desquels le gouvernement est amené à trancher. Ce qui se trouve ainsi questionné, en dernière ligne, c'est la responsabilité politique du gouvernement, autrement dit sa légitimité à agir comme il le fait. Pour reprendre, à nouveau, les termes de la Commission européenne, une situation telle que, en l'espèce, un risque de pandémie, appelle une "décision éminemment politique, fonction du niveau de risque "acceptable" par la société devant supporter ce risque ${ }^{112}$.

\subsubsection{Instances et mécanismes de la décision gouvernementale}

Toutefois, avant d'aborder ces questions, il convient de présenter les instances décisionnelles et les mécanismes précis sur lesquels reposent les décisions gouvernementales. En effet, celles-ci se basent sur un schéma complexe de gestion de crise, au sein duquel les rôles et missions de chacun sont précisément délimités.

L'acteur prépondérant de la gestion des crises pandémiques est, depuis 2005, le Commissariat interministériel Influenza. Sa création a été annoncée le 20 octobre 2005, à l'initiative du Premier ministre Guy Verhofstadt (Open VLD) et du ministre des Affaires sociales et de la Santé publique, Rudy Demotte (PS) ${ }^{113}$. Cherchant à tirer les leçons de la crise de la grippe aviaire - dont la gestion avait été confiée, à défaut

le cas d'implantations d'antennes relais, le Conseil d'État peut «seulement constater qu'il existe des éléments permettant raisonnablement de suspecter un risque pour la santé (...); que si ce risque ne peut être affirmé avec certitude, il ne peut non plus être exclu ». En tenant compte de ces éléments, il se prononcera en défaveur du projet d'implantation d'antennes, pour préserver «la fonction d'habitat de la zone ", à la lumière de ce risque éventuel.

111 Chambre des représentants, Commission de la Santé publique, de l'Environnement et du Renouveau de la société, Compte rendu intégral, CRIV 52 COM 629, 14 juillet 2009, p. 7.

112 Commission des Communautés européennes, Communication de la Commission sur le recours au principe de précaution, op. cit., en particulier p. 15.

13 Compte rendu de la Conférence interministérielle extraordinaire Santé publique "grippe aviaire", op. cit., en particulier p. 17-18. 
d'alternative, à l'Agence fédérale pour la sécurité de la chaîne alimentaire (AFSCA) ${ }^{114}$ -, le gouvernement avait décidé de créer ce commissariat en vue de coordonner les actions et la concertation avec toutes les instances concernées, aux niveaux fédéral, régional et communautaire ${ }^{115}$, par des crises de type " pandémique ${ }^{116}$. Jusqu'alors, il s'agissait d'une compétence attribuée au SPF Santé publique. Désormais, le Commissariat interministériel Influenza est chargé de la mise en œuvre opérationnelle de la gestion de telles crises; il entre ainsi dans ses attributions " de préparer et de réaliser toutes les actions de lutte contre la pandémie ». Le Commissariat fonctionne à l'interface d'une série de ministères et d'instances administratives et reçoit l'appui, dans l'exercice de ses missions, d'un comité scientifique et d'un comité de pilotage ${ }^{117}$.

La composition du Commissariat interministériel Influenza n'est pas rendue publique. Toutefois, le journaliste d'investigation David Leloup est parvenu à obtenir une liste de ses membres à sa création, en octobre 2005. À cette date, le Commissariat se composait de vingt-sept membres, en provenance majoritairement des milieux politico-administratif, académique et hospitalier ${ }^{118}$.

Il importe de ne pas confondre le Commissariat interministériel Influenza avec la Cellule de gestion Influenza, à laquelle incombe la responsabilité de définir «la stratégie et des actions globales (...) [et] le cadre de la gestion (politique) de la pandémie», et qui joue également un rôle important de coordination entre les différentes entités, à ce niveau. Cette cellule se compose de représentants des ministères fédéraux et fédérés concernés ${ }^{119}$. Si le Commissariat interministériel est un

114 P. VAnthemsChe (Commissaire interministériel Influenza) et al., Influenza : un exemple d'analyse interdisciplinaire des risques, s.d., www.influenza.be, p. 5.

115 Le besoin de coordination se manifestait à plusieurs niveaux : l'évaluation scientifique des risques sur le plan de l'épidémiologie humaine, d’une part, et de l'épidémiologie vétérinaire et de la santé publique, d'autre part; une gestion verticale des risques (prévention et gestion de crise) entre les différents niveaux de compétences (autorité fédérale, régions, communautés) ; la gestion horizontale des risques entre les différents départements (Affaires étrangères, Intérieur, Défense, Budget) hormis les départements concernés; la communication sur les risques à l'adresse du grand public et des différents groupes cibles (Ibidem, p. 5).

116 "La grippe "pandémique" est une forme particulière de la grippe humaine qui survient lorsqu'un nouveau virus apparaît. Les caractéristiques d'une grippe pandémique sont les suivantes: le virus nouveau, contre lequel la population n'a aucune résistance, est agressif et se transmet facilement de personne à personne à l'échelle d'un continent ou du monde, avec pour résultat un plus grand nombre de malades et de morts $"$ (Ibidem, p. 4).

117 Le comité scientifique est chargé d'évaluer les risques, tandis que le comité de pilotage est chargé de la gestion de ces risques. Ce dernier est composé de représentants de divers ministères et administrations publics - assez proche en cela de la composition de la Cellule de gestion Influenza. Cette division du travail entre deux comités repose sur l'hypothèse selon laquelle le risque peut être évalué et connu avec certitude, et qu'il appartient ensuite à la décision politique de trancher le niveau de risque jugé acceptable. Nous verrons infra que, dans le cas d'un risque de pandémie, où une forte incertitude caractérise le contexte dans lequel doit s'opérer la décision, cette division ne va pas de soi.

118 D. Leloup, "Grippe A/H1N1 : conflits d'intérêts », Politique. Revue de débats, n 67, 2010, page ???. Sur la question des conflits d'intérêts, cf. infra.

119 La composition de la Cellule de gestion Influenza est la suivante: Premier ministre, ministre de l'Emploi, ministre de l'Intérieur, ministre de la Fonction publique, ministre de la Santé publique, ministre des Entreprises et de la Simplification administrative, ministre des Affaires étrangères, ministre des PME et de la Politique scientifique, ministre des Finances, ministre de la Justice, ministre de la Défense, ministre de la Mobilité, ministre du Budget, ministre de l'Énergie, secrétaire d'État au Budget, ministre-président de la Région wallonne, ministre-président de la Communauté française, ministre-président de la Région de Bruxelles-Capitale, ministre-président du Vlaamse Overheid, ministre-président de la Communauté germanophone, et représentants du Centre de crise, 
organe structurel, la mise sur pied de la Cellule de gestion est, par contre, circonstancielle : elle fait partie intégrante de la mise en ouvre d'un plan spécifique de gestion de crise.

La Cellule de gestion Influenza est habilitée à prendre "les décisions nécessaires à la gestion de la crise». Elle constitue donc l'organe politique auquel échoit la responsabilité politique des choix qui sont effectués. Relativement à la grippe $\mathrm{A}(\mathrm{H} 1 \mathrm{~N} 1)$, la phase fédérale de gestion de crise a été déclenchée sur décision du Conseil des ministres du 30 avril 2009. Elle a été officiellement levée le 25 mars $2010^{120}$. Durant cette période, la Cellule de gestion a été présidée par les ministres de l'Intérieur, A. Turtleboom, et de la Santé publique, L. Onkelinx.

La Cellule de gestion Influenza est épaulée par «les administrations principalement concernées par la situation ${ }^{121}$. En particulier, plusieurs cellules ad hoc sont mises sur pied pour l'appuyer dans son travail. Ainsi, pour ce qui concerne les aspects médicaux de la pandémie, une "cellule d'évaluation et de suivi » est constituée au sein du SPF Santé publique, composée d'" experts et scientifiques issus des différentes autorités ou services fédéraux ou fédérés compétents ${ }^{122}$. Une cellule similaire est constituée auprès du SPF Économie, pour les enjeux socio-économiques de la crise. Enfin, une cellule d' "information" reçoit la mission particulière de communiquer sur la crise ; placée sous l'autorité conjointe du SPF Santé publique et du Commissariat interministériel Influenza, elle « informe la population, notamment par le biais des médias, de l'évolution de la situation et des décisions prises par la Cellule de gestion" ${ }^{123}$. En 2009, la composition type de chacune de ces trois cellules, en ce compris les équilibres fondés au cas par cas entre représentants des administrations, des ministères et des différents experts ou organismes concernés, est reprise dans un mémorandum de "gestion de la pandémie de grippe A/H1N1», publié par le Centre gouvernemental de coordination et de crise, constitué auprès du SPF Intérieur (IBZ) ${ }^{124}$.

Dès 2005, une série de «mesures préventives » sont prises, au rang desquelles figure la constitution d'un stock de vaccins pandémiques. Celles-ci voient le jour dans un contexte fortement marqué par l'épisode de la grippe aviaire et les décisions subséquentes annoncées lors de la conférence interministérielle du 20 octobre 2005. À cette époque en effet, "la vaccination est considérée par toutes les instances scientifiques comme le meilleur moyen de protection durable de la population. Dans la mesure où le virus qui risquerait de générer la pandémie humaine n'est pas encore connu, il est certain qu'il n'existe pas, à l'heure actuelle, de vaccin. Il est donc important de disposer d'une stratégie assurant le développement et la mise à

du Commissariat interministériel Influenza, du SPF Santé Publique, du SPF Intérieur, de la Sécurité civile, de la Police fédérale et de la Commission communautaire commune (Centre gouvernemental de coordination et de crise, Gestion de la pandémie de grippe A/H1N1. Organisation des autorités belges, 13 août 2009, www.crisis.ibz.be).

120 Direction générale Centre de crise, Levée de la phase fédérale de gestion de crise de la pandémie de grippe A/H1N1, Communiqué de presse, 25 mars 2010, www.crisis.ibz.be.

121 Centre gouvernemental de coordination et de crise, Gestion de la pandémie de grippe A/H1N1, op. cit.

122 Ibidem.

123 Ibidem.

124 Ibidem. 
disposition de ce vaccin dans les meilleurs délais possibles ${ }^{125}$. Ainsi, par hypothèse, puisque le virus pandémique n'existait pas encore en 2005, il était entendu que, au cas où il surviendrait, il serait alors forcément le fruit d'un phénomène de mutation inconnu. Le gouvernement belge entendit dès lors mobiliser les ressources à sa disposition pour prévenir un tel cas de figure et lança un appel d'offre orienté autour de deux axes: d'une part, "le développement et la production d'un vaccin "anti H5N1" ou le développement et la production de tout autre vaccin "prototype" potentiellement pandémique, à concurrence de 350000 doses » et, d'autre part, " la garantie d'un approvisionnement de vaccins "anti-pandémie", conformément à la recommandation de l'OMS. Les premières obligations découlant de cette garantie sont estimées à 1500000 euros » ${ }^{126}$.

Donc, au moment où survient le cas de la grippe $\mathrm{A}(\mathrm{H} 1 \mathrm{~N} 1)$, en 2009 , une série de mécanismes de décisions sont déjà mis en œuvre, et de nombreux effets-verrous préexistent aux structures décisionnelles mises en place. Ces mesures sont typiquement préventives, et relèvent d'une gestion " en bon père de famille », bien que leur aptitude à répondre aux spécifités de l'éventuelle situation de crise à venir ne soit pas garantie.

\subsubsection{Un phénomène aux contours flous et alarmants : le risque de pandémie de grippe}

Dans le cas présent, il est avant tout question d'un risque de pandémie dont les conséquences ne sont pas susceptibles d'être établies scientifiquement ${ }^{127}$ : il est impossible de prédire précisément comment le virus est transporté, de le détecter ou de connaitre son degré de transmissibilité à l'être humain ${ }^{128}$. Les rapports préliminaires et les premiers indices qu'ils recèlent ont tout pour susciter l'inquiétude, comme s'en expliquera a posteriori l'OMS : "Il s'agit d'un virus d'origine animale présentant une combinaison unique de gènes des virus de la grippe porcine, aviaire et humaine. La composition génétique de ce virus est nettement différente de celle du virus $\mathrm{H} 1 \mathrm{~N} 1$ plus ancien qui provoquait des épidémies saisonnières depuis 1977. ${ }^{129}$ Tout ce que l'on en connaît est sa vitesse de propagation; on sait que, huit jours à peine après sa première détection au Mexique, le 22 avril 2009, sa présence a été constatée dans 13 autres pays, pour s'étendre à pas moins de 74 pays en date du 11 juin $2009^{130}$. Par ailleurs, le risque d'une crise sanitaire grave se voit à la fois amplifié et crédibilisé. Nous allons examiner ici en détails de quelle manière le risque est

125 Compte rendu de la Conférence interministérielle extraordinaire Santé publique "grippe aviaire", op. cit., p. 14.

126 Ibidem, p. 15

127 Assemblée nationale française, Rapport fait au nom de la commission d'enquête sur la manière dont a été programmée, expliquée et gérée la campagne de vaccination contre la grippe A(H1N1), op. cit., p. 35.

128 Sénat français, Rapport de la commission d'enquête sur le rôle des firmes pharmaceutiques dans la gestion par le gouvernement de la grippe A(H1N1), Document 685, 29 juillet 2010, p. 97-98.

129 OMS, La riposte internationale face à la pandémie de grippe: l'OMS répond aux critiques, Communiqué, 10 juin 2010, www.who.int.

130 OMS, Déclaration de l'Organisation mondiale de la Santé sur les allégations de conflit d'intérêts et de "fausse » pandémie, 22 janvier 2010, www.who.int. 
progressivement cadré par les autorités publiques, impliquant alors la logique d'action à l'œuvre : d'un risque avéré à des mesures de prévention.

Amplifié, le risque potentiel d'une crise sanitaire grave l'est par les interventions diverses de l'OMS. Le sociologue Francis Chateauraynaud a montré les fortes contraintes qui ont pesé sur l'action publique dans le cas des annonces de pandémie due à une autre forme de grippe, la grippe aviaire, entre 1997 et 2007, en raison notamment des prises de position, qu'il qualifie d' " alarmistes », de hauts responsables de l'OMS dans la presse ${ }^{131}$. En 2009, les déclarations de l'OMS sont à nouveau à tout le moins alarmantes ${ }^{132}$. Ainsi, le Programme mondial de lutte contre la grippe, dont s'est dotée l'OMS, entend se prémunir des "graves conséquences sur la santé et sur l'économie» que peut représenter une pandémie "partout dans le monde ${ }^{133}$. À l'appui de ses dires, l'OMS mentionne notamment l'impact d'un fléau de grippe en points de produit intérieur brut (PIB) - un critère propre à tétaniser le décideur, en particulier dans le contexte économique déjà tendu, à cette période, par la crise économique. Plus largement, le simple fait d'évoquer une possible " pandémie » suffit, à lui seul, à frapper les esprits. Ainsi, l'OMS joue indiscutablement le rôle de caisse de résonance du risque suscité par le virus $\mathrm{A}(\mathrm{H} 1 \mathrm{~N} 1)$.

Crédibilisé, le risque de pandémie l'est par les précédents historiques de pandémies et de crises sanitaires. Les rapports de l'OMS font état d'une "mise en série " ${ }^{134}$, en rappelant notamment les cas de la grippe espagnole (1918-1919), de la grippe asiatique (1957-1958) et de la grippe de Hong Kong (1968-1969) ${ }^{135}$. Ces précédents sont abondamment diffusés par les organes ad hoc aux niveaux nationaux. En Belgique, c'est le Commissariat interministériel Influenza qui relaie cet historique ${ }^{136}$. Par ailleurs, soulignons l'influence de la crise due au SARS (Severe Acute Respiratory Syndrome) en 2002-2003 et de la récente pandémie du virus H5N1 en 2005, qui ont fait prendre conscience à de nombreux acteurs de l'existence de vulnérabilités importantes à ces maladies infectieuses dans un monde où le transport des personnes et des marchandises lève les barrières naturelles ${ }^{137}$.

Tout l'enjeu du risque posé par la pandémie se concentre donc dans la question de sa transmissibilité, plus ou moins rapide, d'homme à homme. Il est établi que le virus se propage vite et qu'il est de souche mutante. Toute l'inconnue réside donc dans une interrogation: «Et si une mutation du virus le rendait particulièrement virulent à l'égard des populations humaines? » Cette question est loin d'être anodine.

131 F. Chateauraynaud, Annoncer le pire à l'échelle mondiale. La pandémie de grippe aviaire entre gestion des risques et prophétie de malheur (1997-2007), Document de travail du Groupe de sécurité de la présidence de la République, École des hautes études en sciences sociales, Paris, février 2008, en particulier p. 2-3.

${ }^{32}$ Strategic Advisory Group of Experts, «Rapport de la réunion extraordinaire sur la pandémie 2009 de grippe A (H1N1), Genève, 7 juillet $2009 »$, op. cit., p. 301-308.

133 OMS, Programme mondial de lutte contre la grippe. Préparation et action en cas de grippe pandémique, Document d'orientation, 2009, whqlibdoc.who.int.

134 F. Chateauraynaud, Annoncer le pire à l'échelle mondiale, op. cit., p. 3.

135 OMS, Programme mondial de lutte contre la grippe, op. cit., p. 2

${ }_{137}$ Disponible sur son site Internet : www.influenza.be.

137 C. FALlON, N. Rossignol, C. ZWETKOFF, «Vulnerability and risk: some reflections for a new form of safety governance», Communication orale non publiée, janvier 2012 (Centre d'étude de l'énergie nucléaire, International Workshop on Safety and Security Risk Assessment and Organizational Cultures, Anvers, 19-31 janvier 2012). 
En effet, l'histoire récente montre que sous-estimer cette question, ou ne pas en tirer toutes les conséquences pratiques, s'avère souvent désastreux - sur un plan électoral notamment - pour nombre de formations politiques. De multiples crises sanitaires ont traumatisé les pouvoirs publics en Europe occidentale, avec des scandales à répétition dans les domaines alimentaire, de l'agriculture et de l'élevage notamment: crise de la vache folle au Royaume-Uni, affaire du sang contaminé en France, etc. La Belgique n'est pas en reste, avec une importante crise de la dioxine, qui est restée dans l'histoire comme un déterminant marquant de la lourde défaite électorale subie par les partis sociaux-chrétiens, particulièrement en Flandre, en juin $1999^{138}$. Il avait alors été reproché au gouvernement Dehaene II (CVP / PS / SP / PSC) d'avoir gardé le silence trop longtemps sur des informations sensibles, d'avoir tardé à réagir et, même alors, d'être en décalage avec l'évolution de la situation. Dans la plupart de ces cas, c'est sous l'angle de la protection de la santé publique que les gouvernants ont eu à répondre de leurs actes.

Dans le cas de la grippe $\mathrm{A}(\mathrm{H} 1 \mathrm{~N} 1)$, les autorités savent à quel point il peut s'avérer politiquement désastreux de sous-estimer le risque d'une pandémie. La question qui se pose alors, en termes d'action publique, est celle de la qualification du risque. Jusqu'à quel point faut-il prendre ce risque au sérieux ? La Commission européenne, dans sa communication relative au principe de précaution, évoque l'intervention dudit principe uniquement dans l'hypothèse où l'on a affaire à un «risque potentiel ${ }^{139}$. La potentialité du risque renvoie inévitablement à une incertitude quant à sa survenance, donc incite effectivement à raisonner une décision (peser le pour et le contre) en termes de précaution.

Toutefois, ce n'est pas l'interprétation du risque de pandémie que retiennent les autorités publiques, qui préfèrent évoquer l'existence d'un "risque avéré », comme le feront, par exemple, les rapporteurs de l'Assemblée nationale française : «Le risque constitué avec l'apparition, au printemps 2009, du virus A(H1N1) (...) ne semble pas devoir relever d'une logique de précaution, puisqu'il s'agissait, dès le début, d'un risque avéré. » Le terme " avéré » renvoie bien à la caractéristique de ce qui est donné comme étant certain, établi avec précision.

Ainsi, pour le gouvernement belge, le risque d'une pandémie imminente prend corps, dès le printemps 2009, avec une consistance suffisante pour qu'il juge nécessaire de tenter d'y pallier par tous les moyens à sa disposition, dans une démarche classique de prévention - fourniture de vaccins et campagne de vaccination. D'ailleurs, le fait même que le gouvernement suive un principe d'action immédiat et décide de réagir si rapidement à la situation démontre la pleine utilisation, par lui, du modèle décisionnel de la prévention. On peut le comprendre aux motifs avancés ci-avant.

138 P. BLAISE, «Les résultats des élections législatives du 13 juin 1999. I. La Chambre et le Sénat», Courrier hebdomadaire, CRISP, $\mathrm{n}^{\circ}$ 1653-1654, 1999.

139 «Le recours au principe de précaution n'intervient que dans une hypothèse de risque potentiel» (Commission des Communautés européennes, Communication de la Commission sur le recours au principe de précaution, op. cit., p. 13). 


\subsubsection{L'échec des campagnes de vaccination}

L'urgence qui marque la décision du gouvernement n'a pas le même effet sur les populations, qui se montrent peu empressées d'aller se faire vacciner en dépit des campagnes qui les y incitent.

Il est remarquable que, à situations d'ensemble apparemment comparables, les populations des différents pays témoignent d'une analyse très différente de leurs gouvernements respectifs, en refusant d'aller se faire vacciner, en Europe à tout le moins. S'il n'est pas question ici de tenter de savoir ce qui cause ce phénomène, on peut reprendre, de manière générale, l'idée émise par l'historien Jean-Baptiste Fressoz concernant les campagnes de vaccination au XIX ${ }^{\mathrm{e}}$ siècle, arguant que l'instauration vaccinale est exemplaire d'un gouvernement indirect reposant sur la bonne définition des « choses». Lorsqu'un gouvernement agit avec "douceur», autrement dit qu'il n'impose pas la vaccination, cela implique alors de sa part « un investissement dans le domaine de la raison, de la preuve et de la vérité ${ }^{140}$. Or, il apparaît qu'en 2009, les « choses » ne sont pas définies aussi clairement.

Certes, on peut raisonnablement supposer que le traumatisme des crises sanitaires récentes, dont celles de la dioxine, a tout aussi durablement marqué les citoyens que les membres du gouvernement. En outre, ces derniers ont accès à la même information alarmante et à une évaluation similaire du risque de pandémie. De plus, la décision gouvernementale de constituer un stock de vaccins trouve ses origines, nous l'avons vu, dans l'après-grippe aviaire, dès 2005 ; la signature du contrat avec GSK découle presque naturellement des mesures préventives mises en œuvre dès ce moment, et qui semblent les plus adaptées pour répondre à l'urgence de la situation. Il est vrai que la situation est différente pour le citoyen, dont la décision de se faire vacciner ou pas intervient à partir de novembre 2010. À ce moment-là, le soufflé est nettement retombé, la plupart des autorités concernées reconnaissant une forte diminution du risque, ramené au niveau de mortalité de la grippe saisonnière, voire légèrement en deçà ${ }^{141}$. Ainsi, à peu près au début de la campagne de vaccination, le Commissariat interministériel Influenza fait état de "onze décès attribués à des complications liées à une infection grippale », pour un total de 157123 personnes officiellement contaminées, recensées depuis fin avril. On peut lire dans son rapport hebdomadaire que «la présence de la grippe A/H1N1 n'a actuellement aucun impact significatif sur le taux de mortalité ${ }^{142}$.

Néanmoins, la délivrance d'une autorisation exceptionnelle de mise sur le marché du vaccin, accordée en vertu des circonstances, éveille peut-être une certaine méfiance dans l'opinion publique, au regard des risques éventuels liés à la vaccination. S'il convient de ne pas tirer de conclusions trop hâtives, il est malgré tout légitime de penser que l'incertitude latente autour de la dangerosité du vaccin est loin de satisfaire l’impératif rationalisant évoqué par J.-B. Fressoz.

140 J.-B. FRESSOZ « Le vaccin et ses simulacres : instaurer un être pour gérer une population, 1800-1865 », Tracés, $\mathrm{n}^{\circ}$ 21, 2011, p. 105-106.

141 Chambre des représentants, Compte rendu intégral, CRIV 52 PLEN 117, 15 octobre 2009.

142 Commissariat interministériel Influenza, Évolution de la grippe A/H1N1 en Belgique: rapport hebdomadaire, Communiqué, 12 novembre 2009, www.influenza.be. 
Cela dit, la question n'est pas tant ici de savoir ce qui cause ce refus que de le constater. Ainsi, de manière générale, "peu de pays - en dehors de la Suède, du Canada et dans une moindre mesure des États-Unis - ont réussi à mobiliser leur population et à susciter une adhésion massive à la vaccination, alors même que la plupart d'entre eux se sont engagés (...) dans une importante opération d'acquisition de vaccins $\gg{ }^{143}$.

En Belgique, le taux de vaccination de la population serait de $6,6 \%$, soit un peu plus de 700000 sujets vaccinés ${ }^{144}$. Le tableau 1 permet de situer la Belgique par rapport à douze autres pays. Mais il convient, avant de le consulter, de souligner que jamais l'intention des autorités belges n'a été de couvrir l'ensemble de la population. La commande initiale était destinée à "traiter les patients pour lesquels, sans traitement, la grippe n'est pas sans risque ${ }^{145}$. La ministre de la Santé publique sera sans ambiguité sur ce point lorsqu'elle précisera: "Nous avons décidé, avec le comité scientifique [du Commissariat interministériel Influenza], de cibler les groupes à risques et de ne pas mener une campagne de vaccination ouverte à tous » ${ }^{146}$. Pour comprendre la décision initiale de fixer la commande de Pandemrix à 12,6 millions de doses - chiffre qui, mis en équation avec la population totale du pays, a pu faire croire à d'aucuns que l'objectif premier du gouvernement avait été de vacciner $100 \%$ de celle-ci -, il faut se rappeler que, au moment où elle a été prise, un doute subsistait quant au nombre de doses nécessaires pour vacciner une personne (cf. supra). À noter à ce propos que ce doute n'a manifestement pas encore été totalement levé actuellement, puisqu'en avril 2012, GSK précise toujours dans les mentions légales relatives au Pandemrix que si «les données d'immunogénicité trois semaines après l'administration de Pandemrix (H1N1) lors des essais cliniques suggèrent qu'une seule dose pourrait être suffisante ", il est possible qu'une deuxième dose doive être administrée ${ }^{147}$.

Tableau 1. Éléments de comparaison internationale sur les stratégies vaccinales

\begin{tabular}{|c|c|c|c|}
\hline Pays & $\begin{array}{l}\text { Nombre de doses de } \\
\text { vaccin commandées }\end{array}$ & $\begin{array}{l}\text { Objectif de couverture } \\
\text { vaccinale }\end{array}$ & $\begin{array}{l}\text { Taux de vaccination } \\
\text { effectif }\end{array}$ \\
\hline Suède & 18 millions de doses & $100 \%$ de la population & $64,5 \%$ de la population \\
\hline Canada & 50,4 millions de doses & $\begin{array}{l}\text { entre } 75 \text { et } 80 \% \text { de la } \\
\text { population }\end{array}$ & $\begin{array}{l}\text { entre un tiers et } 45 \% \text { de } \\
\text { la population }\end{array}$ \\
\hline Pays-Bas & 34 millions de doses & $100 \%$ de la population & $32 \%$ de la population \\
\hline États-Unis & 229 millions de doses & $75 \%$ de la population & $23,4 \%$ de la population \\
\hline Japon & 153 millions de doses & $61 \%$ de la population & $17,9 \%$ de la population \\
\hline Allemagne & $\begin{array}{l}20 \text { millions (commande } \\
\text { ferme) ; } 90 \text { millions } \\
\text { supplémentaires }\end{array}$ & $\begin{array}{l}30 \% \text { de la population } \\
\text { (commande ferme); } \\
100 \% \text { (avec les }\end{array}$ & $10 \%$ de la population \\
\hline
\end{tabular}

143 Assemblée nationale française, Rapport fait au nom de la commission d'enquête sur la manière dont a été programmée, expliquée et gérée la campagne de vaccination contre la grippe A(H1N1), op. cit., p. 3032.

144 Ibidem.

145 Commissariat interministériel Influenza, Grippe A/H1N1 : FAQ Citoyens, op. cit. Les groupes cible de cette campagne de vaccination en deux phases ont été précisés supra.

146 Chambre des représentants, Commission de la Santé publique, de l'Environnement et du Renouveau de la société, Compte rendu intégral, CRIV 52 COM 733, 5 janvier 2010, p. 5.

147 Mentions légales concernant le Pandemrix, disponibles sur le site Internet de GSK: http://public.gsk.fr. 


\begin{tabular}{|c|c|c|c|}
\hline & (préréservation) & préréservations) & \\
\hline Russie & 34,36 millions de doses & n.d. & $9,7 \%$ de la population \\
\hline France & 94 millions de doses & $\begin{array}{l}\text { entre } 70 \text { et } 75 \% \text { de la } \\
\text { population }\end{array}$ & $8,5 \%$ de la population \\
\hline $\begin{array}{l}\text { Royaume- } \\
\text { Uni }\end{array}$ & 90 millions de doses & $\begin{array}{l}\text { entre } 70 \text { et } 75 \% \text { de la } \\
\text { population }\end{array}$ & $7,4 \%$ de la population \\
\hline Chine & 101,8 millions de doses & $10 \%$ de la population & $\begin{array}{l}\text { environ } 6 \% \text { de la } \\
\text { population }\end{array}$ \\
\hline Belgique & 12,6 millions de doses & [Inconnu] ${ }^{148}$ & $6 \%$ de la population \\
\hline Espagne & 37 millions de doses & $40 \%$ de la population & $\begin{array}{l}\text { moins de } 4 \% \text { de la } \\
\text { population }\end{array}$ \\
\hline Italie & 24 millions de doses & $40 \%$ de la population & $1,4 \%$ de la population \\
\hline
\end{tabular}

Source: D’après les données fournies par la Direction générale de la Santé (France), reproduites dans Assemblée nationale française, Rapport fait au nom de la commission d'enquête sur la manière dont a été programmée, expliquée et gérée la campagne de vaccination contre la grippe A(H1N1), Document 2698, 6 juillet 2010, p. 157.

Remarque : Par souci de lisibilité, les pays repris dans le tableau ont été classés en fonction du taux effectif de vaccination obtenu (par ordre décroissant).

On constate donc une réaction tout à fait différente entre les gouvernements, qui cherchent à protéger leur population, et lesdites populations, qui se montrent peu convaincues par le mode de protection qui leur est proposé. Comment expliquer cette différence ? L'objet de la présente étude n'est pas de remonter aux facteurs explicatifs d'un refus de se faire vacciner, ni d'analyser les différentes modalités de perception du public, mais bien de comprendre la logique de responsabilité politique qui a animé le gouvernement belge. Notre hypothèse est que sa décision de conclure un contrat de fourniture de vaccins relève d'une logique de prévention, ce que corroborent différents facteurs explicatifs qui nous semblent aptes à en faire la démonstration. Ces facteurs conduisent à distinguer la rationalité propre à la décision gouvernementale de celle des citoyens, qui répond à des impératifs différents.

\subsubsection{Les facteurs décisifs de la décision gouvernementale}

Le 30 avril 2009, le Conseil des ministres décide de passer en "phase fédérale de gestion de crise ». Le 22 juillet, la ministre de la Santé publique signe le contrat avec GSK, suivant en cela les recommandations du Commissariat interministériel Influenza. Deux jours plus tard, le 24 juillet, la Cellule de gestion Influenza est créée; elle a pour principale mission de permettre "aux ministres fédéraux et fédérés concernés de prendre ensemble les décisions les plus adéquates et de coordonner les actions menées à tous les niveaux de pouvoir ${ }^{149}$. Notons que dans ce contexte, les compétences les plus importantes sont entre les mains des ministres fédéraux; il est donc normal que ce soit ceux-ci qui gèrent, en première ligne, la crise en question ${ }^{150}$.

148 Les rapporteurs de l'Assemblée nationale française ont déduit des informations disponibles que ce taux est de $100 \%$, mais il s'agit là, comme nous venons de le voir, d'une erreur d'interprétation.

149 Centre gouvernemental de coordination et de crise, Gestion de la pandémie de grippe A/H1N1. op. cit.

150 Cf. Parlement de la Communauté française, Question orale $n^{\circ} 331$ de P. Dupriez à la ministre de la Culture, de l'Audiovisuel, de la Santé et de l'Égalité des chances concernant l'évaluation de la gestion 
Dans ce cadre, plus que le risque de pandémie en lui-même, quatre facteurs conduisent les autorités à prévenir, dans la mesure de leurs moyens, l'éventuelle propagation de la grippe $\mathrm{A}(\mathrm{H} 1 \mathrm{~N} 1)$ à sa population.

Le premier facteur qui met sous pression l'action du gouvernement belge est l'urgence alléguée de la situation. D'une part, le virus se répand très vite, provoquant un syndrome de crise aigu auprès des médias et des pouvoirs publics. Le 11 juin 2009, l'OMS passe en phase d'alerte maximale, soit la phase d'alerte 6, la phase de pandémie ${ }^{151}$. En l'absence d'informations précises quant aux impacts potentiels du virus pour la population (cf. infra), le gouvernement belge peut difficilement faire l'économie d'une solution, pourvu qu'elle existe. Lorsqu'une telle solution se présente, elle commande dès lors une décision rapide. D'autre part, on appréhende une menace sur les stocks de vaccins: on craint en effet que, dans l'hypothèse de la survenance d'une pandémie particulièrement véloce, il ne sera pas possible de fournir aux populations touchées un nombre suffisant de doses dans un délai utile en raison de la demande massive de vaccins au niveau mondial et du rythme de leur production ${ }^{152}$. À plusieurs reprises, lors d'interventions dans les journaux télévisés, la ministre de la Santé justifie ainsi l'action du gouvernement belge par la nécessité d'assurer une fourniture de vaccins dans un contexte de demande exacerbée. Ainsi, un sentiment d'urgence, dû notamment à une pression supposée sur les stocks, contraint la prise de position politique dans un carcan temporel très étroit.

Le deuxième facteur est le fait que les autorités belges ne disposent que d'une information lacunaire et provenant majoritairement d'une seule source : l'OMS. Très tôt dans la crise, le 30 avril 2009, le Conseil des ministres décide de porter la gestion de crise au niveau fédéral et d'instaurer un comité spécifique au sein de la Direction générale Centre de crise (DGCC) ${ }^{153}$. Ce comité a pour mission de préparer toute décision à prendre dans le cas du risque de pandémie et d'effectuer un monitoring constant de la situation, en recoupant au maximum les données disponibles. Toutefois, ce comité fonctionne dans un contexte général où la seule information pertinente est celle produite par l'OMS et dont les autorités belges se font l'écho ${ }^{154}$.

Un troisième facteur est le nombre limité de fournisseurs de vaccins. Plus tard, la presse belge dénoncera largement la position du groupe GSK, qui se serait trouvé dans

de la grippe A/H1N1 et la capacité d'expertise indépendante de la Communauté française en matière de vaccination, 23 décembre 2010, Bulletin des question et des réponses, 3 ; Assemblée réunie de la Commission communautaire commune, Commission de la Santé, Question orale de B. Debaets au membre du collège réuni compétent pour la Politique de la santé, les Finances, le Budget et les Relations extérieures et au membre du collège réuni compétent pour la Politique de la santé et la Fonction publique concernant la coordination des mesures de lutte contre la pandémie de grippe H1N1, 17 décembre 2009, Compte rendu intégral des interpellations et des questions orales, CRI COM $\mathrm{n}^{\circ} 3$; Parlement wallon, Question écrite $\mathrm{n}^{\circ} 49$ de C. Eerdekens à la ministre de la Santé, de l'Action sociale et de l'Égalité des chances concernant la grippe A(H1N1), 13 janvier 2010, Interpellations et questions, http://parlement.wallonie.be.

151 Commissariat interministériel Influenza, L’OMS passe en phase 6 d'alerte à la pandémie: pas de changement de stratégie en Belgique, Communiqué de presse, 11 juin 2009, www.influenza.be.

152 À notre connaissance, dans le cas spécifique du vaccin Pandemrix produit par GSK, par exemple, aucune étude systématique ne s'est à ce jour penchée sur les capacités de production de la firme à l'été 2009, permettant de confirmer ou d'infirmer la menace de pénurie sur les stocks.

153 Centre gouvernemental de coordination et de crise, Gestion de la pandémie de grippe A/H1N1, op. cit.

154 Ainsi, le Commissariat interministériel Influenza reproduit certains diagnostics de l'OMS et renvoie le grand public, sur son site Internet, aux études scientifiques produites par elle. 
une situation de monopole de fait ${ }^{155}$. Or, il s'avère qu'à l'été 2009 plusieurs firmes, outre GSK, entrent bel et bien en compétition pour obtenir le marché de fourniture des vaccins ${ }^{156}$. C'est après une étude circonstanciée que le gouvernement belge reconnaît à GSK une spécificité qui lui donne deux avantages concurrentiels distinctifs, à savoir une protection plus large et une adaptation du vaccin à moindre prix. D’une part, le Commissariat interministériel Influenza a recommandé à l'État belge « de donner la préférence aux vaccins avec adjuvants parce que ceux-ci offrent une protection plus large lorsque le virus se diversifie. La firme GSK a proposé ce type de vaccin ${ }^{157}$. D'autre part, le vaccin proposé par GSK "est composé de deux éléments - l'antigène et l'adjuvant - qui ne sont pas mélangés a priori et qui peuvent donc être remplacés séparément. Ceci laisse la porte ouverte à une éventuelle adaptation du vaccin à moindre prix si l'on ne devait pas utiliser immédiatement tout le stock commandé et qu'une mutation ou un autre virus devait apparaître ${ }^{158}$.

En l'occurrence, le choix de la Belgique de traiter de manière privilégiée avec GSK résulte d'un examen des offres de différents fournisseurs, et non pas d'une position de monopole de la firme. Quatre groupes pharmaceutiques en concurrence (Baxter, GSK, Novartis et Sanofi) ont proposé à l'État belge des contrats de nature similaire, en portant des revendications groupées telles qu'une clause d'irresponsabilité à inclure dans les contrats - qui n'a pas été retenue (cf. supra) ${ }^{159}$. GSK disposait d'une capacité plus rapide de production et de livraison effectives ${ }^{160}$; vu le caractère d'urgence maintes fois avancé par l'OMS ${ }^{161}$, ce facteur a pesé dans la prise de décision. Mais l'avantage distinctif de GSK a sans doute été sa forte implantation industrielle en Belgique, puisque le groupe fournit un emploi à pas moins de 7500 personnes dans le pays ${ }^{162}$.

La firme GSK alloue des moyens conséquents à l'exercice du lobbying. Selon l'association Alliance for Lobbying Transparency and Ethics Regulation (ALTER-EU), dans un rapport qui évalue la politique de transparence de la Commission européenne ${ }^{163}$, le budget réservé à cet usage par GSK figure parmi les cinq les plus

155 «L'État belge s'est incliné devant GSK », Le Soir, 7 mai 2010.

156 Pour un inventaire complet, cf. Sénat français, Rapport de la commission d'enquête sur le rôle des firmes pharmaceutiques dans la gestion par le gouvernement de la grippe A(H1N1), op. cit., p. 31 .

Commissariat interministériel Influenza, Grippe A/H1N1 : FAQ Citoyens, op. cit. À noter que la même recommandation avait déjà été formulée par le même comité, et suivie d'effets, dans le précédent de la grippe A/H5N1 (cf. D. LELOUP, « Grippe A/H1N1 : conflits d'intérêts », op. cit., p. ???).

158 Chambre des représentants, Projet de loi accordant des pouvoirs au Roi en cas d'épidémie ou de pandémie de grippe. Rapport fait au nom de la Commission de la Santé publique, de l'Environnement et du Renouveau de la société par M. Detiège, DOC 52 2156/002, 8 octobre 2009, p. 8.

159 Assemblée nationale française, Rapport fait au nom de la commission d'enquête sur la manière dont a été programmée, expliquée et gérée la campagne de vaccination contre la grippe $A(H 1 N 1)$, op. cit., p. 53.

160 Ibidem, p. 56

161 Strategic Advisory Group of Experts, «Rapport de la réunion extraordinaire sur la pandémie 2009 de grippe $\mathrm{A}(\mathrm{H} 1 \mathrm{~N} 1)$, Genève, 7 juillet 2009 », op. cit., p. ???.

162 L'information est disponible sur le site Internet du groupe : www.gsk-careers.be. Le groupe a ainsi inauguré en février 2010 sa division Vaccins, dont le nouveau quartier général mondial est établi à Wavre («La grippe a généré 1 milliard d'euros pour GSK Biologicals », Trends Tendance, 25 février 2010).

63 Alliance for Lobbying Transparency and Ethics Regulation (ALTER-EU), The Commission's Lobby Register One Year On: Success or Failure?, juin 2009, p. 21. 
importants «qui aient été déclarés ${ }^{164}$. De manière générale, les firmes pharmaceutiques mènent une activité importante en matière de lobbying. Ainsi, pour 2011, GSK estime y avoir consacré, uniquement auprès des institutions européennes, un budget total oscillant entre 800000 et 825000 euros (à comparer à plus de 5,4 millions de dollars aux États-Unis) ${ }^{165}$. À noter qu'elle figure parmi les rares firmes à faire publiquement état d'une activité soutenue de lobbying (en l'occurrence, par son rapport annuel relatif à sa corporate responsibility, dans lequel elle promeut une éthique faite d'ouverture et de transparence) ${ }^{166}$.

Un nombre important de connections entre la firme GSK, l'OMS et les comités d'experts ont été révélées, en Belgique, par le journaliste d'investigation David Leloup - dont les articles ont été publiés dans Politique. Revue de débats, puis dans Le Soir. D. Leloup relaye notamment " une longue enquête menée par le British Medical Journal $(B M J)$ et le Bureau of Investigative Journalism de Londres, révélant que plusieurs experts ayant participé à la rédaction des directives de l'OMS face à une pandémie grippale ont reçu des rémunérations de Roche et GlaxoSmithKline, deux firmes impliquées dans la fabrication de médicaments ou de vaccins contre la grippe $"{ }^{167}$. En outre, un groupement de firmes pharmaceutiques, dont fait partie GSK, a réuni un comité d'experts européen, l'European Scientific Working Group on Influenza (ESWI), qu'il finance intégralement. L'ancien directeur de ce comité, le Belge René Snacken, est également l'auteur du plan d'action belge en cas de pandémie ${ }^{168}$.

Dans sa réponse au British Medical Journal, la directrice de l'OMS, Margaret Chan, reconnait en juin 2010 l'existence potentielle de conflits d'intérêts («inhérents à toute relation entre une organisation normative et de développement sanitaire (...) et l'industrie, axée sur le profit»), mais réfute toute éventuelle influence d'intérêts commerciaux sur les décisions de l'OMS ${ }^{169}$. Elle annonce également que les noms des membres du Comité d'urgence qui ont conseillé l'OMS lors de la pandémie «seront publiés lorsque le comité aura terminé ses travaux, comme cela était prévu dès le départ. Notre décision de ne pas rendre ces noms publics était motivée par la volonté de protéger les experts d'influences commerciales ou autres». La composition du comité est effectivement divulguée le $1^{\text {er }}$ octobre 2010: sur quinze experts et un conseiller, pas moins de six font état d'intérêts potentiellement susceptibles de compromettre l'indépendance ou l'impartialité de leur expertise, dont cinq en lien direct avec l'industrie pharmaceutique ${ }^{170}$. En elles-mêmes, ces connections ne suffisent en rien à démontrer une intention frauduleuse ou un trafic d'influence, mais elles questionnent lourdement la distribution de l'expertise. À quelles conditions un expert est-il en mesure de présenter toutes les qualités d'indépendance et d'impartialité ? Dans le système actuel, les liens entre firmes, universités et instances

164 Précision importante, puisque la déclaration auprès de la Commission s'effectue sur une base purement volontaire et n'est assortie d'aucun incitant significatif.

65 GSK, Do more, feel better, live longer. Corporate Responsibility Report, 2011, p. 77.

166 Ibidem, p. 2.

167 D. LELOUP, « Grippe A/H1N1 : conflits d'intérêts », op. cit., p. ???.

Ibidem, p. ???.

169 OMS, Lettre de l'Organisation mondiale de la Santé au BMJ, Déclaration, 8 juin 2010, www.who.int.

OMS, Liste des membres et du conseiller du Comité d'urgence du Règlement sanitaire international (2005) concernant la pandémie de grippe (H1N1) 2009, $1^{\mathrm{er}}$ octobre 2010, www.who.int. 
politiques sont fortement encouragés. Cela pose avec acuité le problème des garanties de neutralité des missions d'expertise.

Au niveau belge, des cas potentiels de conflits d'intérêt sont mis au jour relativement à des membres du Commissariat interministériel Influenza. Certes, le manque de publicité donné à la composition de cet organisme et la difficulté d'obtenir des informations transparentes sur les activités de ses membres compliquent singulièrement une telle recherche. Toutefois, en se basant sur un échantillon de leurs publications scientifiques respectives, D. Leloup détecte au moins cinq cas potentiels de conflits d'intérêt sur quinze experts issus des rangs académiques ${ }^{171}$.

Au-delà de ce travail d'investigation, mettre au jour les constellations de liens qui unissent les firmes aux comités d'experts, et ceux-ci aux instances décisionnelles, n'est pas toujours un exercice aisé. En la matière, une certaine "culture du secret» prévaut ${ }^{172}$. Toutefois, un nombre suffisant d'organismes internationaux se sont inquiétés de la question pour lui donner de l'épaisseur. Ainsi, l'Assemblée parlementaire du Conseil de l'Europe s'est dite «alarmée par la façon dont la grippe pandémique $\mathrm{H} 1 \mathrm{~N} 1$ a été gérée, non seulement par l'Organisation mondiale de la santé, mais aussi par les autorités de santé compétentes tant au niveau de l'Union européenne qu'au niveau national ", déplorant notamment un "grave manque de transparence dans les prises de décisions liées à la pandémie, qui soulève des préoccupations quant à l'influence de l'industrie pharmaceutique " ${ }^{173}$. Le Parlement européen, pour sa part, a adopté une résolution par laquelle il appelle des mesures concrètes sur les conflits d'intérêts. Il demande aussi que «soient spécifiés et, le cas échéant, révisés les rôles, devoirs, compétences, limites, relations et responsabilités des acteurs-clés et structures de niveau européen chargés de la gestion des menaces sanitaires $(. .$.$) et que l'information à ce sujet soit rendue publique { }^{174}$. Enfin, il « rappelle à l'[Agence européenne des médicaments] l'obligation réglementaire de rendre accessibles tous les documents relatifs aux essais cliniques, aux protocoles de recherche et aux effets indésirables des médicaments évalués par ses experts ${ }^{175}$.

Enfin, dernier facteur et non des moindres, il faut souligner l'extraordinaire écho médiatique qui a été donné au risque de pandémie. Nous ne rentrerons pas ici dans une analyse détaillée du discours médiatique. Toutefois, il est permis de penser que le temps très court du récit médiatique, combiné à une certaine recherche de sensationnalisme, conduit à rejouer la trame d'une catastrophe au sens étymologique du terme, c'est-à-dire d'un bouleversement majeur qui apporte son dénouement à une tragédie classique ${ }^{176}$. Ce qui plane dans les médias, c'est la menace d'un renversement soudain et irrémédiable de la relative quiétude de la population en termes de santé publique. Sans prolonger la réflexion plus avant, il serait intéressant

\footnotetext{
D. Leloup, « Grippe A/H1N1 : conflits d'intérêts », op. cit., p. ???.

«Des soupçons sur les experts de l'UE », Le Soir, 6 mai 2010.

Assemblée parlementaire du Conseil de l'Europe, Gestion de la pandémie H1N1 : nécessité de plus de transparence, Résolution 1749, points 1 et 2, 24 juin 2010.

174 Parlement européen, Commission de l'Environnement, de la Santé publique et de la Sécurité alimentaire, Rapport sur l'évaluation de la gestion en 2009-2010 de la grippe H1N1 en Europe, 2010/2153(INI), point 2, 9 février 2011.

175 Ibidem, point 25.

176 C. Godin, "Ouverture à un concept: la catastrophe», Le Portique (revue en ligne : http://leportique.revues.org), $\mathrm{n}^{\circ} 22,2009$.
} 
d'étudier de près les ventes des publications qui ont annoncé des «soleils noirs », pour reprendre l'expression du philosophe Régis Debray ${ }^{177}$. S'il était établi que la peur est un facteur qui a fait vendre, comme l'énonce une certaine sagesse populaire, il faudrait alors entreprendre une réflexion sérieuse sur la déontologie médiatique. Enfin, il convient de souligner la caisse de résonance extraordinaire que l'annonce des catastrophes peut dorénavant trouver sur les réseaux sociaux, tels que Facebook ou Twitter. Ceux-ci permettent à tout un chacun de s'approprier le risque, d'échanger à son sujet et faire valoir son point de vue. Toutefois, en l'absence d'une information claire et bien recoupée, ces nouveaux réseaux se prêtent à la propagation de rumeurs infondées ${ }^{178}$, lesquelles peuvent très vite tourner à la cacophonie. On conçoit sans peine les effets problématiques que ce phénomène est potentiellement susceptible de présenter en cas de survenance d'une pandémie à forte létalité.

En bref, c'est dans un contexte pandémique tendu que le gouvernement belge décide en 2009, à l'instar de la plupart de ses homologues et par l'application d'une mesure préventive, de constituer un stock de vaccins, accélérant en cela un processus initié dès 2005. Sa décision est prise en fonction d'une urgence renforcée par la rareté de la ressource, d'une information lacunaire quant aux conséquences respectives d'une pandémie de grippe $\mathrm{A}(\mathrm{H} 1 \mathrm{~N} 1)$ et des effets secondaires d'un vaccin (qui en comporte comme la plupart des médications), des marges étroites dont il dispose face aux positions collectives adoptées par les fournisseurs de vaccins, et d'une certaine pression médiatique. Tous ces éléments ont convergé pour faire percevoir aux responsables politiques l'existence d'un "risque avéré ", auquel il s'agit de parer dans les plus brefs délais.

C'est donc bien une logique de prévention, pure et simple, qui conduit les pouvoirs publics à se prémunir des conséquences d'une pandémie dont, à ce stade, il importe in fine peu de savoir si elle va advenir ou pas, au sens où cette question n'occupe plus une place centrale dans la prise de décision. Les différents facteurs que nous avons listés ont amené l'État belge à conclure qu'il est de sa responsabilité politique, par le déploiement de mesures classiques de prévention, de prémunir sa population contre un risque désormais avéré de pandémie.

\subsubsection{Les risques liés au vaccin Pandemrix}

La décision gouvernementale n'est pas sans poser des risques d'une autre nature, dont il y a tout lieu de croire qu'ils ne sont pas pleinement pris en considération au moment de la conclusion du contrat de fourniture de vaccins. Ces risques sont liés au vaccin Pandemrix lui-même. Ce vaccin pose en effet un double risque, qui justifierait une approche davantage marquée par une logique de précaution. Le premier est d'ordre financier ; son ordre de grandeur est susceptible d'une estimation correcte. Le second, quant à lui, est plus problématique, en ce qu'il porte sur d'éventuels effets secondaires sur le métabolisme des personnes vaccinées et que, étant donné la

177 R. DeBray, Du bon usage des catastrophes, Gallimard, Paris, 2011.

78 Comme l'a par exemple démontré l'état de confusion intense qui a régné simultanément sur la presse en ligne et sur les réseaux sociaux, lors de la tuerie perpétrée à Liège le 13 décembre 2011. 
situation d'urgence, le produit n'a pas bénéficié d'une autorisation de mise sur le marché classique. Comme nous l'avons déjà mentionné, la Commission européenne avait délivré, en 2008, une autorisation de mise sur le marché dans des « circonstances exceptionnelles » et donc sous conditions, étant donné que, sur le plan scientifique, les informations disponibles étaient limitées au moment de l'approbation.

Tout d'abord, le contrat de fourniture du Pandemrix fait peser sur l'État belge un risque de nature financière (cf. supra). Celui-ci n'est pas connu avec exactitude; toutefois, il est possible d'en donner des estimations plausibles. Il inclut le prix des vaccins à proprement parler, qui est fixé contractuellement, ainsi que, pour rappel, le coût final d'éventuelles indemnités versées aux tiers par GSK, remboursées par l'État belge sans aucun plafond. Cette garantie de remboursement intégral présente sans doute un déséquilibre, dans les termes du contrat. À ces montants, s'ajoutent divers coûts logistiques et opérationnels, par exemple sur le plan de la sécurité sociale, pour ce qui concerne la vaccination proprement dite. Toutefois, dans l'appréciation des autorités publiques, le risque financier reste marginal au regard des enjeux de santé publique. Interpellée à la Chambre des représentants, la ministre de la Santé, L. Onkelinx, déclarera ainsi : "Nous paierons évidemment un tribut au principe de précaution, mais il s'agit d'un tribut tout à fait cadré et raisonnable. ${ }^{179}$

Ensuite et surtout, le vaccin représente un risque potentiel pour la santé publique, plus spécifiquement pour les populations vaccinées. Très tôt, des questions liées à l'évaluation de ce risque ainsi que la responsabilité de ses conséquences éventuelles sont d'ailleurs posées au Parlement européen ${ }^{180}$. En Belgique, la presse s'inquiète de potentiels effets dangereux, liés à la présence de certaines substances dans le vaccin : « Le Pandemrix contient du AS03, un adjuvant controversé à base de squalène (huile extraite du foie des requins) et de thiomersal (un conservateur au mercure) », écrit par exemple Le Soir ${ }^{181}$. Selon le même quotidien, ces considérations ont conduit plusieurs États à adopter des mesures politiques qui ne sont pas anodines. Ainsi, la Suisse a purement interdit le vaccin aux personnes âgées de plus de 60 ans et aux femmes enceintes; pour ces dernières, spécifiquement, la France, l'Espagne et le Canada ont commandé des stocks de vaccins sans composé adjuvant ${ }^{182}$.

Ces risques ne se cantonnent pas à un registre spéculatif, puisque des effets secondaires non négligeables se manifestent effectivement. En Finlande, le Terveyden ja hyvinvoinnin laitos (THL, Institut national pour la santé et le bien-être) lance une enquête sur des cas suspects de narcolepsie. La question posée est celle de l'existence d'un lien de causalité avec la prise du Pandemrix. Les résultats finaux, aussi bien en Finlande ${ }^{183}$ qu'en Suède ${ }^{184}$, suggèreront un accroissement du risque en valeur absolue,

${ }_{180}^{179}$ Chambre des représentants, Compte rendu intégral, CRIV 52 PLEN 136, 14 janvier 2010, p. 7.

Parlement européen, Questions parlementaires, Question écrite P-5208/09 de R. Romeva i Reueda à la Commission concernant les responsabilités découlant d'éventuels effets secondaires du vaccin contre la grippe A (H1N1), 21 octobre 2009.

${ }_{182}$ "La grippe A/H1N1 : vaccin », Le Soir, jeudi 6 mai 2010.

182 Ibidem.

183 Terveyden ja hyvinvoinnin laitos, Association between Pandemrix and narcolepsy confirmed among Finnish children and adolescents, Communiqué de presse, $1^{\text {er }}$ septembre 2011, www.thl.fi.

184 Läkemedelsverket [Agence suédoise des médicaments], A Swedish registry based cohort study provides strengthened evidence of an association between vaccination with Pandemrix and narcolepsy in children and adolescents, Communiqué de presse, 29 mars 2011, www.lakemedelsverket.se. Il faut préciser que, 
sa survenance étant toutefois limitée aux cas où la prise du vaccin interagit avec d'autres facteurs, notamment de nature génétique ou environnemental. En septembre 2011, un communiqué de presse du THL précisera que «le groupe de travail national sur la narcolepsie confirme la conclusion expérimentale publiée dans son rapport intérimaire de janvier [2011] que le vaccin de Pandemrix utilisé durant l'hiver du 2009-2010 a contribué à une croissance de l'incidence de la narcolepsie observée parmi la population finlandaise âgée de 4 à 19 ans $"{ }^{185}$. Par ailleurs, ce même communiqué mentionnera que la Norvège et la France ont également rapporté plus de cas de narcolepsie qu'attendus parmi les enfants et adolescents s'étant vus administrer le vaccin. Néanmoins, le lien de causalité n’a pas pu être établi dans ces deux derniers pays, faute de données concernant les personnes non vaccinées.

La communication des premiers résultats de l'Institut national finlandais suscite des questions au Parlement européen, notamment en ce qui concerne un éventuel chevauchement des activités des autorités nationales compétentes et des agences de l'Union européenne ${ }^{186}$. La Commission y répond que toute initiative d'instituts nationaux serait en situation de nourrir de manière intéressante l'opinion de l'Agence européenne des médicaments ${ }^{187}$. En juin 2010, cette agence n'a noté que des effets secondaires mineurs associés à l'utilisation du vaccin : «Les effets secondaires les plus communs avec le Pandemrix (constatés dans plus de $10 \%$ des doses du vaccin) sont le mal de tête, l'arthralgie (douleurs [articulaires] communes), la myalgie (douleurs des muscles), les réactions à l'emplacement de l'injection (durcissement, gonflement, douleur et rougeur), la fièvre et la fatigue. ${ }^{188}$

Cette position évolue toutefois par la suite. Dès mai 2011, l'Agence note dans ses études que le vaccin tend à interagir avec des facteurs génétiques et environnementaux qui pourraient augmenter le risque de narcolepsie. Elle met en évidence la nécessité de mener des recherches plus approfondies, tout en considérant que les bénéfices du vaccin sont bien supérieurs aux risques. Ces éléments seront relayés par la Commission en réponse à des questions parlementaires : "[L'Agence] a conclu que l'équilibre entre risques et avantages reste positif. En ce qui concerne la question spécifique de savoir si l'utilisation du Pandemrix contribue au risque de narcolepsie, l'[Agence] a conclu qu'un tel lien ne peut être ni confirmé ni éliminé sur base des

dans le cas de la Suède, la population vaccinée a atteint $64,5 \%$ des habitants, ce qui est bien supérieur à la moyenne des pays européens (cf. supra: Tableau 1, p....).

185 Terveyden ja hyvinvoinnin laitos, Association between Pandemrix and narcolepsy confirmed among Finnish children and adolescents, op. cit. Cf. également OMS, Comité consultatif mondial sur la sécurité des vaccins, Statement on narcolepsy and vaccination, Communiqué de presse, 8 février 2011, www.who.int ; GSK, Update on Pandemrix and interim Finnish report on narcolepsy et GSK European regulatory update on Pandemrix, Communiqués de presse, $1^{\text {er }}$ et 18 février 2011, www.gsk.com.

186 Parlement européen, Questions parlementaires, Question écrite P-6983/2010 de L. Jaakonsaari à la Commission concernant la réévaluation du vaccin Pandemrix dans le contexte de la grippe porcine et le rôle de la Commission, 3 septembre 2010.

187 Parlement européen, Questions parlementaires, P-6983/2010: Réponse de la Commission à la question écrite P-6983/2010 de L. Jaakonsaari du 3 septembre 2010, 29 septembre 2010.

188 European Medicines Agency, European public assessment report on Pandemrix. Summary for the public, EMA/252208/2010, date ??, www.ema.europa.eu. 
données actuellement disponibles. Le rapport entre Pandemrix et narcolepsie est donc suspendu à des enquêtes postérieures ${ }^{189}$.

En juillet 2011, l'Agence reconnaît finalement la pertinence des études épidémiologiques finlandaise et suédoise, considérant que les résultats de ces études concernant le Pandemrix "montrent une association entre la vaccination par le Pandemrix et la narcolepsie chez les enfants et des adolescents dans ces deux pays $\gg{ }^{190}$. Le 27 juillet 2011, l'Agence délivrera une autorisation totale et non-conditionnelle du Pandemrix ${ }^{191}$.

Bref, à l'été 2009, la décision politique d'agir en procédant à une campagne de vaccination, face à une menace de pandémie alarmante et crédible aux conséquences absolument imprévisibles, l'emporte sur la décision de s'abstenir d'agir pour éviter des effets secondaires éventuels du vaccin, pour les populations concernées, et son coût, direct et indirect, pour les pouvoirs publics. C'est l'attitude qu'adoptent tous les gouvernements d'Europe occidentale, à l'exception notable de la Pologne, qui fait le choix « de ne pas organiser de campagne de vaccination contre le virus $\mathrm{A}(\mathrm{H} 1 \mathrm{~N} 1)$, la ministre de la Santé, Madame Ewa Kopacz, ayant notamment remis en cause devant le Parlement polonais la sécurité des vaccins, pourtant évaluée par l'Agence européenne du médicament $"{ }^{192}$.

Même dans ce cas exceptionnel, les ressorts de la décision du gouvernement polonais semblent n'être pas que d'ordre politique ou sanitaire. Ainsi, la ministre française de la Santé, Roselyne Bachelot-Narquin, indiquera à la commission d'enquête de l'Assemblée nationale que la Pologne a malgré tout engagé des démarches pour l'acquisition de vaccins : « Il semblerait donc que ses négociations avec les laboratoires n'aient pu aboutir, le gouvernement polonais ayant jugé les conditions offertes par les groupes pharmaceutiques inacceptables, tant sur le plan tarifaire qu'en termes de restriction du champ de responsabilité des industriels. (...) Mme Kopacz a (...) expliqué (...) que son département juridique avait trouvé "au moins vingt points douteux dans le contrat" proposé à son pays par les laboratoires, mais qu'elle ne pouvait en dire plus en raison des négociations en cours $»{ }^{193}$. Dès lors, il est permis de se demander ce qui se serait produit si, d'aventure, la pandémie s'était transmise, avec

189 Parlement européen, Questions parlementaires, E-004386/2011: Réponse de la Commission à la question écrite E-004386/2011 de D. Feio du 4 mai 2011, 26 mai 2011.

190 European Medecines Agency, European Medicines Agency recommends restricting use of Pandemrix, Communiqué de presse, EMA/CHMP/568830/2011, 27 juillet 2011, www.ema.europa.eu.

${ }_{91}$ Agence européenne des médicaments, Notification A20/0045 intégrée à la notice Pandemrix. Procedural steps taken and scientific information after the autorisation, www.ema.europa.eu.

192 Assemblée nationale française, Rapport fait au nom de la commission d'enquête sur la manière dont a été programmée, expliquée et gérée la campagne de vaccination contre la grippe A(H1N1), op. cit., p. 27 (sur le cas polonais, cf. en particulier p. 32). De manière générale, loin d’y déceler une posture courageuse ou exemplaire de cet État, les différents rapports parlementaires se montrent plutôt critiques envers les options suivies par le gouvernement polonais (cf. Assemblée parlementaire du Conseil de l'Europe, La gestion de la pandémie H1N1 : nécessité de plus de transparence. Rapport de la Commission des questions sociales, de la santé et de la famille, op. cit., p. 13-14 ; Sénat français, Rapport de la commission d'enquête sur le rôle des firmes pharmaceutiques dans la gestion par le gouvernement de la grippe $A(H 1 N 1)$, op. cit., p. 118-120).

«Audition de la ministre [française] de la Santé et des Sports. Procès-verbal de la séance du 15 juin 2010 », in Assemblée nationale française, Rapport fait au nom de la commission d'enquête sur la manière dont a été programmée, expliquée et gérée la campagne de vaccination contre la grippe A(H1N1), op. cit., p. 710-711. 
une virulence exacerbée, aux populations humaines. Selon toute probabilité, le gouvernement polonais aurait été pointé du doigt et dénoncé pour l'« irresponsabilité » de son inaction, pour reprendre le mot du rapporteur de la commission d'enquête devant l'Assemblée nationale.

Il faut enfin souligner que le risque sur la santé des populations vaccinées n'est pas, lui non plus, anodin: il suffit d'imaginer l'impact qu'aurait, pour les gouvernants, la survenance d'un ou de plusieurs décès, ou d'impacts graves sur la santé, indiscutablement provoqués par l'injection du vaccin. C'est ici que se mesure le mieux le caractère éminemment politique de la décision du gouvernement belge: à l'intersection entre les notions de protection des populations, de mesures préventives et d'usage raisonné du principe de précaution.

\subsection{CONCLUSION INTERMÉDIAIRE : PRINCIPE DE PRÉVENTION ET CONCEPTION ÉTATIQUE DE LA RESPONSABILITÉ}

Pour résumer, on peut dire que dans le cas de la grippe $\mathrm{A}(\mathrm{H} 1 \mathrm{~N} 1)$, le gouvernement belge agit en juillet 2009 en vertu d'une logique de prévention, c'est-à-dire en décidant d'agir rapidement, sur foi de l'expertise disponible. Le danger étant identifié et fortement relayé dans les médias, le gouvernement adopte des mesures de prévention à partir des moyens immédiatement mobilisables et des possibilités technologiques déjà opérationnelles - le Pandemrix. Il s'agit là d'un processus de "mise en boîte noire ${ }^{194}$, c'est-à-dire de stabilisation d'une solution concrète et à portée immédiate, au détriment de toutes les alternatives possibles. Or, dans le cas présent, cette solution élude nécessairement la question des risques liés au vaccin. Nonobstant les qualifications des experts qui ont alimenté le processus décisionnel, la décision de commander les vaccins ne peut être prise en toute connaissance de cause. Les développements ultérieurs concernant la narcolepsie font état de risques qui, s'ils demeurent marginaux, n'en existent pas moins ; il s'en suit l'impossibilité matérielle faute de temps et d'information disponible - de prendre en considération tous les facteurs de risque liés à la décision. Sans aller jusqu'à avancer qu'il faut chercher là les raisons de l'échec de la campagne de vaccination, tout au moins peut-on constater que la population belge, qu'il s'agit de protéger, ne partage pas la même analyse et la même confiance dans le produit que ses autorités gouvernementales.

Pour autant, il ne faudrait pas en conclure que la décision d'agir et de se fournir en vaccins est prise de manière totalement irréfléchie. Tout d'abord, l'ensemble des États membres de l'Union européenne opposent un refus commun à l'introduction d'une clause d'irresponsabilité des laboratoires du fait d'éventuels produits défectueux ${ }^{195}$. Une telle clause s'avérerait d'ailleurs purement et simplement illégale (cf. supra). Toutefois, il convient de tempérer cet argument, puisque sur un plan politique, la

194 M. CAllon, B. Latour, «Le grand Léviathan s'apprivoise-t-il ?», in M. AKrich, M. CALlon, B. Latour, Sociologie de la traduction: textes fondateurs, Mines de Paris, coll. "Sciences sociales", Paris, p. 11-32.

195 Assemblée nationale française, Rapport fait au nom de la commission d'enquête sur la manière dont a été programmée, expliquée et gérée la campagne de vaccination contre la grippe A(H1N1), op. cit., p. 53. 
ministre de la Santé admettra clairement que le dédommagement s'apparente de facto à un partage de responsabilité sur le plan politique: "La firme GSK exigeait un système de responsabilité partagée. Nous n'avions pas le choix, si ce n'est renoncer au vaccin. $"{ }^{196}$

Ensuite, le Commissariat interministériel Influenza a mis en évidence les facultés de réemploi du vaccin Pandemrix, justifiant pour partie la dépense au motif que le vaccin pourrait être partiellement réutilisé, le cas échéant, pour la grippe saisonnière. Dans sa recommandation, le Commissariat a ajouté que le Pandemrix de GSK présente " également un avantage supplémentaire : l'adjuvant et l'antigène sont conditionnés dans des flacons différents. Cette faculté permettra, au cas où toutes les doses commandées ne seraient pas utilisées immédiatement, de conserver malgré tout l'adjuvant et d'échanger uniquement l'antigène dans le cas d'une future épidémie différente de la grippe $\mathrm{A}(\mathrm{H} 1 \mathrm{~N} 1) »{ }^{197}$. Le journaliste D. Leloup fera remarquer que la mise en avant de ce critère, en particulier, qualifiait de facto le Pandemrix comme seul choix possible du gouvernement ${ }^{198}$. Par ailleurs, interpellée en janvier 2010 devant la Chambre des représentants, L. Onkelinx déclarera que «si le virus ne mute pas trop, le même vaccin pourra être réutilisé ; s'il mute beaucoup plus sensiblement, l'adjuvant $(85 \%)$ restera réutilisable. (...) En effet, l'ensemble de notre stock est constitué de vaccins qui, pour l'essentiel, seront réutilisables dans les années qui viennent ${ }^{199}$.

Il convient toutefois de relativiser ces chiffres, plutôt flatteurs pour le gouvernement, à la lueur du rapport annuel de la Cour des comptes, laquelle estime "à 85 millions d'euros le coût de la pandémie grippale $\mathrm{A}(\mathrm{H} 1 \mathrm{~N} 1)$ à charge du SPF Santé publique " sur la période 2009-2010 et constate que « la totalité du stock de vaccins ( 5 millions de doses) et la moitié du stock de masques respiratoires (4,8 millions de masques) sont périmées et devront faire l'objet d'une destruction ${ }^{200}$. À noter néanmoins que les masques ne concernent pas le cas de la grippe $\mathrm{A}(\mathrm{H} 1 \mathrm{~N} 1)$; ils avaient été achetés, en 2006, dans le cadre de la grippe A(H5N1).

Tableau 2. Détail des coûts liés à la pandémie grippale à charge du SPF Santé publique pour les années 2009 et 2010 (en euros)

\begin{tabular}{|l|r|}
\hline Objet de la dépense & \multicolumn{1}{|c|}{ Montant } \\
\hline Achat de vaccins anti-pandémiques & 80206490 \\
\hline Coûts liés à l'achat de matériel d'injection et divers & 3745830 \\
\hline Coût du transport des vaccins et du matériel d'injection & 979289 \\
\hline Coûts de communication, de publicité et de mise en place de staters kits & 370895 \\
\hline Frais de fonction du Commissariat interministériel Influenza & 42868 \\
\hline & Total \\
\hline
\end{tabular}

Source: Cour des comptes, $168^{e}$ Cahier de la Cour des comptes. Observations et documents soumis à la Chambre des représentants, volume 1 : Commentaires, s.l.n.d. [Bruxelles, décembre 2011], p. 120.

En conclusion, le gouvernement belge agit en juillet 2009 en concordance avec l'idée qu'il se fait de sa responsabilité, au sens premier de l'idée d'être « responsable », c'està-dire de « répondre de ». En l'occurrence, il estime, en fonction des facteurs que nous

196 «H1N1 : voici le contrat entre GSK et le gouvernement belge », Le Soir, 5 mai 2010.

${ }_{197}$ Commissariat interministériel Influenza, Grippe A/H1N1 : FAQ Citoyens, op. cit.

198 D. LELOUP, « Grippe A/H1N1 : conflits d'intérêts », op. cit., p. ???.

199 Chambre des représentants, Compte rendu intégral, CRIV 52 PLEN 136, 14 janvier 2010, p. 7.

200 Cour des comptes, $168^{e}$ Cahier de la Cour des comptes, op. cit., p. 116-120. 
avons examinés, qu'il est de son devoir de prémunir sa population contre une menace qui devient « avérée », par l'effet des rapports de l'OMS, de la menace sur les stocks de vaccins et de l'écho médiatique important que reçoit la grippe $\mathrm{A}(\mathrm{H} 1 \mathrm{~N} 1)$. En somme, il s'agit de "répondre de" la santé de la population en parant séance tenante à l'éventualité de la pandémie. Dans ce cadre, les effets secondaires éventuels du vaccin ne sont clairement pas pris en pleine considération. Les éventuelles indemnités à payer sont perçues comme quotité négligeable. Or, la plupart des rapports disponibles aujourd'hui admettent l'existence d'un risque accru de narcolepsie, lié au vaccin. Enfin, les coûts liés à l'achat du vaccin proprement dit, nonobstant la question de son réemploi, jouent manifestement un rôle secondaire dans la prise de décision politique, la priorité perçue étant de protéger la santé de la population, littéralement à tout prix. Il est d'ailleurs piquant de constater combien cet impératif de protection se heurte à un échec lorsqu'il s'agit de le mettre en ouvre au travers d'une campagne de vaccination.

Le gouvernement suit donc bel et bien une logique-type de prévention, et se repose essentiellement sur les avis d'expertise disponibles, en provenance aussi bien de l'OMS que de GSK. Quel que soit le sens que l'on donne à une démarche de précaution, dans le cas présent, elle aurait sans doute consisté à prendre de plus amples informations avant de se prononcer, quant aux capacités réelles de production des vaccins ou quant à leur innocuité, par exemple. Sans aucun doute, une telle démarche aurait conduit, d'une manière ou d'une autre, à relativiser le poids des expertises qui ont influencé la décision politique d'une façon décisive, en fonction par exemple d'autres critères, d'autres analyses, ou d'autres valeurs plus explicitement politiques. Notre analyse démontre que c'est au nom d'une conception étroite de sa responsabilité qu'en juillet 2009, l'État engage son action et se fournit en vaccins, dans une logique préventive de protection de la population, exercice qui montre ses limites lorsque ladite population refuse cette protection. 


\section{CONCLUSION}

Notre étude a consisté en l'analyse du contrat conclu le 22 juillet 2009 entre l'État belge et la firme pharmaceutique GSK, dans le cadre de la fourniture de vaccins Pandemrix en prévision du risque d'une pandémie de grippe de type $\mathrm{A}(\mathrm{H} 1 \mathrm{~N} 1)$. La gestion de cette pandémie par les autorités publiques et sanitaires a fait l'objet de nombreuses critiques : opacité, commande surévaluée de vaccins, liens étroits entre entreprises pharmaceutiques et gouvernants, doutes sur l'absence de nocivité des vaccins, etc. En particulier, le discours médiatique dominant a fortement remis en cause une démission présumée des pouvoirs publics, suspectés d'avoir agi dans la précipitation et d'avoir, de manière condamnable, engagé leur responsabilité.

La première partie du présent Courrier hebdomadaire a porté sur les aspects juridiques du contrat. Elle infirme toute délégation de responsabilité stricto sensu. Elle a toutefois souligné un déséquilibre contractuel patent, dans la mesure où GSK voit sa responsabilité limitée à $50 \%$ des montants payés par la Belgique pour l'achat des vaccins, alors que, en dernière ligne, l'État belge pourrait être amené à assumer des conséquences financières potentiellement illimitées. En ce qui concerne l'indemnisation d'éventuels décès ou lésions corporelles, aucun plafond n'est, en effet, prévu par la loi du 25 février 1991 (alors que cette faculté était offerte par la directive 85/374/CEE). D'autres indemnités, en lien par exemple avec les procédures judiciaires (tels les frais d'avocats), ne sont pas non plus limitées. En pratique, les éventuelles victimes devront s'adresser à GSK, qui paiera les indemnités dues, le groupe pharmaceutique se faisant ensuite rembourser par l'État belge. Cette absence de plafonnement des indemnités est assurément l'élément le plus critiquable du contrat et cadre mal avec l'idée d'une bonne gestion des deniers publics.

La seconde partie de l'étude a porté sur la responsabilité politique engagée par l'État belge. À cet égard, nous avons analysé les logiques d'intervention à l'œuvre en termes de prévention et de précaution. Le premier concept permet de justifier une action publique entreprise pour parer un risque avéré; le second légitime des mesures destinées à contrer un risque potentiel. Dans notre cas d'étude, ces deux logiques sont intimement liées, d'où la nécessité de préciser les logiques et de rectifier les abus de langage souvent constatés. En l'espèce, le gouvernement belge a pris la décision d'agir face à ce qu'il a caractérisé comme un risque avéré, en procédant à une campagne de vaccination. Cette logique l'a emporté sur d'autres, qui auraient pu conduire, par exemple, à une autre temporalité dans la prise de décision et à une plus grande ouverture à d'autres types d'expertise. En l'occurrence donc, la logique de prévention a pris le pas sur la logique de précaution, l'État belge remplissant ainsi efficacement le 
rôle de protection de la population qu'il considère être le sien ${ }^{201}$. Un peu à l'instar du réflexe qui a guidé l'action publique dans le cas de la crise financière de 2008 , le gouvernement belge a agi, dans la mesure des moyens qui étaient les siens dans un contexte d'urgence et d'information lacunaire, pour éviter la survenance potentielle d'un dommage grave et irréversible.

Cependant, de nombreuses questions restent en suspens et mériteraient une investigation plus approfondie. Tout d'abord, les principales critiques ont tourné, non sans raison, autour de la question de l'indépendance de l'expertise ${ }^{202}$. La collecte et la sélection des faits censés guider la prise de décision politique résultent de proximités peu transparentes entre l'OMS, les firmes pharmaceutiques et les multiples commissions d'experts. À cet égard, la première des démarches consisterait sans doute à éclaircir le rôle de chaque intervenant du processus décisionnel. Il reste en outre interpellant que, moins d'un an après les faits générateurs de la crise, les campagnes de vaccination conduisent à un résultat si faible, en dépit des investissements consentis pour l'achat des vaccins - dans un contexte de crise économique. Comment interpréter le fait que les autorités gouvernementales, qui diligentent l'achat de stocks de vaccins, tempèrent nettement leur analyse quant à la gravité de la crise, à seulement quelques mois d'intervalle? Il faut prolonger la réflexion sur les moyens dont disposent les pouvoirs publics dans une situation de crise, les ressources dont ils disposent et les capacités d'expertise dont ils s'entourent pour fonder leurs décisions. Enfin, il faudrait également dresser un éventail exhaustif, d'une part, des options qui se présentent actuellement aux autorités compétentes (leurs atouts et leurs limites) et, d'autre part, des alternatives qui pourraient pallier aux lacunes éventuelles.

Mener à bien ces interrogations implique que certaines «bonnes pratiques » soient adoptées, dans le cadre de la gestion des crises futures. Celles-ci auraient par ailleurs pour mérite d'offrir des garanties plus étendues d'indépendance et d'autonomie du processus décisionnel. Tout d'abord, l'esprit général de la démarche devrait être celui d'une plus grande transparence. Ainsi, la composition des différents organes consultatifs mis en place devrait être rendue publique, et les déclarations d'intérêt devenir la pratique usuelle. Ensuite, au moins au niveau belge, la qualité de la concertation à l'œuvre entre les autorités et les médecins pourrait être renforcée ${ }^{203}$.

201 C. Fallon, S. Brunet et B. Cornélis, «La planification d’urgence sous tension ", Cahier de la Sécurité, 3 : Risques environnementaux. Sommes-nous prêts ?, 2008, p. 72-83. Il n'y a pas lieu de penser que les partis politiques d'opposition aient considéré la situation autrement que ceux de la majorité. En témoigne par exemple la virulence toute relative manifestée par Écolo, seul parti politique francophone d'opposition parlementaire, qui a soigneusement évité de vilipender la ministre de la Santé publique sur le principe même de la fourniture de vaccins (cf. Chambre des représentants, Compte rendu intégral, CRIV 52 PLEN 136, 14 janvier 2010). À noter qu'Écolo s'est toutefois abstenu à l'occasion du vote de la loi du 16 octobre 2009 accordant des pouvoirs au Roi en cas d'épidémie ou de pandémie de grippe, Moniteur belge, 21 octobre 2009. La critique de ce parti a principalement porté sur la proportionnalité d'une telle loi de pouvoirs spéciaux, eu égard à la situation, évitant donc de remettre en cause la logique même de la nécessaire action publique.

202 Pour rappel, une plainte pour corruption et coalition de fonctionnaires a ainsi été introduite contre des agents de l'État belge, accusés d'être en situation de conflit d'intérêts (cf. «Vaccin A/H1N1 : une plainte déposée pour corruption », Le Soir, 25 novembre 2010 ; D. LeLOUP, «Choix du vaccin : cinq experts liés à GSK», Politique, revue de débats, 2010, $\mathrm{n}^{\circ}$ 67, p. ???).

${ }^{203}$ Une spécificité belge est à souligner : contrairement à la situation qui a prévalu dans de nombreux autres pays, la gestion de la crise s'est faite, non exclusivement au sein d'un cercle restreints de décideurs, mais en concertation préalable avec les professionnels de la santé. 
On constate en effet que certains désaccords ont eu lieu entre les autorités et les professionnels de la santé (Ordre des médecins et Association belge des syndicats médicaux, cercles de médecins généralistes et médecins des hôpitaux), notamment en ce qui concerne l'enregistrement des patients sur la plate-forme eHealth, dont l'utilisation pose des questions aussi bien éthiques que pratiques ${ }^{204}$. Enfin, même si cette suggestion peut sembler moins réaliste, il serait utile que les pouvoirs publics fassent l'effort de présenter les choix qui s'offrent à eux et les critères qui conduisent à leur décision, fût-ce à titre rétrospectif. Par exemple, dans la circonstance exceptionnelle d'une pandémie, serait-il possible pour les gouvernements, et à quelles conditions, de tempérer les règles actuelles du régime des brevets?

Les questions de l'indépendance de l'expertise, de la concertation, ainsi que de la temporalité et de l'autonomie de la prise de décision politique, méritent donc de plus amples investigations. Au-delà de ces questions, prolonger la réflexion aboutirait rapidement à s'interroger sur le sens de la démarche de prévention et le rôle de l'État dans la protection des populations.

204 Ordre des médecins, Titre???, Communiqué de presse, date???, www.ordomedic.be ; Association belge des syndicats médicaux, La grippe A/H1N1 est-elle pour la ministre une occasion d'affaiblir le droit des citoyens ?, Communiqué de presse, 8 octobre 2009, www.absym-bvas.be. 


\title{
ANNEXE : EXTRAITS DU CONTRAT CONCLU ENTRE L'ÉTAT BELGE ET GLAXOSMITHKLINE (22 JUILLET 2009) ${ }^{205}$
}

\author{
Préambule \\ Les termes utilisés dans ce préambule sont définis à l'article $1^{\mathrm{er}}$ ci-après. \\ (...)
}

B. Suite à la déclaration de phase 6 de l'Organisation mondiale de la santé le 11 juin 2009, le MSP $^{206}$ a décidé d'accroître le niveau de préparation contre la grippe pandémique en Belgique et, pour ce faire, souhaite acquérir le volume pandémique total et GSK a consenti à lui livrer un pourcentage spécifique et déterminé du volume total de production hebdomadaire à concurrence du volume pandémique total, selon les conditions déterminées dans la présente convention.

C. GSK dispose d'une autorisation de mise sur le marché prototype de l'EMEA et de la Commission européenne pour produire un vaccin contre la souche du virus de la grippe $\mathrm{A} / \mathrm{H} 5 \mathrm{Nl} / \mathrm{Vietnam}$. Cette autorisation règlementaire sera modifiée sur la base d'une souche de grippe pandémique telle que recommandée par l'OMS. Le vaccin pandémique comprendra un composé adjuvant séparé et un composé antigène pandémique séparé.

(...)

F. Les parties reconnaissent l'urgence de la crise de santé publique.

G. Eu égard à ce qui précède, ainsi que, d'une part, à l'urgence de prendre les mesures adaptées à la situation considérée et, d'autre part, au fait que GSK est la seule firme pharmaceutique ayant enregistré un vaccin prototype comprenant un composé antigène et un composé adjuvant séparés, ce qui, le cas échéant, permettrait le remplacement du composé antigène pandémique par un autre composé antigène en cas de mutation ou apparition d'un nouveau virus si le vaccin pandémique n’a pas encore été administré, le Conseil des ministres a décidé de recourir à la procédure négociée, sans publicité, sur la base de l'article $17, \$ 2,1^{\circ} \mathrm{c}$ ) et f) de la loi du 24 décembre 1993 relative aux marchés publics et a donné mandat au MSP pour ouvrir des négociations avec GSK pour acquérir en son nom et pour son compte des vaccins pandémiques, sans préjudice aux autres dispositions légales et réglementaires applicables en matière de marchés publics.

H. Eu égard aux exigences particulières du marché et compte tenu des impératifs de santé publique, notamment de l'urgence s'y rapportant, les parties reconnaissent que (i) le vaccin pandémique pourrait être administré sans autorisation règlementaire, (ii) que le vaccin pandémique fait l'objet d'études cliniques dont les résultats ne sont pas encore connus à la date d'entrée en vigueur et (iii) qu'il est donc indispensable, au-delà de la dérogation aux articles 20 et $66 \mathrm{du}$ Cahier général des charges de l'État (annexe à l'arrêté royal du 26 septembre 1996) prévue dans le Cahier spécial des charges DG2/2009/INFLUENZA/VACCINS et réitérée pour autant que de besoin dans la présente convention, de déroger aux articles $12,15 \$ 2,16,18,19$, 20 et 55 du Cahier général des charges, dans la mesure nécessaire à la prévalence de la présente convention, en particulier de ses articles 11, 12 et 14, sur lesdits articles. GSK reconnaît que le marché découlant de la présente convention est soumis au Cahier spécial des charges $n^{\circ}$ DG2/2009/Influenza/Vaccins pour autant que les dispositions de celle-ci n'y dérogent pas.

Les parties se sont accordées sur les termes de la présente convention.

\section{Article 1.1 (« Définitions »)}

Dans la présente convention, sauf indication contraire ou incohérence avec le contexte, les termes suivants sont définis comme suit :

(...)

${ }^{205}$ La version intégrale du contrat est disponible sur le site Internet www.cadrages.eu.

206 MSP : ministre de la Santé publique belge, ci-après « ministre de la Santé ». 
"Autorisation règlementaire" signifie toute autorisation centralisée de mise sur le marché (ou toute variation de cette dernière) pour le vaccin pandémique émise par l'autorité règlementaire compétente sur la base du règlement (EC) $n^{\circ} 726 / 2004$, ou des règlements ou directives de la Commission mettant en œuvre ce dernier, ainsi que des lignes directrices ou principes adoptés sur la base de tels textes.

(...)

"Autorité règlementaire compétente" signifie l'EMEA et la Commission européenne ou l'AFMPS/FAGG ${ }^{207}$ et le ministre de la Santé publique, ces deux derniers agissant au nom de l'État belge, suivant le contexte.

(...)

"Bonnes pratiques de fabrication" ou "BPF" signifie les bonnes pratiques de fabrication conformément aux standards actuellement exigés par la législation européenne et en particulier ceux définis par la directive CEE/91/356, telle que modifiée par la directive CE/2003/94 et la directive CEE/91/412 telles que celles-ci seront le cas échéant ultérieurement modifiées, ou toute autre réglementation applicable en ce compris en particulier les guidelines déterminées dans le «Volume 4 du EudraLex - Les règles régissant les produits médicaux dans l'Union européenne ».

(...)

"Clients" signifie les États (ou leurs représentants), en ce compris le MSP, qui, au moment où il convient de se référer à ce terme, ont un contrat avec GSK ou toute société affiliée pour la fourniture de vaccins pandémiques dont le composé antigène pandémique est fabriqué à l'infrastructure antigène pandémique pendant la durée.

(...)

"Composé adjuvant" signifie le composé adjuvant du vaccin pandémique tel que décrit plus en détail à l'annexe $\mathrm{A}$ et, dans le cas où le MSP a exercé ses droits en vertu de l'article 3.2, peut également signifier le composé adjuvant de remplacement.

(...)

"Composé antigène pandémique" signifie le composé antigène basé sur la souche virale pandémique de la grippe qui a été identifiée par l'OMS au moment de la déclaration pandémique tel que décrit plus en détail à l'annexe A.

(...)

"Composé(s)" signifie le composé adjuvant et/ou le composé antigène pandémique, en fonction du contexte.

(...)

"Décision" signifie, selon le contexte, toute décision judiciaire, administrative, ou arbitrale non susceptibles de recours en rapport avec une réclamation.

(...)

"Durée" signifie la durée de la présente convention déterminée à l'annexe $\mathrm{B}$, sans préjudice de toute résiliation anticipée conformément à l'article 15.

(...)

"EMEA" signifie l'Agence européenne des médicaments.

"Faute intentionnelle" signifie tout acte ou omission intentionnels, lorsque son auteur a agi dans un but répréhensible ou illicite et sans égard pour un risque évident ou connu, dont l'importance rend hautement probable le fait que le dommage causé excèdera le bénéfice tiré ou pouvant en être tiré.

(...)

"Groupe" signifie GSK et ses sociétés affiliées.

(...)

207 AFMPS/FAGG : Agence fédérale des médicaments et des produits de santé/Federaal Agentschap voor Geneesmiddelen en Gezondheidsproducten. 
"Infrastructure antigène pandémique" signifie les infrastructures de Dresden en Allemagne qui sont la propriété et sont exploitées par une société affiliée.

(...)

"Partie GSK indemnisée" signifie GSK, ses sociétés affiliées et leurs employés, administrateurs ou directeurs, pour autant que GSK, ses sociétés affiliées, leurs employés, administrateurs ou directeurs n'aient pas commis de faute intentionnelle.

(...)

"Réclamation" signifie toute demande adressée à une partie GSK indemnisée en vue de l'obtention d'une indemnisation.

(...)

"Société affiliée" signifie toute société qui contrôle, est contrôlée par ou est sous le contrôle conjoint de GSK et/ou de la société mère chapeautant tout le groupe.

(...)

"Spécifications" signifie les spécifications du vaccin pandémique déterminées à l'annexe A et ainsi qu'elles pourront être mises à jour ou remplacées conformément à la présente convention.

"Vaccin pandémique" signifie le vaccin à virion fragmenté avec adjuvant mis au point par le groupe, qui comprend un composé adjuvant et un composé antigène pandémique séparés, tels que décrits plus en détail dans les spécifications et les références au vaccin pandémique comprennent, le cas échéant, toute référence à chaque composé et/ou nouveau composé en fonction du contexte.

(...)

"Volume pandémique total" signifie la quantité totale de doses de vaccin pandémique devant être livrées en vertu de la présente convention pendant sa durée, soit 12,6 millions de doses.

(...)

Article 11.5 («Autres déclarations et garanties par GSK»)

GSK certifie et garantit, tant pour GSK que, le cas échéant, pour ses sociétés affiliées :

(...)

(d) que tous les clients avec qui GSK ou ses société affiliées ont conclu un contrat pour la livraison d'un vaccin pandémique similaire au vaccin pandémique ont été traités de façon équivalente quant aux points suivants : (i) le prix de l'antigène à 1 euro et de l'adjuvant à 6 euros (le cas échéant, au taux de change applicable au moment de la conclusion des contrats respectifs avec ces États); (ii) le paiement d'un doit de mse à dsposition de 1,50 par dose pour la réservation de capacité de production et la fourniture d'un nouveau vaccin pandémique aux conditions définies à l'article 3.4 en cas de déclaration de nouvelle pandémie après la date d'entrée en vigueur et durant la durée, (iii) le principe d'indemnisation de GSK par l'acheteur pour les dommages nés du fait de la responsabilité du fait des produits visé à l'article 12. 1, et le principe de l'indemnisation réglementaire visé à l'article 12.2 ; (iv) le principe de livraison des vaccins pandémiques sur la base d'un pourcentage attribué spécifique et en fonction de certains critères tels que le rendement de l'antigène et la réception des réactifs calibrés; et (v) le principe de limitation de la responsabilité de GSK.

Les garanties et déclarations décrites dans le présent article 11.5 sont réputées être faites à la date d'entrée en vigueur de la présente convention.

\section{Article 12.1 ( Responsabilité du fait des produits»)}

Le MSP tiendra indemne toute partie GSK indemnisée des conséquences financières ci-dessous énumérées de toute réclamation ou de toute décision ou transaction consécutives à une réclamation en raison d'un préjudice physique ou d'un décès causé par l'utilisation ou l'administration du vaccin pandémique fourni en vertu de la présente convention.

Par «conséquence financière » l'on entend tous frais, dépenses, honoraires, exposés ou payés pour le traitement de la réclamation, en ce compris la contestation de celle-ci, ainsi que les 
indemnités qui seraient payées par toute partie GSK indemnisée en vertu d'une décision ou d'une transaction, à l'exclusion des amendes pénales.

Il est entendu toutefois qu'il n'existe aucune obligation de la part du MSP d'indemniser et de dédommager toute partie GSK indemnisée, lorsqu'il est démontré que ce décès ou ce préjudice physique est directement causé par des défauts de fabrication (en ce compris le remplissage et le conditionnement) du vaccin pandémique, qui sont le résultat (a) soit d'une faute intentionnelle de la part de toute partie GSK indemnisée, (b) soit du fait que le vaccin pandémique n'a pas été fabriqué, rempli, conditionné ou livré par GSK ou ses sociétés affiliées conformément aux BPF applicables (en ce compris en raison d'un manquement à l'obligation générale de prudence et de diligence) auxquelles il n'a pas été dérogé par la présente convention.

\section{Article 12.2 («Indemnisations réglementaires»)}

Le MSP tiendra indemne toute partie GSK indemnisée des conséquences financières ci-dessous énumérées, résultant de toute réclamation trouvant sa cause directe dans le fait que GSK a livré des vaccins pandémiques au MSP, sans autorisation réglementaire, en application de l'article 8.2. de la présente convention.

Par «conséquence financière » l'on entend tous frais, dépenses, honoraires, exposés ou payés pour le traitement de la réclamation, en ce compris la contestation de celle-ci, ainsi que les indemnités qui seraient payées par toute partie GSK indemnisée en vertu d'une décision ou d'une transaction, à l'exclusion des amendes pénales.

\section{Article 12.3 (« Limitations »)}

Aucune indemnité en vertu du présent article 12 ne sera due :

(a) pour toute partie des conséquences financières décrites aux articles 12.1 et 12.2 qui aurait été payée par un tiers, tel qu'une compagnie d'assurance autre qu'une compagnie d'assurance appartenant au groupe GSK étant entendu que GSK utilisera tous les moyens à sa disposition en vue du paiement du montant dû par ce tiers ;

(b) si les réclamations visées aux articles 12.1 et 12.2 découlent de l'utilisation ou de l'administration d'un vaccin pandémique qui n'a pas été agréé par le MSP conformément à l'article 6.1 de la présente convention;

(c) si les réclamations visées aux articles 12.1 et 12.2 n'ont pas été notifiées au MSP dans les trente (30) jours à compter du jour où la partie GSK indemnisée en prend connaissance ou devait raisonnablement en avoir pris connaissance ;

(d) lorsqu'une réclamation visée aux articles 12.1 et 12.2 se rapporte à tout décès ou à tout préjudice physique (i) dont GSK, une société affiliée et/ou une partie GSK indemnisée a eu connaissance par le biais de son système de pharmacovigilance, (ii) qui aurait dû être notifiée en vertu des recommandations de l'EMEA en vigueur intitulées «CHMP Recommendations for the Pharmacovigilance Plan as part of the Risk Management Plan to be submitted with the Marketing Authorisation Application for a Pandemic Influenza Vaccine», dont la version actuelle (révision 1 du 25 juin 2009) est reprise en annexe E et (iii) que GSK, une société affiliée ou une partie GSK indemnisée a omis de notifier, sauf si cette omission ne constitue pas une faute lourde eu égard à toutes les circonstances pertinentes. $(\ldots)$

\section{Article 14.2 ( Limitation de responsabilité »)}

Par dérogation au droit commun, la responsabilité de GSK envers le MSP pour l'ensemble des réclamations et/ou demandes généralement quelconques découlant de ou en relation avec la présente convention, indépendamment de la forme dans laquelle la responsabilité doit être invoquée, que ce soit en matière contractuelle, extracontractuelle (en ce compris quasidélictuelle), violation d'une obligation légale, violation d'une garantie, faute propre ou toute autre action de toute nature, et pour toute mesure de redressement, quelle qu'elle soit, quelle que soit sa cause ou le moment auquel elle se produit, sera limitée à et n'excèdera pas, selon le cas : 
a) un montant équivalant à cinquante pourcents $(50 \%)$ du prix du volume pandémique total, à majorer, le cas échéant, du prix des nouveaux composés commandés conformément à l'article 3.2 et 3.3 de la présente convention;

b) un montant équivalant à cinquante pourcents $(50 \%)$ du prix du nouveau volume pandémique total.

Article 16.12 ( Traitement des réclamations»)

Le MSP pourra intervenir dans toute procédure ou toute négociation de transaction résultant d'une réclamation, ou d'une demande susceptible de conduire à une réclamation, formulée à l'encontre de GSK.

Pour permettre au MSP d'exercer ce droit d'intervention :

a- GSK notifiera sans délai au MSP l'existence de toute réclamation, ou d'une demande susceptible de conduire à une réclamation, formulée à son encontre, informera régulièrement le MSP de l'état de la procédure ou de la négociation, selon le cas, et consultera le MSP au préalable avant de prendre quelque décision que ce soit susceptible d'avoir un effet sur le résultat de la procédure ou de la négociation.

b- GSK communiquera immédiatement au MSP une copie de tout document qui lui est adressé par la partie ayant formulée la réclamation, ou la demande susceptible de conduire à une réclamation, en rapport avec cette dernière et donnera au MSP la possibilité de faire valoir ses observations et arguments.

c- GSK communiquera immédiatement au MSP une copie de toute note de frais qui lui est adressée dans le cadre de la gestion de la procédure ou de la négociation d'une transaction.

d- Le MSP nommera, s'il le souhaite, des conseils externes.

e- Le MSP prendra en considération les arguments raisonnables de GSK en sorte d'assurer, dans la mesure du possible, la cohérence de la défense développée à l'encontre de la réclamation avec les défenses développées le cas échéant dans d'autres pays à l'encontre de réclamations similaires.

f- Aucune reconnaissance de responsabilité ne peut avoir lieu, aucune obligation de faire ou ne pas faire ne peut être contractée et aucune transaction ne peut être conclue sans que les parties n'y aient au préalable donné leur accord écrit.

g- Dans la conduite de la procédure ou de la négociation, selon le cas, le MSP fera ses meilleurs efforts pour ne rien faire ou ne rien communiquer qui puisse avoir un impact défavorable sur les intérêts commerciaux, la réputation de GSK ou du vaccin ou qui emporterait dénigrement de GSK, du vaccin, de ses composants ou d'autres produits de GSK, ou des sociétés affiliées.

h- À la demande du MSP, GSK pourra fournir des informations confidentielles aux conseils externes du MSP à la condition que lesdits conseils respectent le caractère confidentiel desdites informations, notamment - sauf avis contraire de GSK - à l'égard du MSP.

i- À tout moment, GSK pourra renoncer à son droit aux indemnités qui seraient dues par le MSP en exécution de la présente convention au titre de la réclamation concernée et mener librement la conduite de la procédure ou de la négociation, selon le cas. L'exercice par GSK de son droit à renonciation dans le cadre d'un litige est sans incidence sur le droit à indemnité de GSK de la part du MSP dans le cadre des autres litiges.

j- Lorsque le MSP interviendra dans la défense du litige en application du présent paragraphe, et sous réserve de l'application des paragraphes (a) à (h) ci-dessus, le MSP pourra choisir librement la stratégie de défense.

Dans l'hypothèse où le MSP choisit d'intervenir dans le cadre de la procédure, les parties demanderont à leurs conseils externes de collaborer dans la mesure du possible. 


\section{Derniers numéros parus}

$2137 \quad$ La politique pénitentiaire

Philippe Mary

2135-2136 Grèves et conflictualité sociale en 2011

Iannis Gracos

2133-2134 L'évolution du CDH (2004-2011). II. Décembre 2007-décembre 2011 Paul Wynants

2131-2132 L'évolution du CDH (2004-2011). I. Juin 2004-décembre 2007 Paul Wynants

2129-2130 Les aspects bruxellois de l'accord de réformes institutionnelles du 11 octobre 2011

Jean-Paul Nassaux

2127-2128 Les aspects sociaux de l'accord de réformes institutionnelles du 11 octobre 2011

Paul Palsterman

2126 Les discussions communautaires sous le gouvernement Leterme II (2009-2010)

Serge Govaert

2125 Les électeurs de la N-VA aux élections fédérales du 13 juin 2010 Marc Swyngedouw et Koen Abts

2123-2124 Histoire de la Centrale générale des syndicats libéraux de Belgique (CGSLB)

Jean Faniel et Kurt Vandaele

\section{CENTRE DE RECHERCHE ET D'INFORMATION SOCIO-POLITIQUES}

Fondateur : Jules Gérard-Libois

Président : Xavier Mabille

Équipe de recherche :

Étienne Arcq, Pierre Blaise (secrétaire général), Fabienne Collard, Vincent de Coorebyter (directeur général), Jean Faniel, Valérie Géonet, Christophe Goethals (coordinateur adjoint du secteur Économie), Cédric Istasse, Anne Tréfois, Anne Vincent (coordinatrice du secteur Économie), Marcus Wunderle

Conseil d'administration :

Louise-Marie Bataille, Jacques Brassinne de La Buissière (vice-président honoraire), Francis Delpérée, Hugues Dumont, José Gotovitch, Nadine Gouzée, Serge Govaert, Laura Iker, Patrick Lefèvre, Xavier Mabille (président), Roland Michel (administrateur délégué), Michel Molitor (vice-président), Pierre Reman, Robert Tollet (vice-président), Els Witte, Paul Wynants 